\title{
14-3-3 Proteins Reduce Cell-to-Cell Transfer and Propagation of Pathogenic $\alpha$-Synuclein
}

\author{
Bing Wang, ${ }^{1}$ Rachel Underwood, ${ }^{1}$ Anjali Kamath, ${ }^{1}$ Colleen Britain, ${ }^{1}$ Michael B. McFerrin, ${ }^{1}$ Pamela J. McLean, ${ }^{3}$

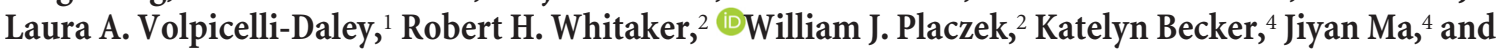 \\ Talene A. Yacoubian ${ }^{1}$ \\ ${ }^{1}$ Center for Neurodegeneration and Experimental Therapeutics, Department of Neurology, ${ }^{2}$ Department of Biochemistry and Molecular Genetics, \\ University of Alabama at Birmingham, Birmingham, Alabama 35294, ${ }^{3}$ Department of Neuroscience, Mayo Clinic, Jacksonville, Florida 32224 , and ${ }^{4}$ Center \\ for Neurodegenerative Science, Van Andel Research Institute, Grand Rapids, Michigan 49503
}

$\alpha$-Synuclein ( $\alpha$ syn) is the key protein that forms neuronal aggregates in the neurodegenerative disorders Parkinson's disease (PD) and dementia with Lewy bodies. Recent evidence points to the prion-like spread of $\alpha$ syn from one brain region to another. Propagation of $\alpha$ syn is likely dependent on release, uptake, and misfolding. Under normal circumstances, this highly expressed brain protein functions normally without promoting pathology, yet the underlying endogenous mechanisms that prevent $\alpha$ syn spread are not understood. 14-3-3 proteins are highly expressed brain proteins that have chaperone function and regulate protein trafficking. In this study, we investigated the potential role of the 14-3-3 proteins in the regulation of $\alpha$ syn spread using two models of $\alpha$ syn spread. In a paracrine $\alpha$ syn model, 14-3-3 $\theta$ promoted release of $\alpha$ syn complexed with 14-3-3 $\theta$. Despite higher amounts of released $\alpha$ syn, extracellular $\alpha$ syn showed reduced oligomerization and seeding capability, reduced internalization, and reduced toxicity in primary mixed-gender mouse neurons. 14-3-3 inhibition reduced the amount of $\alpha$ syn released, yet released $\alpha$ syn was more toxic and demonstrated increased oligomerization, seeding capability, and internalization. In the preformed fibril model, 14-3-3 $\theta$ reduced $\alpha$ syn aggregation and neuronal death, whereas 14-3-3 inhibition enhanced $\alpha$ syn aggregation and neuronal death in primary mouse neurons. 14-3-3s blocked $\alpha$ syn spread to distal chamber neurons not exposed directly to fibrils in multichamber, microfluidic devices. These findings point to 14-3-3s as a direct regulator of $\alpha$ syn propagation, and suggest that dysfunction of 14-3-3 function may promote $\alpha$ syn pathology in PD and related synucleinopathies.

Key words: 14-3-3 proteins; aggregation; $\alpha$-synuclein; dementia with Lewy bodies; exosome; Parkinson's disease

Significance Statement

Transfer of misfolded aggregates of $\alpha$-synuclein from one brain region to another is implicated in the pathogenesis of Parkinson's disease and other synucleinopathies. This process is dependent on active release, internalization, and misfolding of $\alpha$-synuclein. 14-3-3 proteins are highly expressed chaperone proteins that interact with $\alpha$-synuclein and regulate protein trafficking. We used two different models in which toxicity is associated with cell-to-cell transfer of $\alpha$-synuclein to test whether 14-3-3s impact $\alpha$-synuclein toxicity. We demonstrate that 14-3-3 $\theta$ reduces $\alpha$-synuclein transfer and toxicity by inhibiting oligomerization, seeding capability, and internalization of $\alpha$-synuclein, whereas 14-3-3 inhibition accelerates the transfer and toxicity of $\alpha$-synuclein in these models. Dysfunction of 14-3-3 function may be a critical mechanism by which $\alpha$-synuclein propagation occurs in disease.

\section{Introduction}

$\alpha$-Synuclein ( $\alpha$ syn) is the key protein implicated in the pathogenesis of Parkinson's disease (PD) and dementia with Lewy bodies

Received May 1, 2018; revised July 23, 2018; accepted July 25, 2018.

Author contributions: W.J.P., J.M., and T.A.Y. edited the paper; T.A.Y. wrote the first draft of the paper; P.J.M., L.A.V.-D., W.J.P., J.M., and T.A.Y. designed research; B.W., R.U., A.K., C.B., M.B.M., R.H.W., K.B., and T.A.Y. performed research; P.J.M., L.A.V.-D., J.M., and T.A.Y. contributed unpublished reagents/analytic tools; B.W., R.U., A.K., C.B., M.B.M., K.B., and T.A.Y. analyzed data; T.A.Y. wrote the paper.

This work was supported by NIH [R01 NS088533 (T.A.Y.), R01NS060729 (J.M.), R21 NS101676 (J.M.), T32 NS048039 (R.H.W.), R01 GM117391 (W.J.P.)], American Parkinson Disease Association, and the Parkinson Associa-
(DLB). Recent evidence points to the possibility that $\alpha$ syn has prion-like properties. Fetal grafts transplanted into PD patients

tion of Alabama. We thank Dr. Terje Dokland and Cynthia Rodenburg for assistance with the cryo-EM work, which was performed in the UAB Cryo-EM facility, Department of Microbiology, University of Alabama at Birmingham; Dr. Yi Zhou at Florida State University who provided the difopein mouse line that was used in the fibril studies; Dr. Mary Ballestas and the UAB Neuroscience Core C (NINDS P30 NS047466) for assistance with preparation of the lentiviruses; Valentina Krendelshchikova for preparation of $\alpha$ syn fibrils used for primary culture studies; and Dr. Charlotte Chung for advice regarding the use of multifluidic chambers.

Conflict-of-Interest: T.A.Y. has a U.S. Patent No. 7,919,262 on the use of 14-3-3s in neurodegeneration. The remaining authors declare no competing financial interests. 
develop $\alpha$ syn aggregates, suggesting cell-to-cell transmission of the disease process, and stem cells transplanted into mice overexpressing $\alpha$ syn show similar effects (Kordower et al., 2008; Desplats et al., 2009; Hansen et al., 2011). $\alpha$ Syn protofibrils cause aggregation of endogenous $\alpha$ syn and neuronal death in primary neuronal culture (Volpicelli-Daley et al., 2011), and fibrils injected into rodent striatum leads to $\alpha$ syn aggregation in the substantia nigra (SN) with subsequent dopaminergic loss and aggregation in other brain regions including the amygdala and frontal cortex (Luk et al., 2012; Masuda-Suzukake et al., 2014; Paumier et al., 2015; Abdelmotilib et al., 2017). Transmission of pathologic $\alpha$ syn likely depends on misfolding, release, and uptake of $\alpha$ syn. Potential cellular mechanisms implicated in $\alpha$ syn release include exosomal and non-exosomal secretion pathways and transfer through tunneling nanotubes, among other possible mechanisms (Lee et al., 2005; Liu et al., 2009; Emmanouilidou et al., 2010; Hasegawa et al., 2011; Danzer et al., 2012; Abounit et al., 2016). The endogenous mechanisms that normally prevent the spread of the highly abundant $\alpha$ syn are not well elucidated.

14-3-3 proteins comprise a family of seven conserved proteins that are highly expressed in the brain. These proteins are critical to neuronal function through their roles affecting protein folding, protein trafficking, and neurite growth among other functions (Vincenz and Dixit, 1996; Mrowiec and Schwappach, 2006; Yano et al., 2006; Kajiwara et al., 2009; Ramser et al., 2010; Shandala et al., 2011; Winter et al., 2012; Yoon et al., 2012; Marzinke et al., 2013; Foote et al., 2015; Lavalley et al., 2016; Kaplan et al., 2017; Sluchanko and Gusev, 2017). 14-3-3s interact with key proteins implicated in PD, including $\alpha$ syn, parkin, and LRRK2 (Ostrerova et al., 1999; Xu et al., 2002; Sato et al., 2006; Dzamko et al., 2010; Nichols et al., 2010; Li et al., 2011). 14-3-3s colocalize with $\alpha$ syn in Lewy Bodies in both PD and DLB (Kawamoto et al., 2002; Berg et al., 2003). Our work reveals a reduction of 14-3-3 levels in cellular and mouse $\alpha$ syn models and in the temporal cortices of patients with DLB (Yacoubian et al., 2008, 2010; Ding et al., 2013; McFerrin et al., 2017). Transcriptional analysis of PD patients points to $14-3-3$ s as a critical hub of dysregulated proteins in PD (Ulitsky et al., 2010). 14-3-3 overexpression is protective in neurotoxin and LRRK2 models, whereas 14-3-3 inhibition with the pan 14-3-3 inhibitor promotes toxicity (Yacoubian et al., 2010; Slone et al., 2011, 2015; Ding et al., 2015; Lavalley et al., 2016).

Because of their functions in protein folding and protein trafficking, we hypothesized that 14-3-3s regulate $\alpha$ syn transmission. Certain 14-3-3 isoforms, particularly 14-3-30, reduce fibrillization of recombinant $\alpha$ syn in vitro (Plotegher et al., 2014). 14-3-3s regulate non-classical protein secretion in association with the GTPase Rab11 (Shandala et al., 2011), a Rab protein previously shown to promote $\alpha$ syn secretion (Liu et al., 2009; Chutna et al., 2014; Goncalves et al., 2016). 14-3-3s also mediate exosomal release of LRRK2 (Fraser et al., 2013). We propose that 14-3-3s serve as part of an endogenous system that normally prevents $\alpha$ syn transmission, yet under disease condition, lower levels of $14-3-3$ s are unable to handle excess $\alpha$ syn. Here we examine the effect of 14-3-3 proteins, with an emphasis on 14-3-30, on $\alpha$ syn toxicity in two separate $\alpha$ syn models, and evaluate $14-3-3 s^{\prime}$ impact on $\alpha$ syn release, oligomerization, seeding, and internalization. We found that $14-3-3 \theta$ prevents $\alpha$ syn transmission and

Correspondence should be addressed to Dr. Talene A. Yacoubian, Civitan International Research Center 560D, 1719 6th Avenue South, Birmingham, AL 35294. E-mail: tyacoubian@uabmc.edu.

https://doi.org/10.1523/JNEUROSCl.1134-18.2018

Copyright $\odot 2018$ the authors $\quad 0270-6474 / 18 / 388212-22 \$ 15.00 / 0$ neuron death by reducing $\alpha$ syn oligomerization, seeding, and internalization despite increasing total $\alpha$ syn release.

\section{Materials and Methods}

Mice. Mice were used in accordance with the guidelines of the National Institute of Health (NIH) and University of Alabama at Birmingham (UAB) Institutional Animal Care and Use Committee (IACUC). Animal work performed in this study was approved by UAB's IACUC. Transgenic mice expressing human 14-3-3 $\theta$ tagged with a hemagglutinin (HA) epitope tag at the C-terminal end under the neuronal promoter Thy1.2 were previously developed in our laboratory (Lavalley et al., 2016). Transgenic mice expressing difopein-enhanced yellow fluorescent protein (eYFP) under the neuronal promoter Thy1.2 were obtained from Dr. Yi Zhou at Florida State University (Qiao et al., 2014). 14-3-30 hemizygous mice and difopein hemizygous mice were bred with C57BL/6J mice from The Jackson Laboratory (catalog \#000664; RRID:IMSR_JAX:000664).

Cell lines. Isyn cells were previously created by infecting SK-N-BE(2)M17 (M17) male neuroblastoma cells (obtained and authenticated by ATCC; catalog \#CRL-2267; RRID:CVCL_0167) with the doxycyclineinducible $\alpha$ syn pSLIK lentivirus in the presence of $6 \mu \mathrm{g} / \mathrm{ml}$ polybrene followed by selection for stable transfection with G418 (Slone et al., 2015). Isyn cells were maintained in 1:1 Eagle's MEM/F12K containing $10 \%$ fetal bovine serum (FBS), 1\% penicillin/streptomycin, and G418 $(500 \mu \mathrm{g} / \mathrm{ml})$ at $37^{\circ} \mathrm{C}$. To induce $\alpha$ syn expression, cells were treated with doxycycline (doxy) at $10 \mu \mathrm{g} / \mathrm{ml}$.

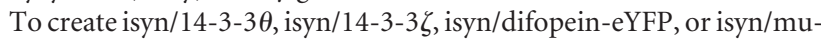
tant difopein-eYFP lines, isyn cells were transduced with the doxyinducible 14-3-3 $\theta, 14-3-3 \zeta$, difopein-eYFP, or mutant difopein-eYFP pSLIK-hygro lentiviruses, followed by selection for stable transfection with hygromycin $(100 \mu \mathrm{g} / \mathrm{ml})$ in addition to G418. The difopein-eYFP and mutant difopein-eYFP pSLIK constructs were created by the UAB Neuroscience Core Center by first cloning difopein-eYFP or mutant difopein-eYFP into the pEN_TTmcs vector, followed by recombination with the hygromycin-selectable pSLIK lentiviral construct (Shin et al., 2006). The $14-3-3 \theta$ and $14-3-3 \zeta$ pSLIK constructs were similarly constructed. Lines were maintained in 1:1 Eagle's MEM/F12K containing $10 \% \mathrm{FBS}, 1 \%$ penicillin/streptomycin, G418 (500 $\mu \mathrm{g} / \mathrm{ml})$, and hygromycin $(100 \mu \mathrm{g} / \mathrm{ml})$ at $37^{\circ} \mathrm{C}$. To induce expression, cells were treated with doxy at $10 \mu \mathrm{g} / \mathrm{ml}$.

SH-SY5Y cells were obtained and authenticated by ATCC (Cat \#CRL2266 RRID:CVCL_0019). SH-SY5Y cells were maintained in 1:1 Eagle's MEM/F12K containing 10\% FBS, and 1\% penicillin/streptomycin. For differentiation, SH-SY5Y cells were treated with retinoic acid $(10 \mu \mathrm{M})$ for $5-7 \mathrm{~d}$.

H4 neuroglioma cells were obtained and authenticated by ATCC (catalog \#HTB-148; RRID:CVCL_1239). H4 cells were maintained in OptiMEM media with $10 \%$ FBS.

Primary neuronal culture preparation. Hippocampi or cortices were dissected from male and female postnatal day (P) 0 mice and incubated in papain for $25 \mathrm{~min}$ at $37^{\circ} \mathrm{C}$. Cells were thoroughly washed using neurobasal-A media containing B-27 supplement and 5\% FBS before tituration using fire polished glass pipettes. After centrifugation at 1500 rpm for $5 \mathrm{~min}$, the cell pellet was layered on 4\% BSA in HBSS and centrifuged at $700 \mathrm{rpm}$ for $5 \mathrm{~min}$. Resuspended cells were plated on 18 $\mathrm{mm}$ glass coverslips coated with poly-D-lysine. After $12-16 \mathrm{~h}$, media was replaced by neurobasal-A media containing B-27 supplement and Arabinose $\mathrm{C}$ at $6 \mu \mathrm{m}$. Fifty percent media changes were made every $7 \mathrm{~d}$.

For preformed fibril (PFF) experiments, neurons underwent a complete media change and were treated with PBS, monomeric human $\alpha$ syn, or human $\alpha$ syn PFFs in neurobasal-A media with B-27 supplement at $5 \mathrm{~d}$ in vitro (DIV).

Preparation of conditioned media. For preparation of conditioned media (CM), isyn cells were switched to serum-free Eagle's MEM/F12K. At time of collection, $\mathrm{CM}$ was removed from cells and then underwent serial centrifugations at $800 \mathrm{~g}$ for $5 \mathrm{~min}$, then at $2000 \times g$ for $10 \mathrm{~min}$, and then at $10,000 \times g$ for $30 \mathrm{~min}$ at $4^{\circ} \mathrm{C}$ to remove cellular debris. For Western blot analyses, CM was then concentrated using a $3 \mathrm{kDa}$ Amicon Ultra- 4 centrifugal filter at $4000 \times g$ for $2 \mathrm{~h}$ and then dialyzed. Protein concentrations of CM samples were assessed by BCA assay (ThermoFisher Sci- 
entific), and equal protein amounts were loaded for each CM sample for Western blot analysis.

For toxicity experiments, isyn cells were induced with doxycycline in Eagle's MEM/F12K with $10 \%$ FBS for 1 week and then switched to serum-free Eagle's MEM/F12K for $48 \mathrm{~h}$. Collected CM underwent centrifugation at $800 \times g$ for $5 \mathrm{~min}$, then at $2000 \times g$ for $10 \mathrm{~min}$, and then at $10,000 \times g$ for 30 min before transfer to primary neuronal cultures or differentiated SH-SY5Y cells.

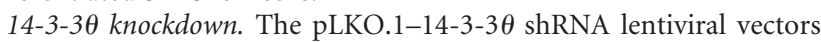
were originally purchased from Open Biosystems and previously tested for efficacy in reducing 14-3-3 $\theta$ protein expression (Yacoubian et al., 2010). Isyn cells were transduced with the empty vector pLKO.1 virus or 14-3-3 $\theta$ shRNA virus previously shown to have high efficacy in 14-3-3 $\theta$ protein knockdown in the presence of $6 \mu \mathrm{g} / \mathrm{ml}$ polybrene. Transduced cells were selected with $2 \mu \mathrm{g} / \mathrm{ml}$ puromycin $72 \mathrm{~h}$ later.

Ethidium D cell death assay. Cells were rinsed in PBS and then incubated in $1 \mu \mathrm{M}$ ethidium $\mathrm{D}$ and $2 \mu \mathrm{g} / \mathrm{ml}$ Hoechst 33342 in culture media for $30 \mathrm{~min}$ at $37^{\circ} \mathrm{C}$. Ten high-power $(20 \times)$ fields per well were randomly selected for quantification, and the number of ethidium D-positive cells and the total number of cells stained by Hoechst 33342 were counted per high-power field with the rater blind to experimental conditions.

Western blot. Cell pellets were sonicated in lysis buffer $(150 \mathrm{mM} \mathrm{NaCl}$, 10 mm Tris-HCl, pH 7.4, 1 mm EGTA, 1 mm EDTA, 0.5\% NP-40, protease inhibitor cocktail; ThermoFisher Scientific) and then underwent centrifugation at $16,000 \times g$ for $10 \mathrm{~min}$. Protein concentrations were assessed by BCA assay (ThermoFisher Scientific). Cell lysate and CM samples were boiled in $4 \times$ DTT sample loading buffer $(0.25 \mathrm{M}$ Tris- $\mathrm{HCl}$, pH 6.8, 8\% SDS, 200 mм DTT, 30\% glycerol, Bromophenol Blue). Equal protein amounts were loaded per well for the CM samples and for cell lysate samples, resolved on $12 \%$ SDS-polyacrylamide gels, and transferred to nitrocellulose membranes. After blocking in 5\% nonfat dry milk in TBST (25 mм Tris-HCl, pH 7.6, $137 \mathrm{~mm} \mathrm{NaCl}, 0.1 \%$ Tween 20), membranes were incubated overnight in primary antibody at $4{ }^{\circ} \mathrm{C}$ and then in HRP-conjugated goat anti-mouse or anti-rabbit secondary antibodies (1:2000; Jackson ImmunoResearch) for $2 \mathrm{~h}$. Primary antibodies used are listed in Table 1. After washing in TBST six times, blots were developed with enhanced chemiluminescence method (GE Healthcare). Images were scanned and analyzed using Un-ScanIT software for densitometric analysis of bands.

Immunoprecipitation. Ten microliters of protein G-conjugated Dynabeads (ThermoFisher Scientific) were incubated overnight with mouse IgG, mouse monoclonal antibody against $\alpha$ syn (final concentration 0.5 or $1 \mu \mathrm{g} / \mathrm{ml}$; BD Biosciences, 610787), or mouse monoclonal against V5 (final concentration $10 \mu \mathrm{g} / \mathrm{ml}$; ThermoFisher Scientific, R960-25) before adding to CM. Antibody-coupled Dynabeads was incubated with $3 \mathrm{ml}$ $\mathrm{CM}$ overnight. $\mathrm{CM}$ after immunodepletion was then used for toxicity assays.

ELISA. $\alpha$ Syn levels in CM were measured using an ELISA for $\alpha$ syn (ThermoFisher Scientific), according to the manufacturer's instructions.

Exosome fractionation. For exosome preparation, we followed the protocol described in (Thery et al., 2006). Briefly, cells were incubated to serum-free Eagle's MEM/F12K for 96 h. CM underwent serial centrifugations at $800 \times g$ for $5 \mathrm{~min}, 2000 \times g$ for $10 \mathrm{~min}$, and $10,000 \times g$ for 30 min to remove cellular debris at $4^{\circ} \mathrm{C}$. Debris-free media was then spun at $100,000 \times g$ for $2 \mathrm{~h}$ at $4^{\circ} \mathrm{C}$. The supernatant was saved as the nonexosomal fraction. The pellet was resuspended in PBS and then spun again at $100,000 \times g$ for $80 \mathrm{~min}$ at $4^{\circ} \mathrm{C}$. The pellet was resuspended in PBS with protease inhibitors.

Iodixanol gradient. A discontinuous gradient from $50 \%$ to $10 \%$ of OptiPrep (Axis Shield) was used to fractionate exosome pellets. The exosome pellet was resuspended in $200 \mu \mathrm{l} 50 \%$ OptiPrep and stepgradients of OptiPrep decreasing $10 \%$ with each step were carefully layered on top. The step-gradient was centrifuged at $110,000 \times g$ for $16 \mathrm{~h}$ at $4^{\circ} \mathrm{C}$. Fractions of $110 \mu \mathrm{l}$ were carefully removed from the top down, diluted with PBS to $1 \mathrm{ml}$, and centrifuged at $110,000 \times g$ for $1 \mathrm{~h}$ to repellet exosomes. The pellets were resuspended in PBS and analyzed by Western blot.

Nanosight. The size and concentration of exosomes was determined on a NanoSight NS300 (Malvern Instruments). Following isolation by ul-

\section{Table 1. List of primary antibodies used for immunostaining,} immunoprecipitation, or Western blot studies

\begin{tabular}{|c|c|c|}
\hline Primary antibodies & Source & Identifier \\
\hline Mouse monoclonal anti-14-3-3 $\theta$ & Abcam & Catalog \#ab10439 AB_297180 \\
\hline Mouse monoclonal anti-pan $14-3-3$ s & $\begin{array}{l}\text { Santa Cruz } \\
\text { Biotechnology }\end{array}$ & Catalog \#sc1657 AB_626618 \\
\hline Mouse monoclonal anti- $\alpha$-synuclein & BD Biosciences & Catalog \#610787 AB_398108 \\
\hline Rabbit polyclonal anti- $\alpha$-synuclein & $\begin{array}{l}\text { Cell Signaling } \\
\text { Technologies }\end{array}$ & Catalog\#2642SAB_10695412 \\
\hline $\begin{array}{l}\text { Mouse monoclonal anti-phospho-S129 } \\
\quad \alpha \text {-synuclein }\end{array}$ & BioLegend & Catalog \#825701 AB_2564891 \\
\hline $\begin{array}{l}\text { Rabbit polyclonal anti-phospho-S129 } \\
\quad \alpha \text {-synuclein }\end{array}$ & Abcam & Catalog \#ab168381 \\
\hline $\begin{array}{l}\text { Rabbit monoclonal anti-phospho-S129 } \\
\quad \alpha \text {-synuclein }\end{array}$ & Abcam & Catalog \#ab51253 AB_869973 \\
\hline Mouse monoclonal anti-flotillin 1 & BD Biosciences & Catalog \#610820 AB_398139 \\
\hline Rabbit monoclonal antibody against GFP & $\begin{array}{l}\text { Cell Signaling } \\
\text { Technologies }\end{array}$ & Catalog \#2956S AB_1196615 \\
\hline Mouse monoclonal antibody against $\mathrm{HA}$ & Covance & Catalog \#MMS-101P AB_2314672 \\
\hline Mouse monoclonal antibody against V5 & ThermoFisher & Catalog \#R960-25 AB_2556564 \\
\hline $\begin{array}{l}\text { Mouse monoclonal antibody against } \\
\alpha \text {-tubulin }\end{array}$ & Sigma-Aldrich & Catalog \#T9026AB_477593 \\
\hline
\end{tabular}

tracentrifugation, exosome pellets were resuspended in $60 \mu \mathrm{l}$ cold PBS with repeated pipetting and vortexed for $10 \mathrm{~s}$. Then $15 \mu \mathrm{l}$ of the exosome suspension was diluted to a total volume of $1 \mathrm{ml}$ PBS and analyzed on a NanoSight NS300 infused with a syringe pump set at 25 a.u. Data were collected for each sample in 10 repeats of $60 \mathrm{~s}$ video and analyzed using NanoSight NTA 3.0 software.

Cryo-EM. For Cryo-EM, $3 \mu$ l of exosome sample was applied to glowdischarged 200 mesh Quantifoil R 2/1 grids (Electron Microscopy Sciences) and vitrified in liquid ethane using an FEI Vitrobot Mark IV as previously described (Dearborn et al., 2017). Frozen grids were transferred to a Gatan 622 cryo-holder and observed in an FEI Tecnai F20 electron microscope (FEI) operated at $200 \mathrm{kV}$. Images were collected under low-dose conditions on a Gatan Ultrascan 4000 CCD camera with magnifications from $38,000-65,500 \times$ and $2.0-3.0 \mu \mathrm{m}$ defocus.

Complementation assay. $\alpha$ Syn complementation assay was performed as previously described (Danzer et al., 2011). Briefly, H4 neuroglioma cells were cotransfected with $\alpha$ syn-hGLuc1 (S1), $\alpha$ syn-hGLuc2 (S2), and either empty vector, 14-3-30, difopein-eYFP, or mutant difopein-eYFP using SuperFect transfection reagent (Qiagen). Cells were incubated in serum-free and phenol red-free OptiMEM media. At $48 \mathrm{~h}$ after transfection, $\mathrm{CM}$ was spun at $3000 \times \mathrm{g}$ for $5 \mathrm{~min}$ to remove cellular debris and then was transferred to a separate 96 -well plate. Luciferase activity was measured at $480 \mathrm{~nm}$ using a Synergy 2 plate reader (BioTek) following addition of $40 \mu \mathrm{m}$ coelenterazine.

Size exclusion chromatography. For analytical size exclusion chromatography (SEC) of $\alpha$ syn, CM from induced isyn cells was diluted in $1 \times$ PBS, pH 6.8, to $4 \mathrm{mg} / \mathrm{ml} .20 \mu \mathrm{l}(80 \mu \mathrm{g})$ was then loaded onto a NGC FPLC (Bio-Rad Laboratories), injected on a Yarra $3 \mu \mathrm{m}$ SEC-2000 column $(300 \times 7.8 \mathrm{~mm}$, Phenomenex), and run at $0.7 \mathrm{ml} / \mathrm{min}$ in $1 \times \mathrm{PBS}$, $\mathrm{pH} 6.8$. Fractions $(250 \mu \mathrm{l})$ were collected from elution volume $4-12.5 \mathrm{ml}$. This corresponds to the end of the void volume, as determined by a Blue Dextran standard, and the buffer front, as determined by imidazole elution. After SEC, $\alpha$ syn in $50 \mu$ l of each fraction was measured using an ELISA for $\alpha$ syn.

Protein misfolding cyclic amplification of $\alpha$ syn. Recombinant human $\alpha$ syn was purified according to the method previously published (Volpicelli-Daley et al., 2014). Upon thawing, purified $\alpha$ syn protein was centrifuged at $100,000 \times g$ for $30 \mathrm{~min}$ at $4^{\circ} \mathrm{C}$ to remove any aggregates that may have formed during the freeze-thaw process. Monomer $\alpha$ syn was then diluted to $50 \mu \mathrm{M}$ concentration in $10 \mathrm{~mm}$ Tris, $\mathrm{pH}$ 7.6, with 150 $\mathrm{mm} \mathrm{NaCl}$ in $0.2 \mathrm{ml}$ PCR tubes with zirconium oxide beads. Twenty-five microliters of culture media from various cells were added to each PMCA reaction. PCR tubes were then placed in Q700 sonicator (Qsonica) where they received repeated cycles of $10 \mathrm{~s}$ sonication, followed by $30 \mathrm{~min}$ incubation at $37^{\circ} \mathrm{C}$. Thioflavin $\mathrm{T}(\mathrm{ThT})$ readings were performed at various time points by transferring $2 \mu \mathrm{l}$ of sample into wells of a black 
a

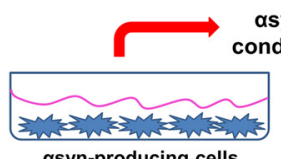

asyn-producing cells (asyn-inducible M17 cells) asyn-enriched conditioned media

C

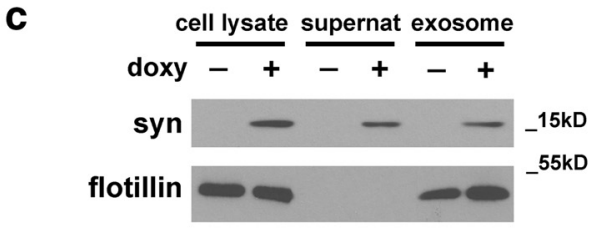

d

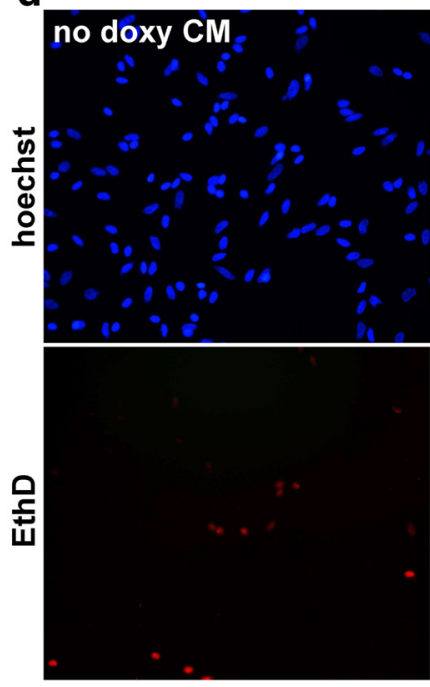

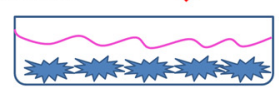

target cells (primary neurons or differentiated SH-SY5Y cells
ditiset cells (primary neurons or

b

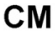

lysate
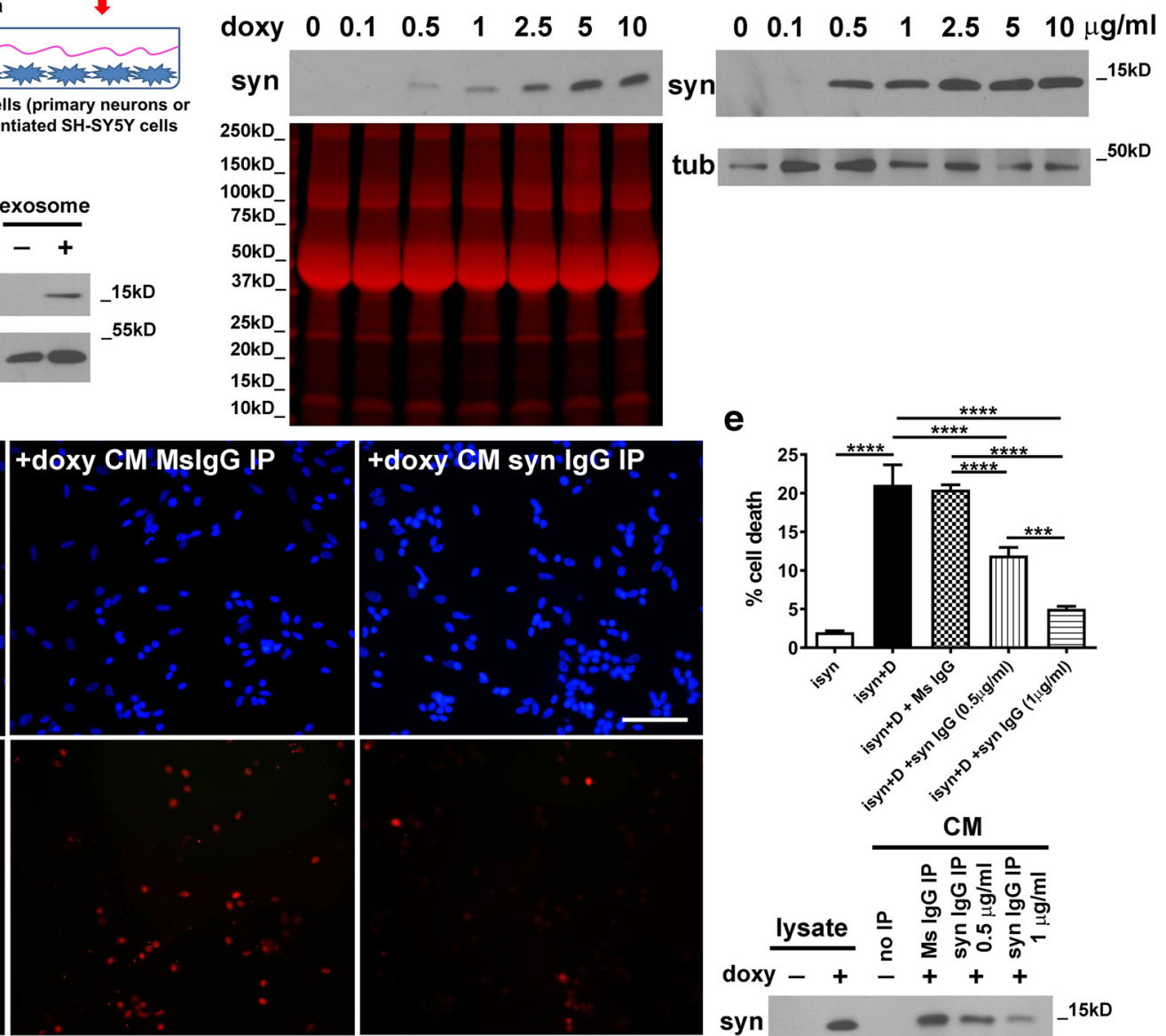

e

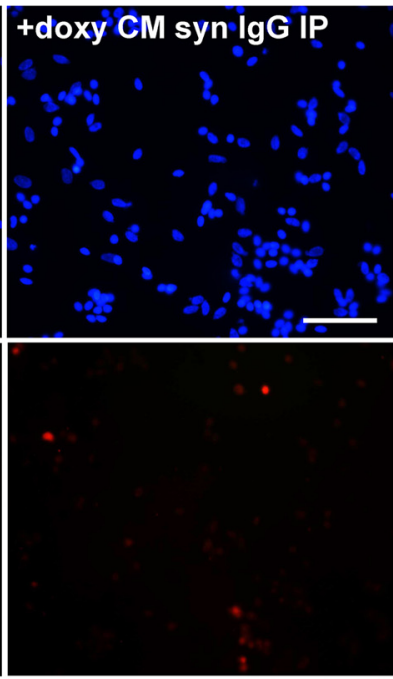

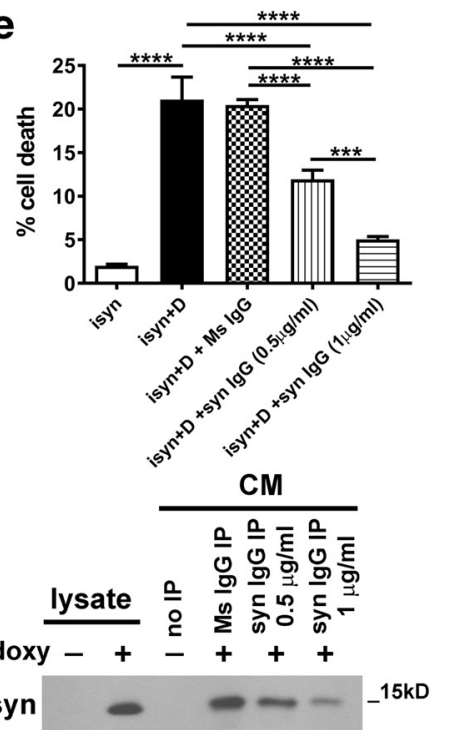

Figure 1. Paracrine $\alpha$ syn model. $\boldsymbol{a}$, Schematic of isyn cell model. In response to doxycycline treatment, doxy-inducible $\alpha$ syn cells produce an excess of $\alpha$ syn that is released into the $C M$. When transferred to separately cultures neurons, $\alpha$ syn-enriched CM induces neuronal death. $\boldsymbol{b}$, Doxy dose-response. Increasing doxy concentrations induced higher amounts of $\alpha$ syn in the cell lysates of isyn cells, and, correspondingly, higher amounts of $\alpha$ syn is released into the CM. Equal protein levels were loaded for each CM sample. Coomassie stain confirmed equal protein loading for the CM. c, $\alpha$ Syn that is released in response to $\alpha$ syn induction is found in both the exosomal and non-exosomal fractions of $C M$ after high-speed ultracentrifugation of the CM. $d$, CM from doxy-induced isyn induces cell death in differentiated SH-SY5Y cells that are separately cultured. Representative images of differentiated SH-SY5Y cells treated with CM from uninduced or induced isyn cells. Ethidium D labels nuclei of dying cells, while Hoechst 33342 stains the nuclei of all cells. Scale bar, $100 \mu \mathrm{m}$. $\boldsymbol{e}$, Immunoprecipitation of $\alpha$ syn from CM by $\alpha$ syn-directed monoclonal antibody reduces the toxicity of the CM in a dose-dependent manner. Quantification of cell death in differentiated SH-SH5Y cells treated with CM from induced isyn cells in which $\alpha$ syn was immunodepleted. Western blot of $\mathrm{CM}$ after immunoprecipitation confirms reduction of $\alpha$ syn from the CM. $n=3-5$ per condition. ${ }^{* * *} p=0.0005,{ }^{* * *} p<0.0001$ (Tukey's multiple-comparison test). Error bars represent SEM. D, Doxy.

bottomed 96-well plate, and incubating with $198 \mu \mathrm{l} 20 \mu \mathrm{M}$ ThT solution (20 $\mu \mathrm{M}$ ThT, $50 \mathrm{~mm}$ glycine, $\mathrm{pH} 8.5$ ) for $5 \mathrm{~min}$. ThT fluorescence readings were performed on a Tecan M200 plate reader with an excitation of 440 $\mathrm{nm}$ and an emission of $480 \mathrm{~nm}$.

$\alpha$ Syn fibril preparation. Fibrils were generated by incubating purified monomeric $\alpha$ syn at a concentration of $5 \mathrm{mg} / \mathrm{ml}$ in $50 \mathrm{~mm}$ Tris, $\mathrm{pH} 7.5$, with $166 \mathrm{~mm} \mathrm{KCl}$ with constant agitation at $700 \mathrm{rpm}$ at $37^{\circ} \mathrm{C}$ for $7 \mathrm{~d}$. Before addition to primary neurons, $\alpha$ syn fibrils were diluted in PBS to 1 $\mathrm{mg} / \mathrm{ml}$ and then sonicated with a $1 / 8$ inch probe tip sonicator (Fisher Scientific, model 120) for 65 pulses over $40 \mathrm{~s}$ at power level 2. Sonicated $\alpha$ syn fibrils were added to primary neuronal cultures at 0.5 or $1 \mu \mathrm{g} / \mathrm{ml}$ in neuronal media.

Microfluidic chambers. Primary neurons were plated in microfluidic chambers with three cell compartments (TCND1000, Xona Microfluidics) per the manufacturer's instructions. At 5 DIV, PBS or PFFs were added to Chamber 1 only. A $75 \mu$ l difference in media volume was maintained between each chamber with the lowest volume in Chamber 1 to control the direction of media flow.

Immunocytochemistry. Primary neurons were fixed in $4 \%$ paraformaldehyde with $4 \%$ sucrose and $1 \%$ Triton X-100 for 15 min. After washing in PBS, neurons were permeabilized with $3 \%$ BSA and $0.1 \%$ Triton
X-100 in PBS for 10 min and then blocked with 3\% BSA in PBS for 20 min. Neurons were incubated overnight with pS129- $\alpha$ syn antibody (Abcam, ab51253) in 3\% BSA. After washing, neurons were incubated with goat anti-rabbit or anti-mouse secondary antibody in 3\% BSA. Neurons were imaged using an Olympus BX51 epifluorescence microscope. Ten high-power $(20 \times)$ fields per well were randomly selected for quantification, and the percentage of area positive for $\mathrm{pS} 129-\alpha$ syn immunoreactivity was quantitated using ImageJ with the rater blind to experimental conditions (Schneider et al., 2012). For triple-chamber slides, images of the whole chamber were taken for quantification of pS129- $\alpha$ syn immunoreactivity.

Experimental design and statistical analysis. GraphPad Prism 7 was used for statistical analysis of experiments. Data were analyzed by either Student's $t$ test or by one-way or two-way ANOVA, followed by post hoc pairwise comparisons using Sidak's or Tukey's multiple-comparison tests. Figures $1 e, 2 b-f, 3 b-e, 4 b, c, f, h, i, 5 b-f, 6 f$, and $9 a, b$ use one-way ANOVA followed by post hoc Tukey's multiple-comparison test if necessary. Figures $4 d, e, k, 10 b, c, 11 b, c$, and $12 b, c$ use two-way ANOVA followed by post hoc Sidak's multiple-comparison test. Figures $6 c-e, 7 a, c, 8 b, d, e, f$, $11 e$, and $12 e$ use unpaired Student's $t$ test. Statistical significance was set at $p \leq 0.05$. 
For Figures $13 c, d$, and $14 b, c$, data were log transformed before unpaired Student's $t$ test with correction for multiple comparisons using the Holm-Sidak method.

All the details of experiments can be found in Results or the figure legends. All data values are presented as mean \pm SEM. ANOVA related statistics ( $F$ statistic, $p$ values) are noted in the results section, whereas the post hoc test results are found in the figure legends. For $t$ tests, the $t$ statistic and $p$ values are noted in Results.

\section{Results}

\section{4-3-3 $\theta$ reduces toxicity of released $\alpha$ syn in a non-cell autonomous manner}

We have developed a paracrine $\alpha$ syn model to evaluate the toxicity associated with neuronally-released $\alpha$ syn (Fig. 1). We created a doxy-inducible neuroblastoma line, termed isyn, which upon doxy treatment releases $\alpha$ syn into the CM (Fig. 1a). This paracrine system is similar to those developed by other groups in which $\alpha$ syn overexpression in neuronal lines promotes $\alpha$ syn release into the conditioned media with resultant toxicity to neighboring neurons (Desplats et al., 2009; Emmanouilidou et al., 2010; Danzer et al., 2011). Induction of $\alpha$ syn expression with doxy in isyn cells led to the detection of $\alpha$ syn in the CM in a dose-dependent manner (Fig. $1 b$ ). Previous research has shown that $\alpha$ syn is released through exosomal and non-exosomal pathways (Lee et al., 2005; Liu et al., 2009; Emmanouilidou et al., 2010; Hasegawa et al., 2011; Danzer et al., 2012). We fractionated the CM into exosomal and non-exosomal fractions by sequential, high ultracentrifugation techniques (Thery et al., 2006) and found that $\alpha$ Syn was released into both exosomal and nonexosomal fractions (Fig. 1c). This neuronally-released $\alpha$ syn is toxic to separately cultured neurons: transfer of $\alpha$ syn-enriched CM from induced isyn cells induces cell death of separately cultured differentiated SH-SY5Y neuroblastoma cells and primary neurons (Fig. 1d). Toxicity from $\alpha$ syn-enriched CM depends on $\alpha$ syn, as immunodepletion of $\alpha$ syn from the CM eliminated toxicity in a dose-dependent manner (Fig. 1d,e; one-way ANOVA, $\left.F_{(4,15)}=96.84, p<0.0001\right)$.

We tested whether 14-3-3 proteins could affect the toxicity of released $\alpha$ syn. Isyn cells were transduced with a V5-tagged 143-3 $\theta$ doxy-inducible lentivirus and selected for polyclonal stable transfection. Toxicity of $\alpha$ syn-enriched CM was reduced to basal levels when 14-3-3 $\theta$ was co-overexpressed with $\alpha$ syn upon doxy induction in isyn cells. Separately-cultured primary hippocampal neurons showed $31 \%$ cell death at $24 \mathrm{~h}$ when treated with CM from induced isyn cells, but toxicity was back to baseline when treated with CM from induced 14-3-3 $\theta$-overexpressing isyn cells (Fig. $2 a, b$; one-way ANOVA: $F_{(3,18)}=43.81, p<0.0001$ ). Similarly, 14-3-3 $\theta$ overexpression in isyn cells also reduced the toxicity of $\alpha$ syn-enriched CM that was transferred to cortical neurons (Fig. $2 c$; one-way ANOVA: $F_{(3,12)}=202.7, p<0.0001$ ) or differentiated SH-SY5Y cells (Fig. $2 d$; one-way ANOVA: $F_{(2,9)}=348.3$, $p<0.0001)$ back to baseline. Cellular $\alpha$ syn levels in isyn cells were not reduced but slightly increased with 14-3-3 $\theta$ overexpression (see Fig. $4 c$; one-way ANOVA: $F_{(3,20)}=259, p<0.0001$ ).

We next tested whether the overexpression of 14-3-3 $\theta$ in target neurons impacted the toxicity of CM from induced isyn cells. Hippocampal neurons cultured from 14-3-3 $\theta$ transgenic mice were resistant to $\alpha$ syn-enriched CM toxicity compared with neurons cultured from nontransgenic littermates (Fig. $2 e$; one-way ANOVA, $\left.F_{(3,44)}=8.242, p=0.0002\right)$.

We next examined whether the protective effects of 14-3-3 $\theta$ against the toxicity of released $\alpha$ syn was specific to $14-3-3 \theta$ or whether other 14-3-3 isoforms could be protective. Isyn cells were transduced with a V5-tagged 14-3-3 $\zeta$ doxy-inducible lenti- virus and selected for polyclonal stable transfection. Toxicity of $\alpha$ syn-enriched CM was minimally reduced when 14-3-3 $\zeta$ was co-overexpressed with $\alpha$ syn upon doxy induction in isyn cells (Fig. $2 f$; one-way ANOVA, $F_{(5,30)}=407.3$, $p<0.0001$ ).

14-3-3 proteins have been shown to promote cell survival (Porter et al., 2006), and we previously demonstrated that 143-3 $\theta$ overexpression reduces cell death in neurotoxin and mutant LRRK2 models in a cell autonomous manner (Yacoubian et al., 2010; Slone et al., 2011, 2015; Ding et al., 2015; Lavalley et al., 2016). We hypothesized that protection against $\alpha$ syn-enriched CM when 14-3-3 $\theta$ was overexpressed in isyn cells could be mediated by the transfer of exogenous V5-tagged 14-3-3 $\theta$ into the target neurons exposed to the CM. Exogenous V5-tagged 14-3-3 $\theta$ could not be detected by Western blot or immunocytochemistry in differentiated SH-SY5Y cells exposed to CM from 14-3-30overexpressing isyn cells (Fig. $2 g, h$ ). We conclude that the protective effect of 14-3-3 $\theta$ when overexpressed in isyn cells is not likely due to the transfer of exogenous V5-tagged 14-3-3 $\theta$ into target neurons.

\section{4-3-3 inhibition increases the toxicity of released $\alpha$ syn}

We next tested whether inhibition of endogenous 14-3-3s would impact the toxicity of neuronally-released $\alpha$ syn. Difopein (dimeric 14-3-3peptide inhibitor) is a high-affinity 14-3-3 competitive antagonist peptide that disrupts 14-3-3/ligand interactions by binding within the amphipathic groove of 14-3-3s without selectivity among the different isoforms (Masters and Fu, 2001). Mutant difopein is a control peptide with two amino acid mutations that prevents the difopein peptide from binding 14-3-3s (Masters and $\mathrm{Fu}, 2001$ ). iSyn cells were transduced with a doxyinducible difopein tagged with eYFP lentivirus (isyn/dif) or with a doxy-inducible mutant difopein tagged with eYFP lentivirus (isyn/yfp). Difopein-eYFP increased toxicity by twofold in primary hippocampal neurons at $24 \mathrm{~h}$ after treatment with $\alpha$ synenriched CM compared with mutant difopein-eYFP control (Fig. $3 a, b$; one-way ANOVA: $\left.F_{(3,26)}=72.27, p<0.0001\right)$. Similarly, difopein-eYFP increased toxicity to $45.9 \%$ in differentiated $\mathrm{SH}$ SY5H cells at $48 \mathrm{~h}$ after treatment with $\alpha$ syn-enriched CM (Fig. $3 c$; one-way ANOVA: $\left.F_{(3,12)}=42.68, p<0.0001\right)$. Whereas doxy treatment dramatically increased cellular $\alpha$ syn levels, difopein expression did not alter intracellular $\alpha$ syn levels in isyn cells (see Fig. $5 c$; one-way ANOVA: $\left.F_{(3,12)}=412.4, p<0.0001\right)$.

To confirm whether CM toxicity was still secondary to $\alpha$ syn released in the CM when difopein was coexpressed, we immunoprecipitated $\alpha$ syn from the CM of difopein-eYFP and mutant difopein-eYFP (control) expressing isyn cells using an $\alpha$ synspecific antibody before transfer of the CM to differentiated $\mathrm{SH}$ SY5Y cells (Fig. $3 d$ ). Toxicity of CM from difopein-eYFP or mutant difopein-eYFP isyn cells was eliminated by $\alpha$ syn immunoprecipitation (Fig. $3 d$; one-way ANOVA: $F_{(5,30)}=71.23, p<$ $0.0001)$. This finding suggests that the enhanced toxicity of $\mathrm{CM}$ from difopein-expressing isyn cells was due to $\alpha$ syn and not due to the release of other factors that may promote toxicity.

To test whether specific inhibition of endogenous 14-3-3 $\theta$ was sufficient to reduce $\alpha$ syn release, we used a shRNA targeting 14-

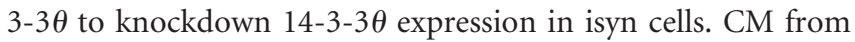
isyn cells in which 14-3-3 $\theta$ expression was reduced (isyn/1433KD cells) induced a 2.7-fold increase in cell death compared with that of isyn cells transfected with control shRNA (isyn/plko cells; Fig. $3 e$; one-way ANOVA: $\left.F_{(5,30)}=99.77, p<0.0001\right)$. 
a
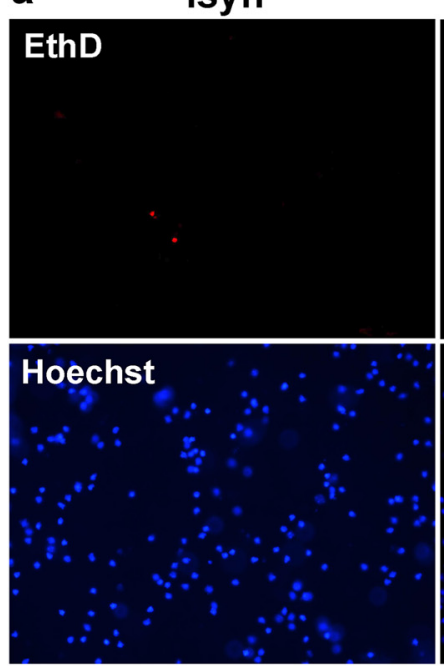

b primary hippocampal neurons

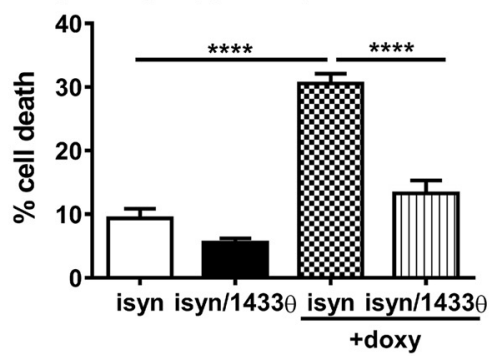

e

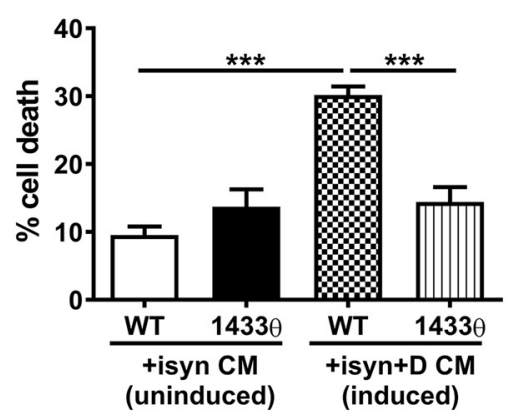

g

\section{isyn $/ 1433 \theta$ cells}

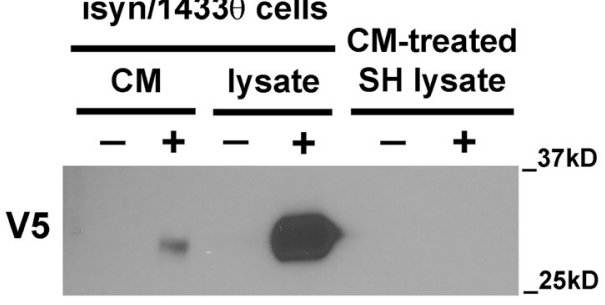

C isyn $/ 1433 \theta$

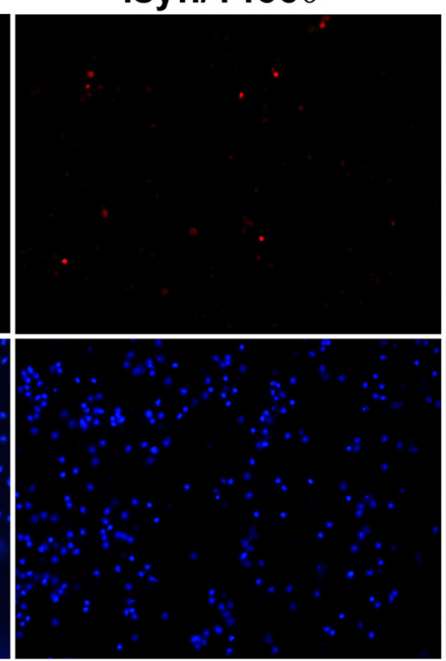

primary cortical neurons
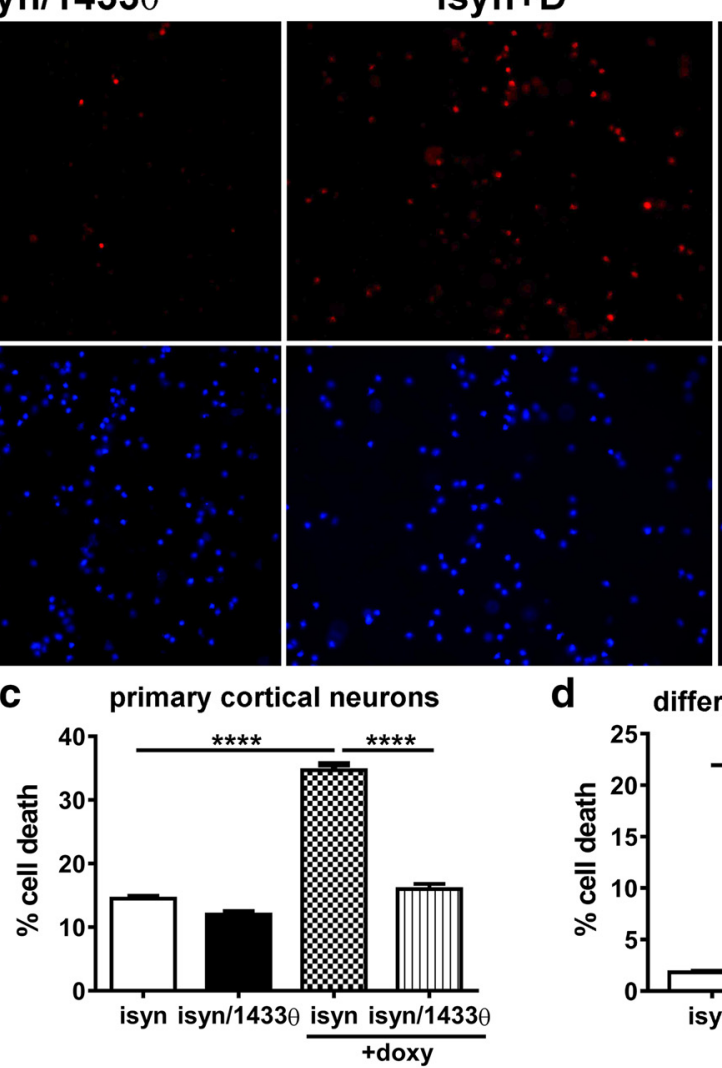

isy $n / 1433 \theta+D$

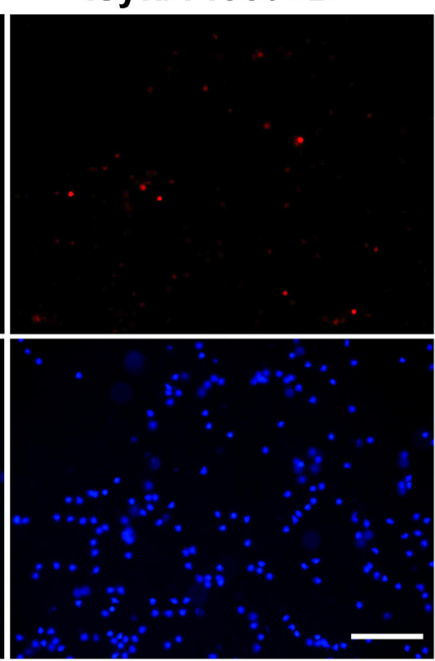

d

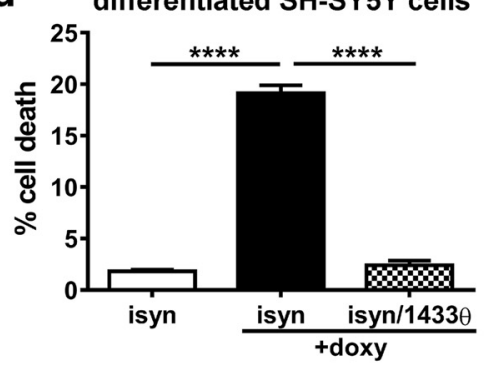

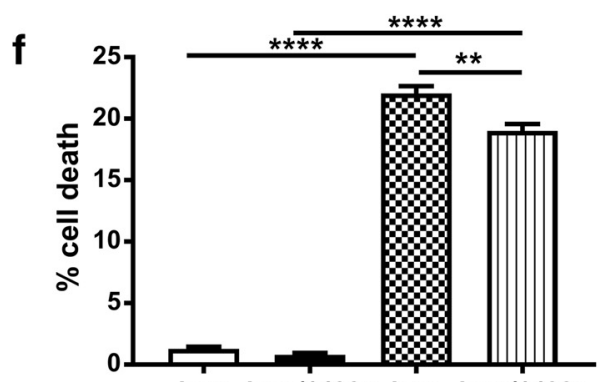

isyn isyn/1433 $\zeta$ isyn isyn/1433

+ doxy
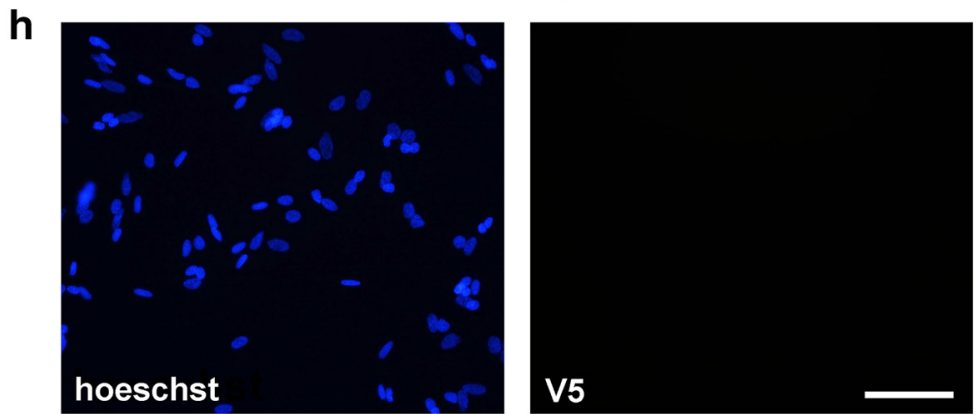

Figure 2. 14-3-3 $\theta$ overexpression in isyn cells reduces the toxicity of $\alpha$ syn-enriched CM. $\boldsymbol{a}$, Representative images of primary hippocampal neurons treated with CM from isyn cells or isyn cells expressing an inducible 14-3-3 $\theta$ construct. Ethidium D labels the nuclei of dying cells, whereas Hoechst 33342 stains the nuclei of all cells. Scale bar, $100 \mu m$ m. $\boldsymbol{b}$, Quantification of cell death in primary hippocampal neurons treated with CM from isyn or isyn/14-3-3 $\theta$ cells for $24 \mathrm{~h} . n=3$ independent rounds with two replicates per round. $c$, Quantification of cell death in primary cortical neurons treated with CM from isyn or isyn/14-3-3 $\theta$ cells for 24 h. $n=4$. $d$, Quantification of cell death in differentiated SH-SY5Y cells treated with CM from isyn or isyn/14-3-3 $\theta$ cells at 48 h. $n=3$ independent rounds with one to two replicates per round. $e$, Overexpression of 14-3-3 $\theta$ in target primary neurons also reduces toxicity of induced CM from isyn cells. Quantification of cell death in primary hippocampal neurons from nontransgenic or 14-3-3 $\theta$ transgenic mice treated with CM from isyn cells at $24 \mathrm{~h} . n=4$ independent rounds with one to six replicates/round. $f$, Quantification of cell death in differentiated SH-SY5Y cells treated with CM from isyn or isyn/14-3-3 $\zeta$ cells at $48 \mathrm{~h} . n=3$ independent rounds with two replicates per round. $\boldsymbol{g}$, Western blot of cell lysates from differentiated SH-SY5Y cells treated with CM from induced isyn/14-3-3 $\theta$ cells. Although the V5 tag of exogenous 14-3-3 $\theta$ is detected in lysates from induced isyn/14-3-3 $\theta$ cells and in the CM, V5 is not detected in lysates from differentiated SH-SY5Y cells treated with CM. $\boldsymbol{h}$, Exogenous V5-tagged 14-3-3 $\theta$ is not transferred to target neurons exposed to CM from isyn/14-3-3 $\theta$ cells. Immunocytochemistry for V5 tag in differentiated SH-SY5Y cells treated with CM from isyn/14-3-3 $\theta$ cells with or without induction. ${ }^{* *} p<0.01,{ }^{* * *} p<0.001,{ }^{* * *} p<0.0001$ (Tukey's multiple-comparison test). Error bars represent SEM. D, Doxy. 
a
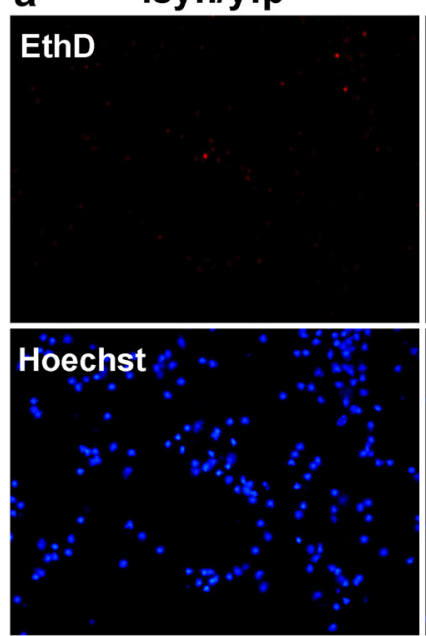

b primary hippocampal neurons

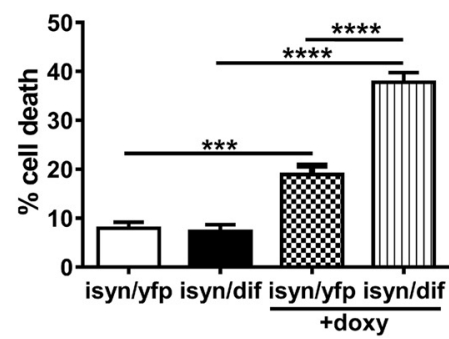

e

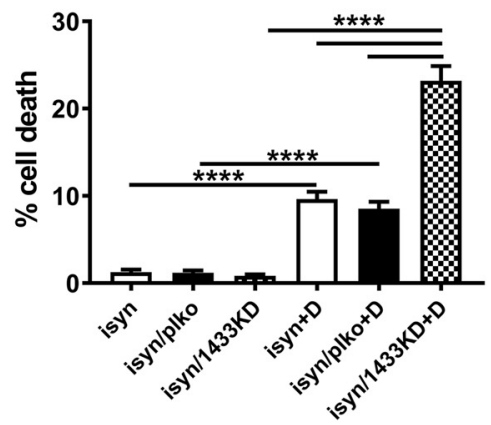

isyn/difopein
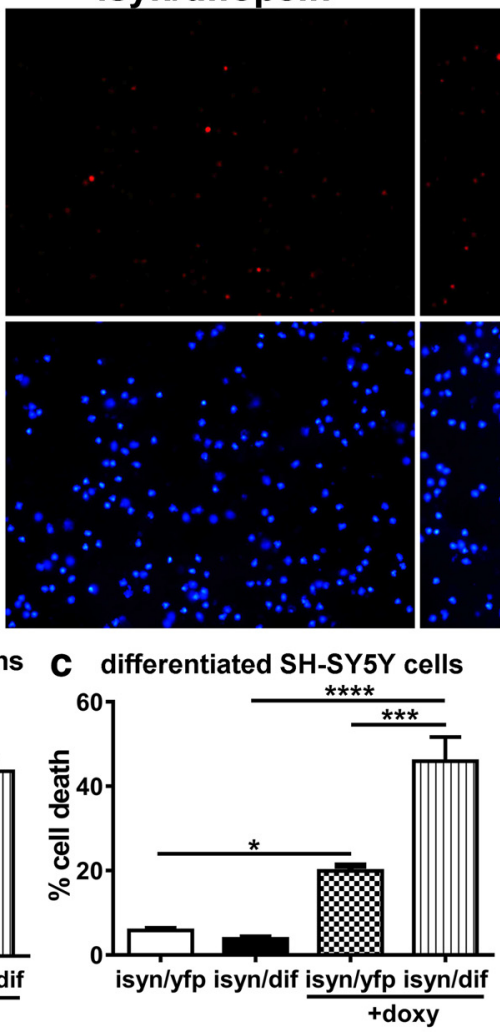

isyn/yfp+D

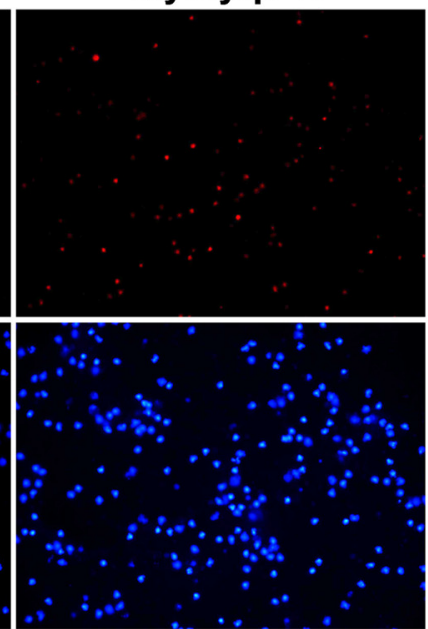

d

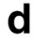

asyn pulldown

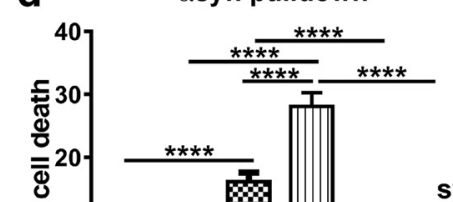

syn
isyn/difopein+D

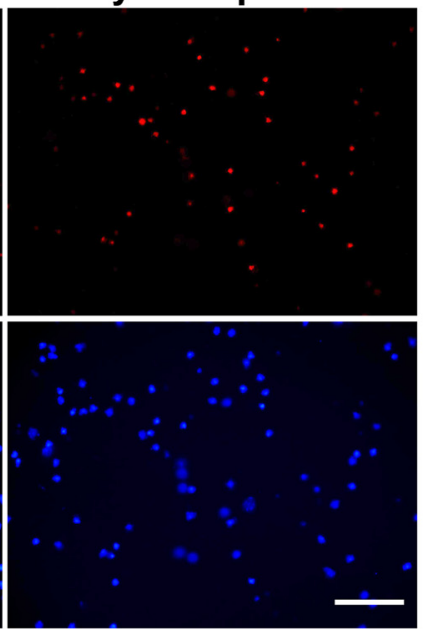

CM post CM post

CM post CM post
IgG IP synIP
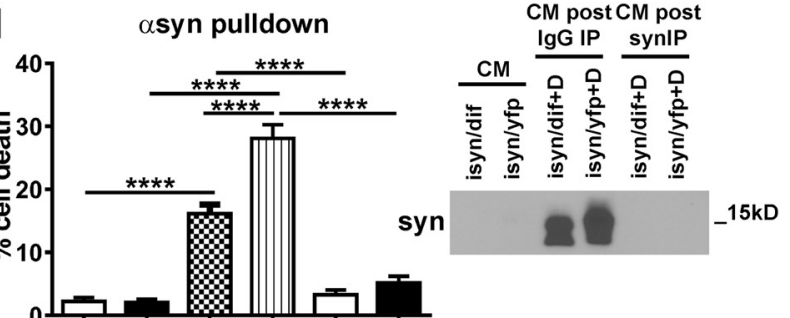
$15 \mathrm{kD}$

14-3-3 $\theta$

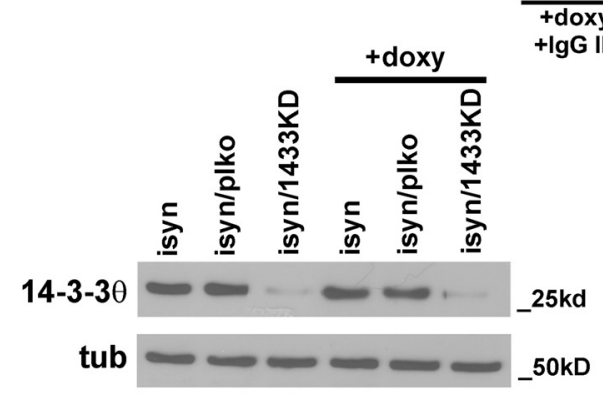

Figure 3. 14-3-3 inhibition in isyn cells increases the toxicity of $\alpha$ syn-enriched CM. $a$, Representative images of primary hippocampal neurons treated with CM from isyn cells expressing either an inducible difopein-eYFP (isyn/dif) construct or an inducible mutant difopein-eYFP construct (isyn/yfp; control). Scale bar, $100 \mu \mathrm{m} . \boldsymbol{b}, 0$ uantification of cell death in primary hippocampal neurons treated with CM from isyn/ difopein-eYFP cells (isyn/dif) or control isyn/mutant difopein-eYFP (isyn/yfp) cells at $24 \mathrm{~h}$. $n=$ three independent rounds with two to three replicates per round. $c$, Quantification of cell death in differentiated SH-SY5Y cells treated with CM from isyn/ difopein-eYFP cells (isyn/dif) or control isyn/mutant difopein-eYFP (isyn/yfp) cells at $48 \mathrm{~h}$. $n=4$ independent rounds with one replicate per round. $\boldsymbol{d}$, Immunoprecipitation of $\alpha$ syn from CM by $\alpha$ syn-directed monoclonal antibody eliminates the toxicity of CM from induced control isyn/mutant difopein-eYFP (isyn/yfp) cells and from induced isyn/difopein-eYFP (isyn/dif) cells. Quantification of cell death in differentiated SH-SY5Y cells treated with CM from isyn/dif or control isyn/yfp cells with or without $\alpha$ syn immunodepletion. Western blot of CM after $\alpha$ syn immunoprecipitation confirms that $\alpha$ syn is eliminated from the CM. $n=4$ rounds with one to two replicates/round. , Quantification of cell death in differentiated SH-SY5Y cells treated with CM from isyn cells (isyn), control isyn/plko.1 empty vector cells (isyn/plko), or isyn/14-3-3 $\theta$ shRNA (isyn/14-3-3 KD) cells at 48 h. $n=3$ independent rounds with two replicates per round. Western blot of cell lysates confirms $14-3-3 \theta$ protein levels are reduced in isyn/14-3-3 KD cells. ${ }^{*} p<0.05$, ${ }^{* * *} p<0.001,{ }^{* * *} p<0.0001$ (Tukey's multiple-comparison test). Error bars represent SEM. D, Doxy.

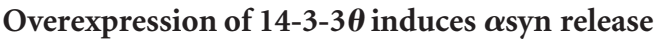

As 14-3-3 $\theta$ reduced the toxicity of $\alpha$ syn released by isyn cells, we next examined whether 14-3-3 $\theta$ regulated the amount of $\alpha$ syn released in this paracrine model system. Surprisingly, when both $\alpha$ syn and $14-3-3 \theta$ overexpression were induced by $10 \mu \mathrm{g} / \mathrm{ml}$ doxy, we observed a 2.6-fold increase in the amount of $\alpha$ syn released into the $\mathrm{CM}$ as measured by Western blot (Fig. $4 a-c$; one-way ANOVA: $\left.F_{(3,24)}=61.91, p<0.0001\right)$. To control for any potential differences between $\alpha$ syn expression in the cell lysates, we also normalized $\alpha$ syn in the CM to $\alpha$ syn expression in the cell lysates and still observed a 2.1-fold increase in $\alpha$ syn release (unpaired, two-tailed Student's $t$ test: $\left.t_{(10)}=5.796, p=0.0002\right)$.
14-3-3 $\theta$ overexpression promoted higher levels of $\alpha$ syn release into the CM compared with control at multiple doses of doxy induction (Fig. $4 d$; two-way ANOVA, treatment: $F_{(1,24)}=34.58$, $p<0.0001$; dose: $F_{(5,24)}=29.23 ; p<0.0001$; interaction: $F_{(5,24)}=$ $3.584 p=0.0146)$.

To test whether $\alpha$ syn release induced by $14-3-3 \theta$ changed over time, we measured $\alpha$ syn release into the CM at 2, 3, 4, and $7 \mathrm{~d}$ after $10 \mu \mathrm{g} / \mathrm{ml}$ doxy induction by ELISA. A difference in total $\alpha$ syn release was noted as early as at $3 \mathrm{~d}$ but became statistically significant at 4 and $7 \mathrm{~d}$ after treatment (Fig. $4 e$; two-way ANOVA, treatment: $F_{(1,16)}=471.6, p<0.0001$; time: $F_{(4,16)}=1751, p<0.0001$; interaction: $F_{(4,16)}=454.4, p<$ 


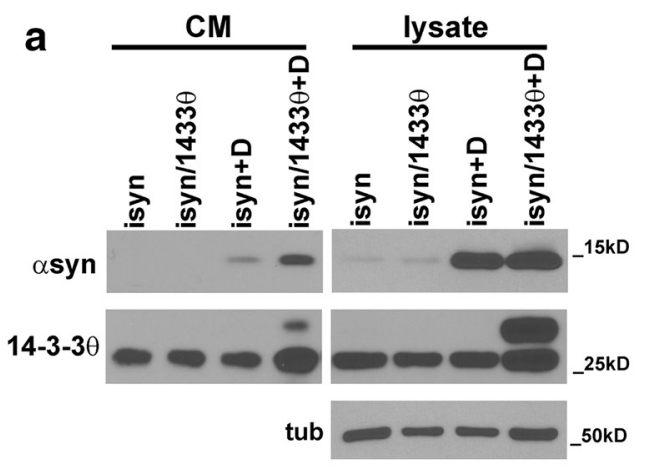

b

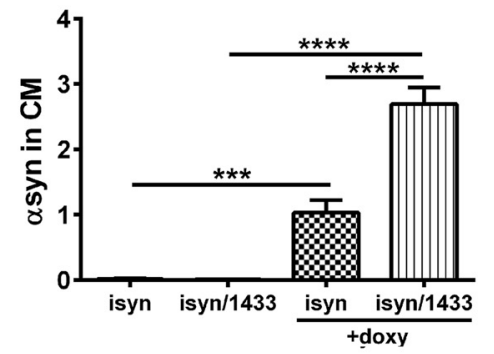

d

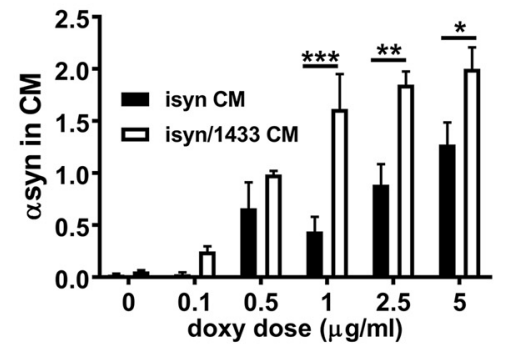

9

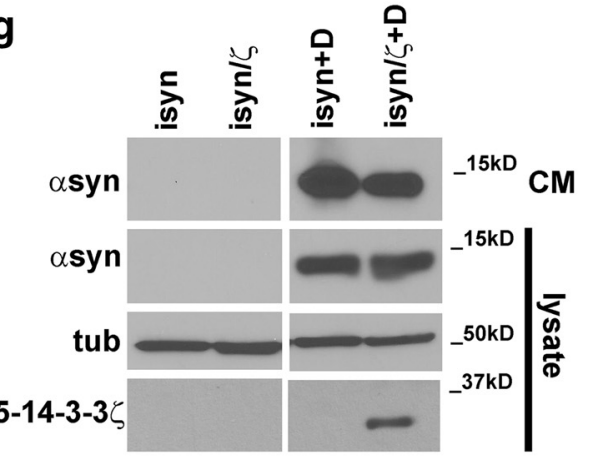

e

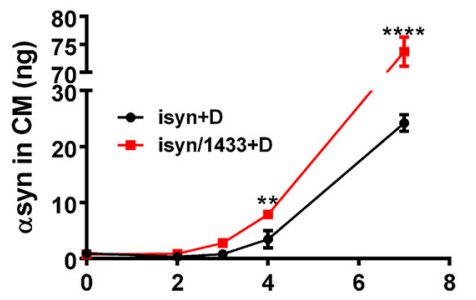

h

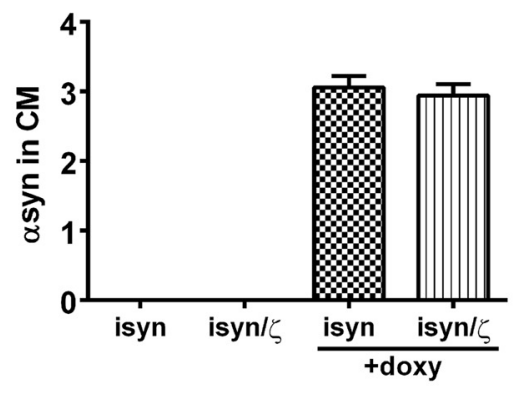

C
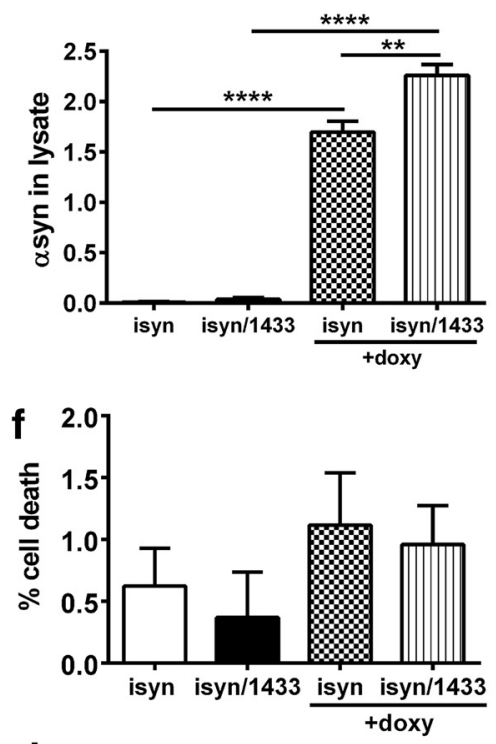

i

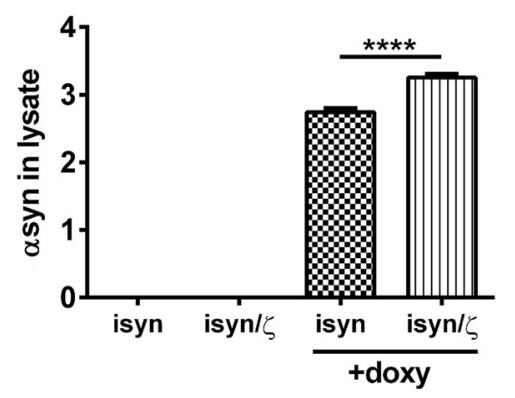

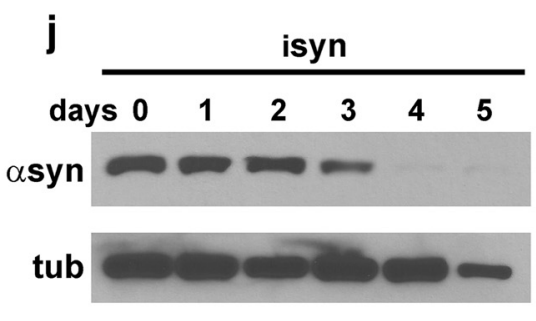
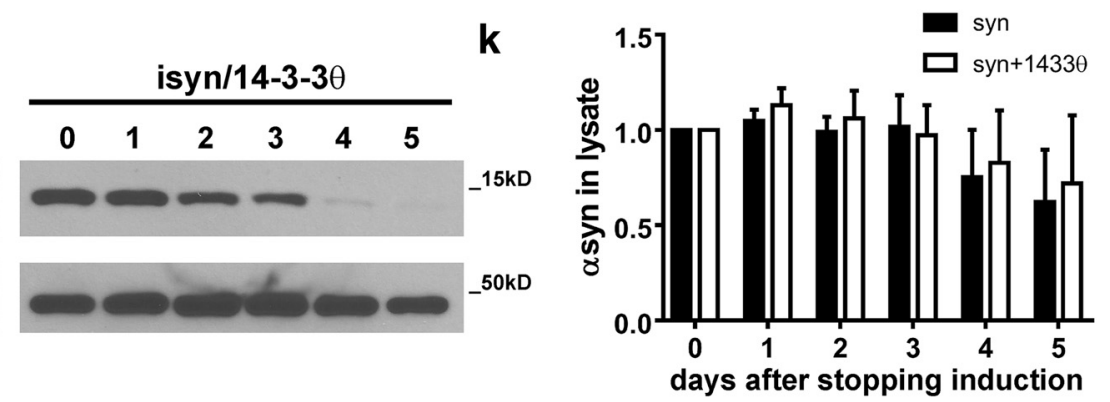

Figure 4. 14-3-3 $\theta$ increases $\alpha$ syn release into the CM. $\boldsymbol{a}$, Representative Western blot of CM and cell lysate from uninduced and induced isyn cells and isyn/14-3-3 $\theta$ cells after doxycycline (10 $\mu \mathrm{g} / \mathrm{ml}$ ) induction for $96 \mathrm{~h}$. Equal protein levels were loaded for each CM sample. $\boldsymbol{b}$, Quantification of $\alpha$ syn in the CM from isyn and isyn/14-3-3 $\theta$ cells with and without $96 \mathrm{~h}$ induction by Western blot. Equal protein amounts were loaded for each CM sample. $n=5$ independent rounds with 1-2 replicates per round. $c$, Quantification of $\alpha$ syn in the cell lysates from isyn and isyn/14-3-3 $\theta$ cells with and without $96 \mathrm{~h}$ induction by Western blot. $\alpha$ Syn in lysates was normalized to tubulin. $n=5$ independent rounds with one to two replicates per round. $\boldsymbol{d}$, Quantification of $\alpha$ syn in the $\mathrm{CM}$ from isyn and isyn/14-3-3 $\theta$ cells treated with increasing doses of doxy for $96 \mathrm{~h}$ by Western blot. Equal protein amounts were loaded for each CM sample. $n=3$ independent rounds.e, Quantification of $\alpha$ syn in the CM from isyn and isyn/14-3-3 $\theta$ cells by ELISA at 2,3,4, and $7 \mathrm{~d}$ after induction. Equal protein amounts were loaded for each CM sample. $n=3$ independent rounds with two replicates per round. $f$, Quantification of cell death in isyn and isyn/14-3-3 $\theta$ cells with and without induction. Number of Ethidium D-positive cells is normalized to total cell count, as determined by Hoechst 33342 staining. $n=3$ independent rounds. $9,14-3-3 \zeta$ does not alter $\alpha$ syn release. Representative Western blot of CM and cell lysate from uninduced and induced isyn cells and isyn/14-3-3 $\zeta$ cells after doxycycline (10 $\mu \mathrm{g} / \mathrm{ml})$ induction for $96 \mathrm{~h}$. $\boldsymbol{h}$, Quantification of $\alpha$ syn in the $\mathrm{CM}$ from isyn and isyn/14-3-3 $\zeta$ cells with and without $96 \mathrm{~h}$ induction by Western blot. Equal protein amounts were loaded for each CM sample. $n=4$ independent rounds. $i$, Quantification of $\alpha$ syn in the cell lysates from isyn and isyn/14-3-3 $\zeta$ cells with and without $96 \mathrm{~h}$ induction by Western blot. $\alpha$ Syn was normalized to tubulin. $n=4$ independent rounds. $\boldsymbol{j}, \boldsymbol{k}, 14-3-3 \theta$ does not alter $\alpha$ syn clearance. $\alpha$ Syn levels in cell lysates after withdrawal of doxycycline after $3 \mathrm{~d}$ of induction. Representative Western blot (j) and quantification ( $\mathrm{k}$ ) of $\alpha$ syn in cell lysates from isyn and isyn/14-3-3 $\theta$ cells each day after withdrawal of doxycycline. $\alpha$ Syn was normalized to tubulin. ${ }^{*} p<0.05$, ${ }^{* *} p<0.01$, ${ }^{* * *} p<0.001,{ }^{* * * *} p<0.0001$ (Tukey's multiple-comparison test). Error bars represent SEM. D, Doxy.

0.0001). The difference in $\alpha$ syn release was maintained over time with 14-3-3 $\theta$ overexpression. Differences in release were not due to cell death, as cell death was limited to $\sim 1 \%$ in induced isyn cells with and without 14-3-30 overexpression
(Fig. $4 f$; one-way ANOVA: $\left.F_{(3,8)}=0.8929, p=0.4854\right)$. Based on these data, we conclude that the ability of $14-3-3 \theta$ to reduce the toxicity of $\alpha$ syn-enriched CM was not secondary to a reduction in the total amount of $\alpha$ syn released. 


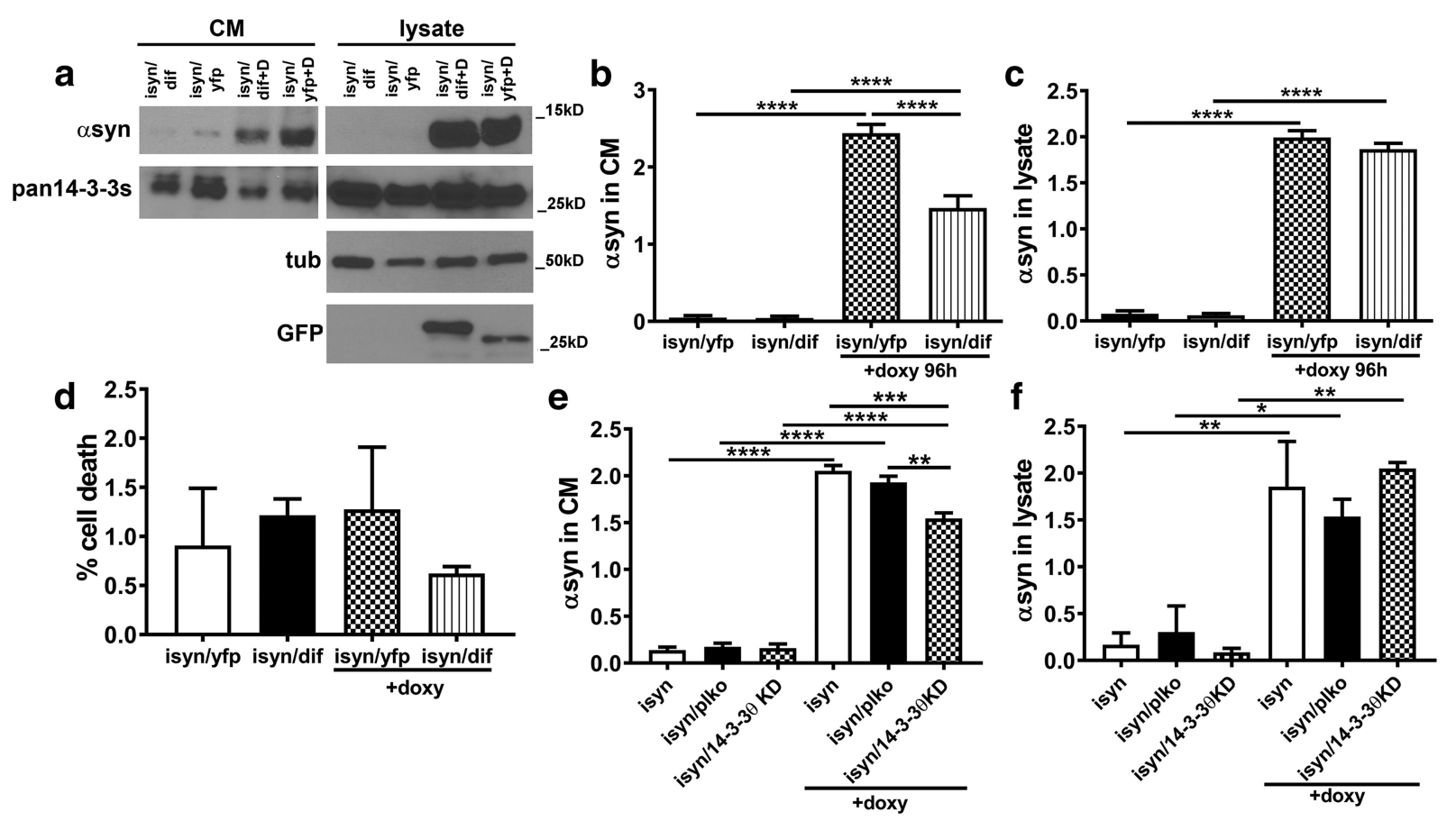

Figure 5. 14-3-3 inhibition reduces $\alpha$ syn release into the CM. $\boldsymbol{a}$, Representative Western blot of CM and cell lysate from uninduced and induced isyn/difopein-eYFP (isyn/dif) cells and control isyn/mutant difopein-eYFP (isyn/yfp) cells after doxy $(10 \mu \mathrm{g} / \mathrm{ml}$ ) induction for $96 \mathrm{~h}$. Equal protein levels were loaded for each CM sample. $\boldsymbol{b}$, Quantification of $\alpha$ syn in the CM from isyn/difopein-eYFP (isyn/dif) cells and control isyn/mutant difopein-eYFP (isyn/yfp) cells with and without $96 \mathrm{~h}$ induction by Western blot. Equal protein amounts were loaded for each CM sample. $n=4$ independent rounds. c, Quantification of $\alpha$ syn in the cell lysates from isyn/difopein-eYFP (isyn/dif) cells and control isyn/mutant difopein-eYFP (isyn/yfp) cells with and without $96 \mathrm{~h}$ induction by Western blot. $\alpha$ Syn in lysates was normalized to tubulin. $n=4$ independent rounds. $\boldsymbol{d}$, Quantification of cell death in isyn/difopein-eYFP (isyn/dif) and control isyn/mutant difopein-eYFP (isyn/yfp) cells with and without induction. $n=3$ independent rounds. , Quantification of $\alpha$ syn in the CM from isyn cells and isyn cells transfected with either plko.1 empty vector control lentivirus or 14-3-3 $\theta$ shRNA lentivirus with and without $96 \mathrm{~h}$ induction by Western blot. Equal protein amounts were loaded for each CM sample. $n=3$ independent rounds. $f$, Quantification of $\alpha$ syn in the cell lysates from isyn cells and isyn cells transfected with either plko.1 empty vector control lentivirus or 14-3-3 $\theta$ shRNA lentivirus with and without $96 \mathrm{~h}$ induction by Western blot. $\alpha$ Syn in lysates was normalized to tubulin. $n=3$ independent rounds. ${ }^{*} p<0.05,{ }^{* *} p<0.01,{ }^{* *} p<0.001,{ }^{* * * *} p<0.0001$ (Tukey's multiple-comparison test). Error bars represent SEM. D, Doxy.

We next examined whether another 14-3-3 isoform affected $\alpha$ syn release in a similar manner. Isyn cells were transduced with a doxy-inducible 14-3-3 $\zeta$ lentivirus and then selected for polyclonal stable transfection by hygromycin. While induction of $\alpha$ syn by doxy promoted $\alpha$ syn release, no change in the amount of released $\alpha$ syn was noted in isyn cells also overexpressing $14-3-3 \zeta$ compared with isyn cells (Fig. $4 g-i$; one-way ANOVA, $F_{(3,12)}=$ 228.8, $p<0.0001)$.

\section{4-3-3 $\theta$ overexpression does not alter $\alpha$ syn clearance}

Inhibition of the autophagy-lysosomal pathway increases $\alpha$ syn release from neurons (Emmanouilidou et al., 2010; Jang et al., 2010; Alvarez-Erviti et al., 2011; Danzer et al., 2012; Lee et al., 2013). We tested whether 14-3-3 $\theta$ overexpression reduced clearance of $\alpha$ syn which then indirectly increased $\alpha$ syn release. iSyn cells with and without 14-3-3 $\theta$ overexpression were induced with doxy for $4 \mathrm{~d}$ for maximal induction and then switched to doxyfree culture media up to another $5 \mathrm{~d}$. Lysates from isyn cells were then collected and probed for $\alpha$ syn by Western blot. In the absence of doxy, isyn cells slowly reduced $\alpha$ syn levels near baseline levels over $5 \mathrm{~d}$. We observed no differences in the rate of decline of total intracellular $\alpha$ syn levels from isyn cells with or without 143-3 $\theta$ overexpression (Fig. 4j, $k$; two-way ANOVA, treatment: $F_{(1,34)}=0.2133, p=0.6472$; time: $F_{(5,34)}=1.547, p=0.2017$; interaction: $\left.F_{(5,34)}=0.05065 ; p=0.9983\right)$. This finding suggests that 14-3-3 $\theta$ in isyn cells does not promote $\alpha$ syn release by slowing the clearance of $\alpha$ syn.
Inhibition of 14-3-3s reduces $\alpha$ syn release

We next tested whether inhibition of endogenous 14-3-3s would impact $\alpha$ syn release. $\alpha$ Syn released into the CM was reduced in isyn cells expressing the pan 14-3-3 inhibitor difopein-eYFP by $\sim 40 \%$ compared with control isyn cells expressing mutant difopein-eYFP (Fig. $5 a-c$; one-way ANOVA: $F_{(3,12)}=136.4, p<$ $0.0001)$. While total $\alpha$ syn levels were dramatically increased with doxy induction, there was no difference in the cell lysates between induced isyn cells expressing difopein-eYFP or mutant difopeineYFP (Fig. $5 c$; one-way ANOVA: $F_{(3,12)}=412.4, p<0.0001$ ). Cell death in isyn cells expressing either difopein-eYFP or mutant difopein-eYFP was only $1 \%$ (Fig. $5 d$; one-way ANOVA: $F_{(3,8)}=$ $0.4744, p=0.7087)$, such that cell death was not the cause of differences in $\alpha$ syn release.

To test whether specific inhibition of endogenous $14-3-3 \theta$ was sufficient to reduce $\alpha$ syn release, we tested the effect of a shRNA targeting 14-3-3 $\theta$ in isyn cells. 14-3-3 $\theta$ knockdown caused a reduction in the total amount of $\alpha$ syn released (Fig. $5 e$; one-way ANOVA: $\left.F_{(5,12)}=317, p<0.0001\right) . \alpha$ Syn levels in cell lysates were increased upon doxy treatment in control shRNA and 143-3 $\theta$ shRNA transduced isyn cells, but there was no difference in cellular $\alpha$ syn levels between the different lines (Fig. $5 f$; one-way ANOVA: $\left.F_{(5,12)}=13.47, p=0.0001\right)$.

\section{4-3-3 $\theta$ overexpression increases $\alpha$ syn release through exosomal and non-exosomal pathways}

Based on our release data, the protective effect of 14-3-3 $\theta$ on the toxicity of neuronally-released $\alpha$ syn is not secondary to a reduc- 
tion in the total amount of $\alpha$ syn released into the CM. Previous research has shown that $\alpha$ syn is released through exosomal and non-exosomal pathways, and certain studies have suggested that exosomally-released $\alpha$ syn may have increased toxic potential (Lee et al., 2005; Liu et al., 2009; Emmanouilidou et al., 2010; Hasegawa et al., 2011; Danzer et al., 2012; Stuendl et al., 2016; Ngolab et al., 2017). We fractionated the CM into exosomal and non-exosomal fractions by sequential, high ultracentrifugation techniques (Thery et al., 2006) to test whether 14-3-30 possibly preferentially directed release through non-exosomal pathways. To rule out the possibility that $\alpha$ syn that precipitated with exosomal pellets were not just large aggregates unassociated with exosomes that spun down due to high centrifugation speeds, we layered exosomal pellets after ultracentrifugation onto a discontinuous iodixanol gradient followed by ultracentrifugation at $250,000 \times g$ for $2 \mathrm{~h}$. $\alpha$ Syn was found only in the fractions that were positive for the exosomal marker flotillin (Fig. 6a). This confirmed that $\alpha$ syn that precipitated into the exosomal pellets was indeed associated with the exosomes. Cryo-EM and nanosight analysis revealed nanometer-sized vesicles consistent with exosomes (Fig. 6b,e).

The vast majority of released $\alpha$ syn in our model was associated with the non-exosomal fraction from isyn cells. Only $\sim 0.6 \%$ of total $\alpha$ syn was associated with the exosomal fraction. When 143-3 $\theta$ was overexpressed in isyn cells, the amount of $\alpha$ syn released in the exosomal fraction was increased nearly twofold (Fig. $6 c$; unpaired, two-tailed $t$ test: $\left.t_{(6)}=4.306, p=0.0051\right)$. $\alpha$ Syn released in the non-exosomal fraction was also increased by 143-3 $\theta$ overexpression (Fig. $6 c$; unpaired, two-tailed $t$ test: $t_{(6)}=$ $4.742, p=0.0032$ ). Conversely, we also examined the effect of 14-3-3 inhibition by difopein on exosomal and non-exosomal $\alpha$ syn release. When isyn cells expressed the 14-3-3 inhibitor difopein-eYFP, $\alpha$ syn release was reduced in both the exosomal (unpaired, two-tailed $t$ test: $t_{(4)}=7.246, p=0.0019$ ) and nonexosomal fractions (unpaired, two-tailed $t$ test: $t_{(4)}=4.877, p=$ 0.0082 ) compared with isyn cells expressing mutant difopeineYFP (Fig. $6 d$ ). Thus, the total change in $\alpha$ syn release induced by 14-3-3 manipulation occurred through both exosomal and nonexosomal pathways, and 14-3-3s did not lead to preferential release from one pathway versus the other.

We have previously shown that 14-3-3s increase the release of LRRK2 into exosomes (Fraser et al., 2013). To examine whether 14-3-3 $\theta$ overexpression could promote exosomal release in general, we used Nanosight analysis to determine the amount of exosomes released (Fig. 6e). We observed no difference in total exosomal counts between doxy-induced isyn cells or isyn/14$3-3 \theta$ cells (Fig. $6 e$ : unpaired, two-tailed $t$ test: $t_{(10)}=0.7024, p=$ $0.4984)$. Similarly, exosomal counts from induced isyn/difopeineYFP cells were similar to that from isyn/mutant difopein-eYFP control cells (Fig. $6 e$; unpaired, two-tailed $t$ test: $t_{(6)}=0.3996, p=$ $0.7033)$.

\section{Exosomal $\alpha$ syn does not mediate $\alpha$ syn toxicity in the paracrine system}

To determine whether the toxicity of $\alpha$ syn-enriched CM from isyn cells was mediated by the exosomal and/or non-exosomal fractions, we fractionated the $\alpha$ syn-enriched CM and then transferred each fraction to target cells to measure toxicity. We found that almost all of the toxicity due to released $\alpha$ syn was associated with the non-exosomal fraction (Fig. 6f; one-way ANOVA, $F_{(6,35)}=$ 50.27, $p<0.0001)$.

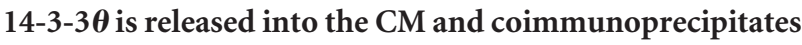 with $\alpha$ syn}

We next examined whether 14-3-3 $\theta$ levels were altered in the CM by 14-3-3 manipulation. Exogenous V5-tagged 14-3-3 $\theta$ and endogenous 14-3-3 $\theta$ levels were increased in the CM from isyn cells overexpressing 14-3-3 $\theta$ compared with control isyn cells (Fig. $7 a$; unpaired, two-tailed $t$ test: $\left.t_{(14)}=7.833, p<0.0001\right)$. 14-3-3 $\theta$ coimmunoprecipitated with $\alpha$ syn from the CM from induced isyn cells. In the presence of 14-3-3 $\theta$ overexpression, exogenous V5-tagged 14-3-3 $\theta$ and higher amounts of endogenous 14-3-3 $\theta$ coimmunoprecipitated with the released $\alpha$ syn, whose total levels were increased (Fig. $7 b$ ).

In contrast, $14-3-3 \theta$ levels in the CM were significantly decreased from isyn cells expressing difopein-YFP compared with isyn cells expressing mutant difopein-YFP (Fig. $7 c$; unpaired, two-tailed $t$ test: $t_{(4)}=6.505, p=0.0029$ ). This finding suggests that 14-3-3 inhibition interfered with the secretion of 14-3-3 $\theta$. In addition, less endogenous 14-3-3 $\theta$ coimmunoprecipitated with $\alpha$ syn from the CM of isyn cells expressing difopein-eYFP compared with that of isyn cells expressing mutant difopein-eYFP (Fig. 7d).

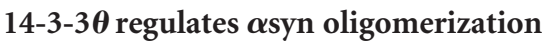

Oligomerization of $\alpha$ syn is an important feature promoting $\alpha$ syn toxicity. 14-3-3 $\theta$ overexpression reduces intracellular $\alpha$ syn aggregation in $\mathrm{H} 4$ neuroglioma cells (Yacoubian et al., 2010), and $14-3-3 \theta$ and $14-3-3 \eta$ reduce recombinant $\alpha$ syn aggregation as demonstrated by atomic force microscopy (Plotegher et al., 2014). Since $\alpha$ syn released into the CM was complexed with 14 $3-3 \theta$, we hypothesized that $14-3-3 \theta$ could impact $\alpha$ syn oligomerization. We first fractionated CM from induced isyn cells by size exclusion chromatography and observed that the released $\alpha$ syn from induced isyn cells was primarily eluted in fractions $\sim 7-8.5$ $\mathrm{ml}$ (Fig. 8a), fractions representing molecular sizes $>14 \mathrm{kDa}$, the expected monomeric $\alpha$ syn size. Others groups have similarly shown that released $\alpha$ syn under overexpression conditions is found in higher molecular weight fractions by SEC (Emmanouilidou et al., 2010; Danzer et al., 2011). When 14-3-3 $\theta$ was overexpressed in isyn cells, the amount of released $\alpha$ syn found in these higher molecular weight fractions was significantly reduced (Fig. $8 a, b$; unpaired, two-tailed $t$ test: $t_{(4)}=3.237, p=0.0318$ ). This reduction in higher molecular weight $\alpha$ syn when $14-3-3 \theta$ was overexpressed was associated with an increase in $\alpha$ syn in fractions in which monomeric $\alpha$ syn is expected (Fig. $8 a$ ). ELISA of the total CM before SEC fractionation confirmed that total $\alpha$ syn levels was overall higher in CM from isyn/14-3-3 $\theta$ cells compared with that from isyn cells despite the reduction in higher molecular weight $\alpha$ syn.

In contrast, expression of difopein-eYFP in isyn cells increased the amount of released $\alpha$ syn in the higher molecular weight fractions compared with that from control isyn cells expressing mutant difopein-eYFP (Fig. $8 c$, $d$; unpaired, two-tailed $t$ test: $\left.t_{(4)}=2.947, p=0.0421\right)$. In addition, there was a relative shift in the size of $\alpha$ syn released from isyn cells expressing difopein-eYFP toward larger molecular weight size (Fig. 8c). ELISA of total CM before SEC fractionation confirmed that total $\alpha$ syn levels was overall lower in the CM from difopein-expressing isyn cells compared with that from control cells despite the increase in higher molecular weight $\alpha$ syn.

While SEC fractionation demonstrated that $14-3-3 \theta$ regulates the biochemical and conformational profile of released $\alpha$ syn, it is unclear whether $\alpha$ syn eluted in higher molecular weight fractions is truly oligomeric or may instead reflect native $\alpha$ syn in an ex- 

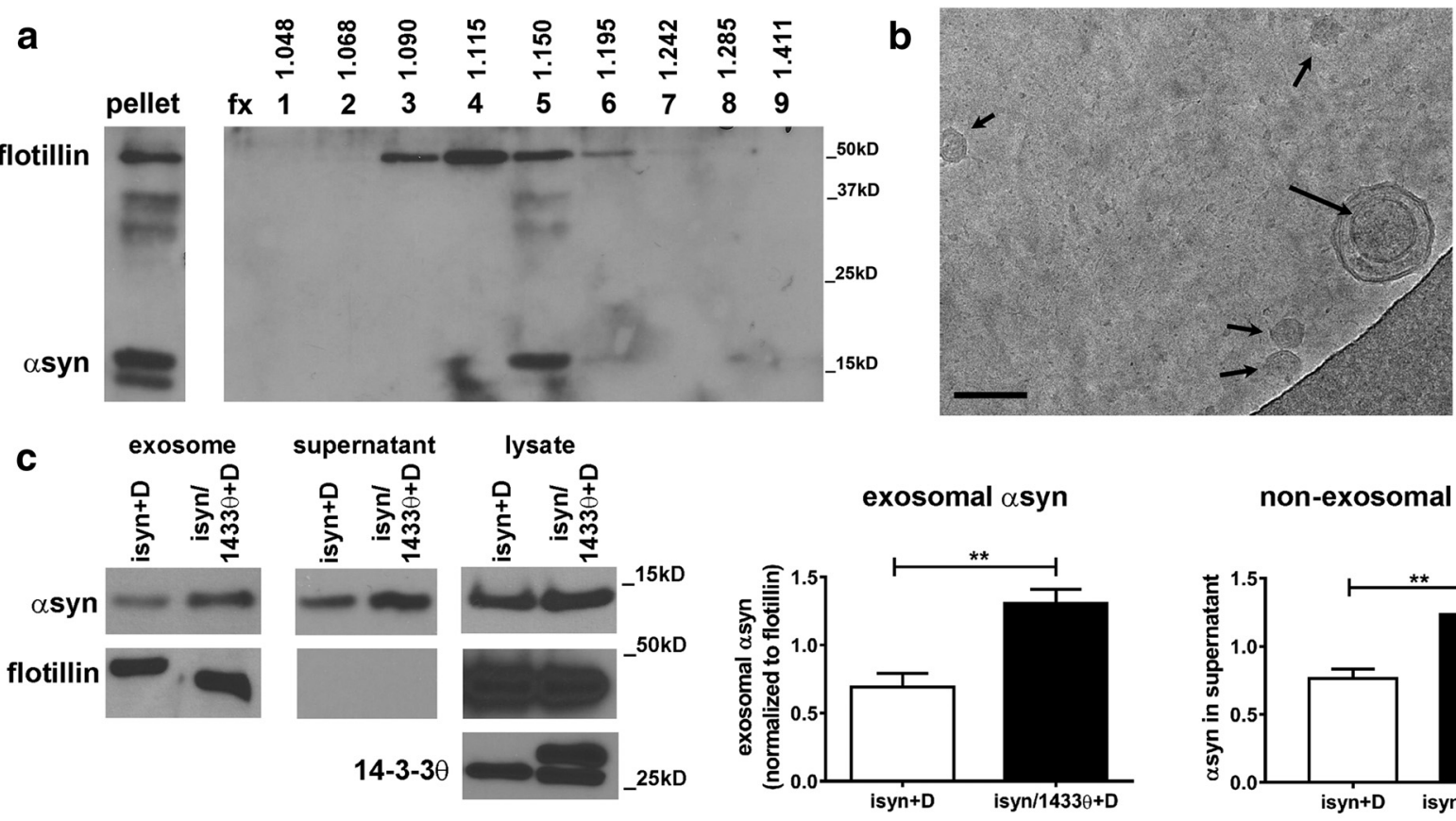

\section{non-exosomal $\alpha$ syn}
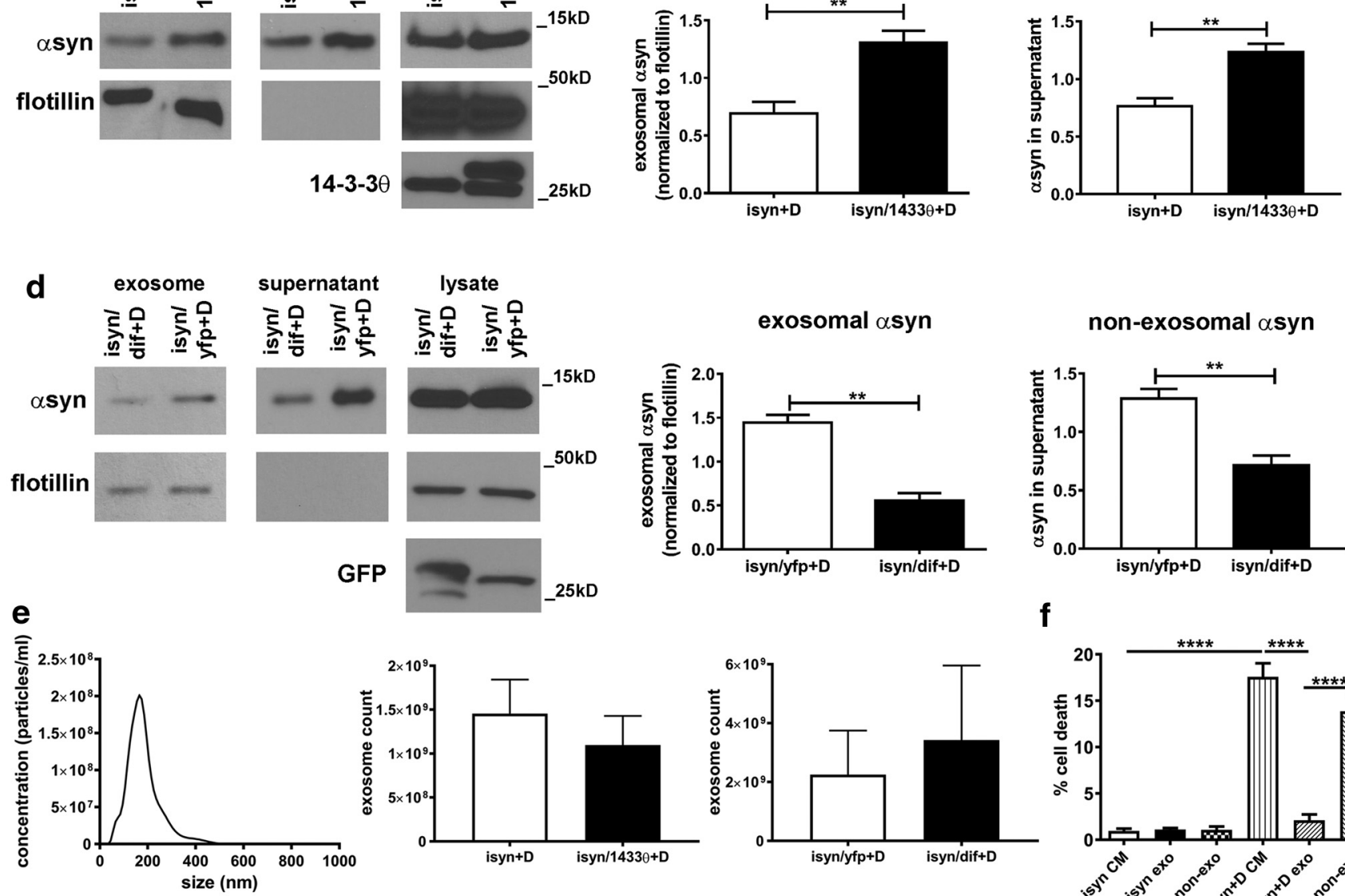

non-exosomal $\alpha$ syn
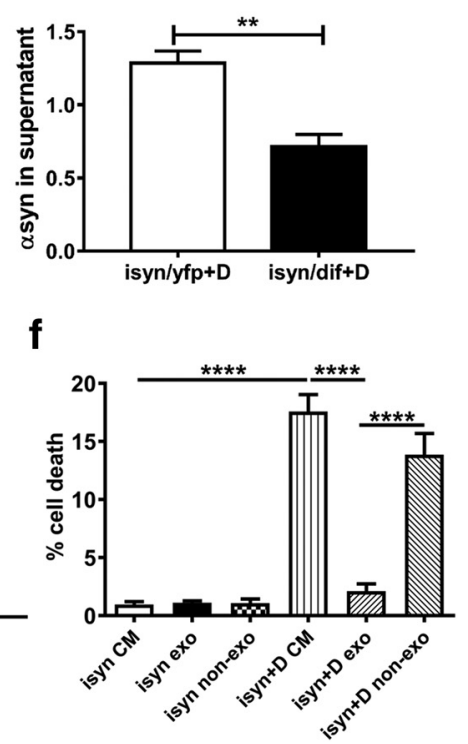

Figure 6. 14-3-3 $\theta$ regulates $\alpha$ syn release into both exosomal and non-exosomal fractions. $\boldsymbol{a}$, Exosomal pellet obtained by ultracentrifugation of CM from induced isyn cells was layered onto a discontinuous iodixanol gradient and then underwent ultracentrifugation. $\alpha$ Syn was found only in the fractions that were positive for the exosomal marker flotillin. Density is shown above each fraction. $\boldsymbol{b}$, Cryo-EM of exosomal pellet from induced isyn cells reveals vesicular structures of appropriate diameters for exosomes. Scale bar, $100 \mathrm{~nm}$. c, Quantification of $\alpha$ syn in the exosomal and non-exosomal (supernatant) fractions from isyn and isyn/14-3-3 $\theta$ cells with and without $96 \mathrm{~h}$ induction by Western blot. $n=4$ independent rounds. Exosomal $\alpha$ syn was normalized to flotillin . Equal protein amounts were loaded for each supernatant fraction. ${ }^{* *} p<0.01$ (Student's $t$ test). $\boldsymbol{d}$, Quantification of $\alpha$ syn in the exosomal and non-exosomal (supernatant) fractions from isyn/difopein-eYFP (isyn/dif) and isyn/mutant difopein-eYFP (isyn/yfp) control cells with and without $96 \mathrm{~h}$ induction by Western blot. $n=3$ independent rounds. Exosomal $\alpha$ syn was normalized to flotillin. Equal protein amounts were loaded for each supernatant fraction. ${ }^{* *} p<0.01$ (Student's $t$ test).e, Total exosome counts from exosomal fraction from CM of isyn cells, isyn/14-3-3 $\theta$ cells, isyn/difopein-eYFP (isyn/dif) cells, and isyn/mutant difopein-eYFP (isyn/yfp) control cells after $96 \mathrm{~h}$ of induction with doxycycline. $f$, Quantification of cell death in differentiated SH-SY5Y cells treated with the non-exosomal or exosomal fraction from CM of induced isyn cells. The non-exosomal fraction of the CM from induced isyn cells is toxic to differentiated SH-SY5Y cells, but the exosomal fraction of the CM lacks significant toxicity. $n=3$ independent rounds with two replicates per round. ${ }^{* * * *} p<0.0001$ (Tukey's multiple-comparison test). D, Doxy.

tended conformation, as has been suggested previously (Fauvet et al., 2012; Lashuel et al., 2013). As an alternative measure of the oligomerization of released $\alpha$ syn, we used a bioluminescent protein-fragment complementation assay in which a luciferase signal is generated when $\alpha$ syn fused to a non-bioluminescent amino terminal luciferase fragment (S1) interacts with $\alpha$ syn fused to a carboxy-terminal luciferase fragment (S2; Danzer et al., 2011). The luciferase signal generated by syn-syn interaction is a measure of oligomeric $\alpha$ syn that falls within the dimer to $\sim 30$ mer range (Danzer et al., 2011). Using this assay, we 

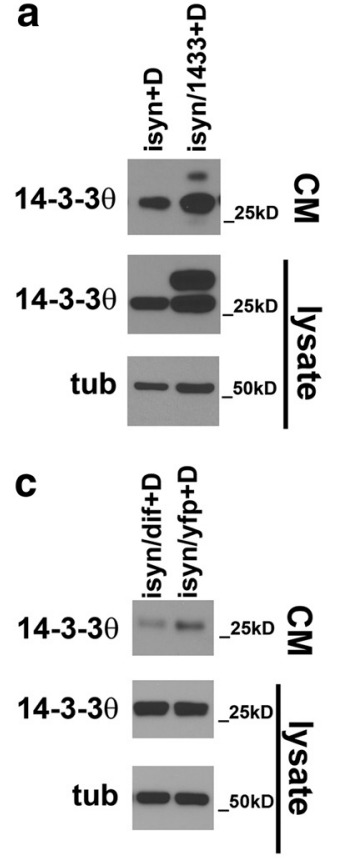
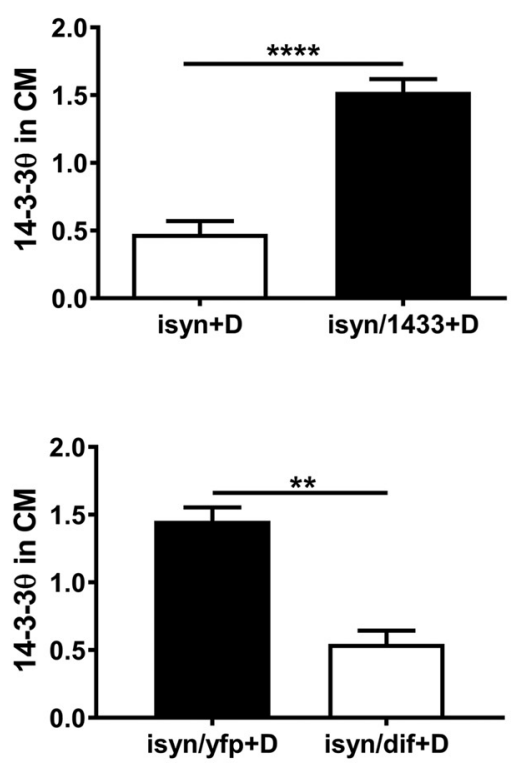

b

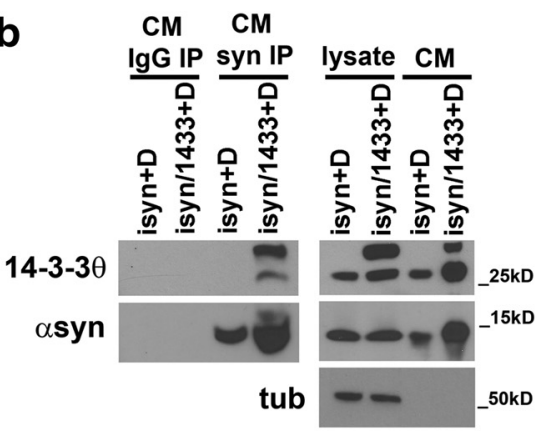

d
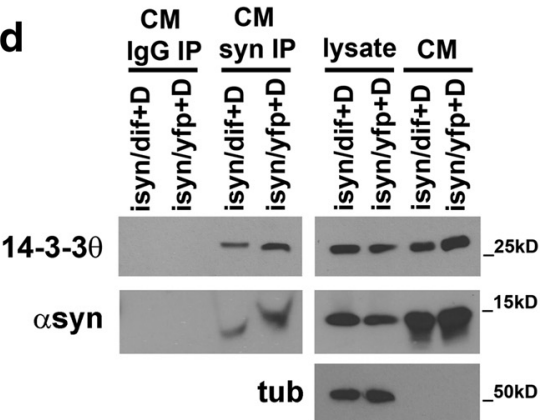

Figure 7. 14-3-3 inhibition reduces 14-3-3 $\theta$ release and its association with $\alpha$ syn in CM. $\boldsymbol{a}$, Quantification of endogenous and exogenous 14-3-3 $\theta$ released into CM from induced isyn and isyn/14-3-3 $\theta$ cells. Exogenous V5-tagged 14-3-3 $\theta$ runs slightly higher than endogenous 14-3-3 $\theta$ due to the V5-his epitope tag. Equal protein amounts were loaded for each CM sample. $n=8$ independent rounds. ${ }^{* * *} p<0.0001$ (Student's t test). $\boldsymbol{b}$, Representative blot of coimmunoprecipitation of $14-3-3 \theta$ with $\alpha$ syn from CM from induced isyn cells and from induced isyn/14-3-3 $\theta$ cells. Similar results were obtained on three additional independent runs. c, Quantification of endogenous 14-3-3 $\theta$ released into CM from induced isyn/difopein-eYFP (isyn/dif) and isyn/mutant difopein-eYFP (isyn/yfp) control cells. Equal protein amounts were loaded for each CM sample. $n=3$ independent rounds. ${ }^{* *} p=0.0029$ (Student's $t$ test).d, Representative blot of coimmunoprecipitation of 14-3-3 $\theta$ with $\alpha$ syn from CM from induced isyn/difopein-eYFP (isyn/dif) and isyn/mutant difopein-eYFP (isyn/yfp) control cells. Similar results were obtained on three additional independent runs. Error bars represent SEM. D, Doxy.

found that $14-3-3 \theta$ overexpression significantly reduced the amount of luciferase signal in the CM from $\mathrm{H} 4$ cells transfected with S1-syn and S2-syn compared with control (Fig. 8e; unpaired, two-tailed $t$ test: $t_{(17)}=4.188, p=0.0006$ ). Conversely, compared with mutant difopein-eYFP, difopein-eYFP increased the luciferase signal in the CM from $\mathrm{H} 4$ cells transfected with S1-syn and S2-syn (Fig. 8f; unpaired, two-tailed $t$ test: $\left.t_{(16)}=6.632, p<0.0001\right)$.

\section{4-3-3 $\theta$ reduces the seeding capability of released $\alpha$ syn}

We next tested whether 14-3-3 $\theta$ could regulate the seeding potential of $\alpha$ syn-enriched CM using the PMCA assay. PMCA is a technique initially developed to accelerate amplification of prion protein aggregates and has been adapted for measuring the growth of $\alpha$ syn aggregates (Herva et al., 2014; Shahnawaz et al., 2017; Becker et al., 2018). In this assay, recombinant $\alpha$ syn is incubated with minute amounts of potential misfolded $\alpha$ syn "seeds" in $\alpha$ syn-enriched CM to induce $\alpha$ syn polymerization; after a brief period of aggregation, the mixture is sonicated to break down the polymers into smaller sizes to generate more seeds for aggregation. Repeated cycles of sonication and incubation allow for exponential growth of polymers, and fibrillization of protein is measured by ThT fluorescence. We confirmed that CM from induced isyn cells induced fibrillization of recombinant $\alpha$ syn, while CM from uninduced isyn cells failed to induce significant seeding (Fig. 9a). CM from induced isyn cells overexpressing 14-3-3 $\theta$ showed a significant delay in $\alpha$ syn fibrillization compared with CM from induced isyn cells (Fig. 9a; one-way ANOVA: $\left.F_{(2,69)}=18.49, p<0.0001\right)$. This is despite the fact that higher total levels of $\alpha$ syn are present in the CM from isyn cells overexpressing 14-3-3 $\theta$. In contrast, CM from induced isyn cells expressing difopein-eYFP seeded $\alpha$ syn fibrillization more quickly than that from induced isyn cells expressing mutant difopeineYFP control peptide despite the finding that difopein reduces the total amount of $\alpha$ syn released into the CM (Fig. $9 b$; one-way ANOVA: $\left.F_{(2,69)}=23.04, p<0.0001\right)$. These findings suggest that endogenous $14-3-3$ s normally maintain $\alpha$ syn in a protein conformation that has reduced capability of inducing the misfolding of $\alpha$ syn molecules. These findings also demonstrate that the protein conformation and not the total amount of $\alpha$ syn released into the $\mathrm{CM}$ is important for inducing fibrillization.

\section{4-3-3 $\theta$ reduces internalization of released $\alpha$ syn by primary neurons}

Another key feature for $\alpha$ syn spread is the binding, uptake, and internalization of $\alpha$ syn by target neurons exposed to released $\alpha$ syn. We examined whether the number of cells that stained for human $\alpha$ syn was altered by manipulation of 14-3-3s in isyn cells that release $\alpha$ syn. To measure the uptake and internalization of released $\alpha$ syn, we took advantage of the species difference between human $\alpha$ syn released by the human neuroblastoma line and the endogenous mouse $\alpha$ syn expressed by primary hippocampal neurons. After treatment of the mouse hippocampal cultures with $\alpha$ syn-enriched CM, we detected human $\alpha$ syn expression in mouse neurons using a human-specific $\alpha$ syn antibody as early as $6 \mathrm{~h}$ after treatment. Confocal imaging revealed that human $\alpha$ syn was internalized into neurons exposed to $\alpha$ synenriched CM (Fig. 10a). Interestingly, human $\alpha$ syn appeared to be localized to the nucleus in neurons exposed to $\alpha$ syn-enriched CM. The percentage of cells that stained for human $\alpha$ syn increased with time, with maximal percentage of cells positive for human $\alpha$ syn noted at 24 h (Fig. 10b; two-way ANOVA, time: 

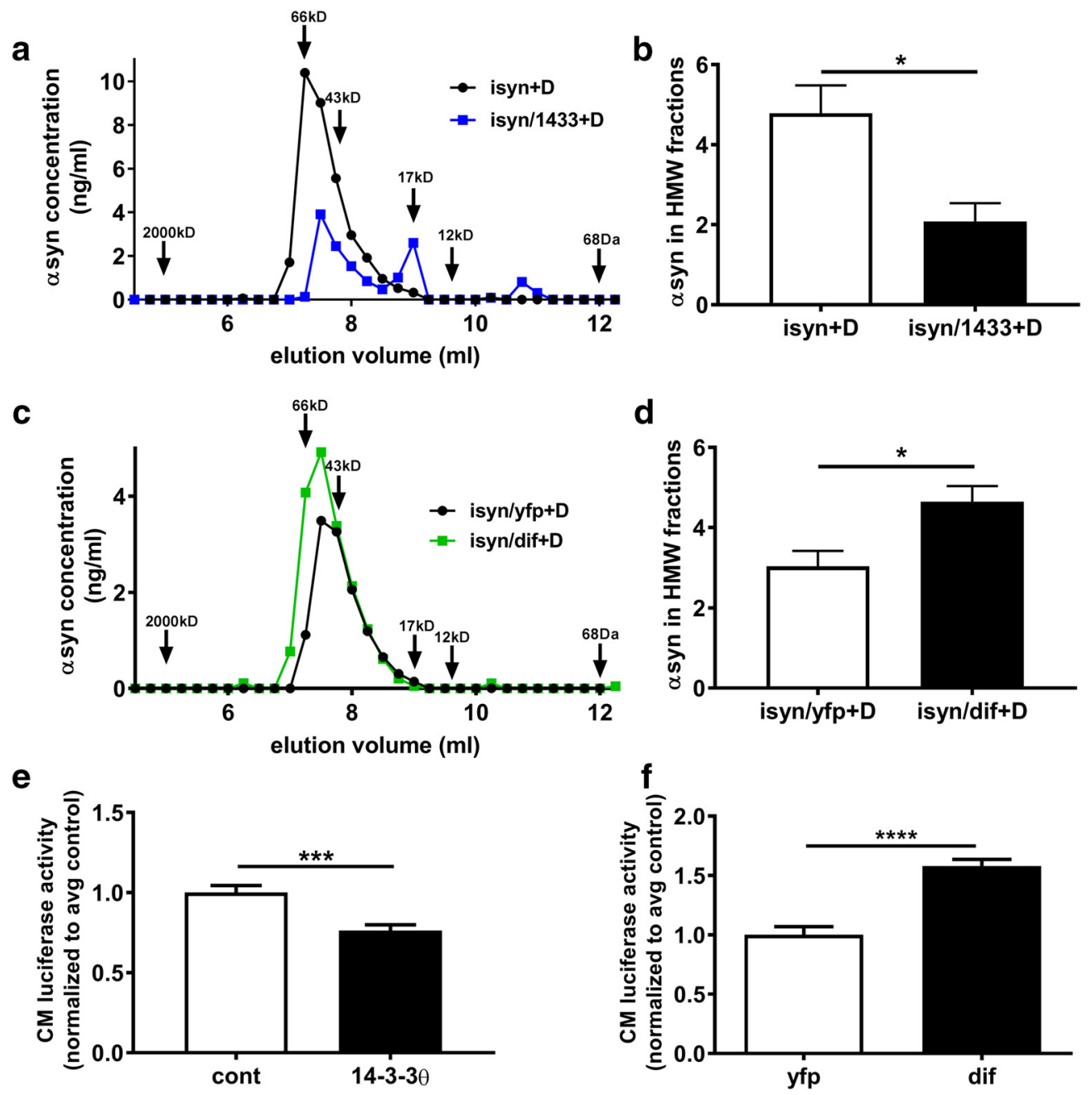

Figure 8. $\quad 14-3-3 \theta$ reduces oligomerization of released $\alpha$ syn. $\boldsymbol{a}, \alpha$ Syn levels in SEC fractions of CM from induced isyn cells or from induced isyn/14-3-3 $\theta$ cells. Equal protein amounts (80 $\mu \mathrm{g})$ per sample were loaded onto the column, and $250 \mu \mathrm{l}$ fractions were collected from elution volume $4-12.5 \mathrm{ml}$. $\alpha$ Syn in each fraction was measured by ELISA. $\alpha$ Syn from CM from induced isyn cells was primarily found in fractions with molecular weights greater than the expected $14 \mathrm{kDa}$ size of monomeric $\alpha$ syn, whereas $\alpha$ syn from CM from induced isyn/14-3-3 $\theta$ cells was partially shifted into lower molecular weight fractions. Data are representative of three independent experiments. $\boldsymbol{b}$, Quantification of released $\alpha$ syn detected in high molecular weight (HMW) SEC fractions collected between elution volumes $6-8.5 \mathrm{ml} . n=3$ independent rounds ${ }^{*} p=0.0318$ (Student's $t$ test). c, $\alpha$ Syn levels in SEC fractions of CM from induced isyn/mutant difopein-eYFP (yfp) cells or from induced isyn/difopein-eYFP (dif) cells. Equal protein amounts $(80 \mu \mathrm{g})$ per sample were loaded onto the column. Data are representative of three independent experiments. $\boldsymbol{d}$, Quantification of released $\alpha$ syn detected in HMW SEC fractions collected between elution volumes $6-8.5 \mathrm{ml} . n=3$ independent rounds ${ }^{*} p=0.0421$ (Student's t test). D, Doxy.e, Quantification of luciferase activity of CM from H4 neuroglioma cells transfected with S1-syn, S2-syn, and either empty vector (cont) or 14-3-3 $\theta . n=4$ rounds with two to three replicates per round. ${ }^{* * *} p=0.0006$ (Student's $t$ test). $\boldsymbol{f}$, Quantification of luciferase activity of CM from H4 neuroglioma cells transfected with S1-syn, S2-syn, and either difopein-eYFP (dif) or mutant difopein-eYFP (yfp). $n=3$ rounds with three replicates per round. ${ }^{* * *} p<0.0001$ (Student's $t$ test).

$\left.F_{(3,40)}=22.22, p<0.0001\right)$. In mouse neurons treated with $\mathrm{CM}$ from induced isyn cells, we observed $15 \%$ of mouse neurons that stained positive for human $\alpha$ syn at $24 \mathrm{~h}$ (Fig. 10b). In contrast, only $7 \%$ of mouse neurons stained positive for human $\alpha$ syn when treated with CM from induced 14-3-3 $\theta$-overexpressing isyn cells at $24 \mathrm{~h}$ (Fig. 10b; two-way ANOVA, treatment: $F_{(1,40)}=16.57$, $p=0.0002$; treatment $\times$ time interaction: $F_{(3,40)}=2.74, p=$ $0.0559)$. This reduction in neurons positive for human $\alpha$ syn was despite the higher amount of total $\alpha$ syn in the CM from 14-3-3 $\theta$ overexpressing isyn cells.

We also tested the impact of 14-3-3 inhibition on $\alpha$ syn uptake and internalization. The percentage of mouse neurons that were positive for human $\alpha$ syn at $24 \mathrm{~h}$ was increased to $26 \%$ when cells were treated with CM from induced isyn/difopein-eYFP cells compared with $14 \%$ from induced isyn/mutant difopein-eYFP control cells (Fig. 10c; two-way ANOVA, treatment: $F_{(1,40)}=$ $14.59, p=0.0005$; time: $F_{(3,40)}=28.41, p<0.0001$; interaction:
$\left.F_{(3,40)}=2.46, p=0.0766\right)$. This increase in neurons positive for human $\alpha$ syn occurs despite the lower amount of total $\alpha$ syn in the CM from difopein-expressing isyn cells. Although positive staining for human $\alpha$ syn in mouse neurons points toward uptake and internalization of human $\alpha$ syn from the CM, this staining could also reflect slowing of the degradation of internalized $\alpha$ syn in mouse neurons.

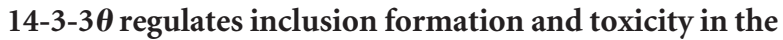 preformed fibril model}

Our studies in the paracrine $\alpha$ syn model reveals that, despite promoting $\alpha$ syn release, 14-3-3 $\theta$ ultimately reduces $\alpha$ syn transmission and toxicity by reducing $\alpha$ syn oligomerization, seeding, and internalization by other neurons exposed to released $\alpha$ syn. We next examined whether 14-3-3 $\theta$ could impact spread in another $\alpha$ syn model, the preformed fibril model. In this model, fibrils prepared from recombinant $\alpha$ syn induce misfolding of 
a

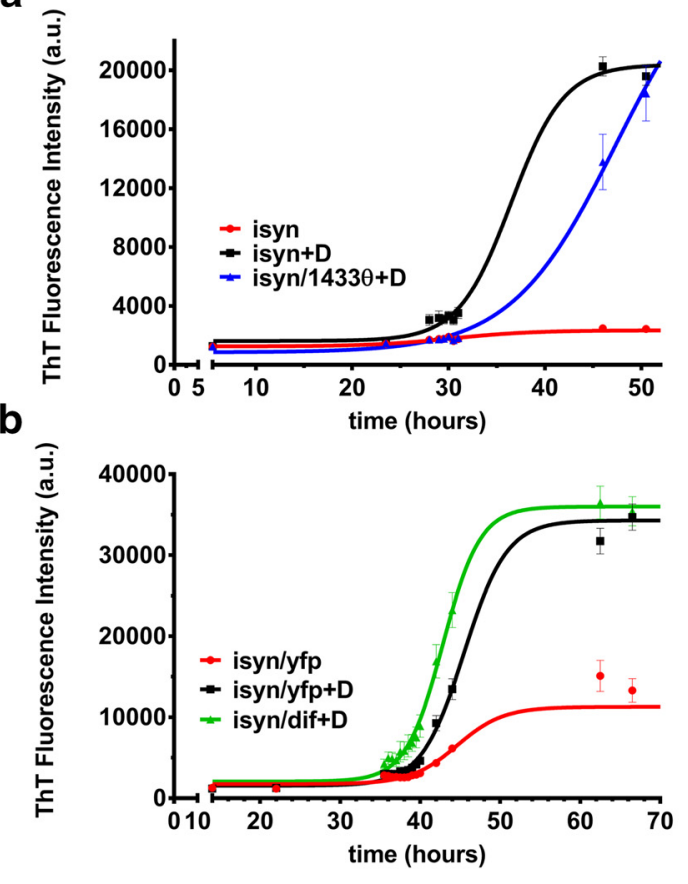

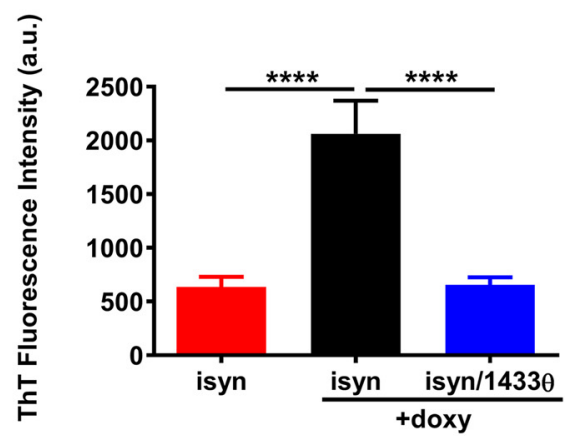

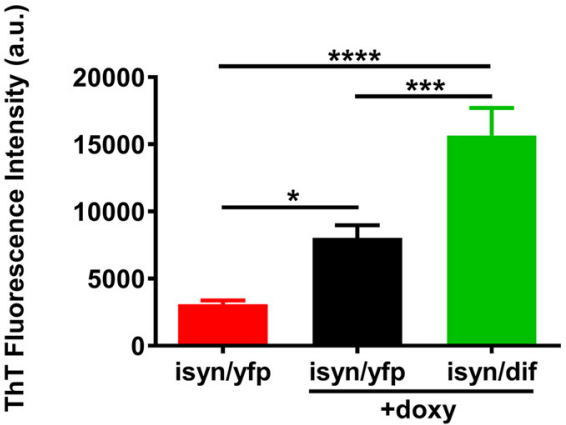

Figure 9. 14-3-3 $\theta$ reduces seeding potential of released $\alpha$ syn. $\boldsymbol{a}$, Effect of 14-3-3 $\theta$ overexpression on seeding potential of $\alpha$ syn-enriched CM. $\alpha$ Syn fibril formation was measured by the enhancement over time of ThT fluorescence intensity. Left hand graph shows time lapse curves of ThT fluorescence intensity measurements during PMCA assay of recombinant $\alpha$ syn treated with CM from isyn or isyn/14-3-3 $\theta$ cells. Right hand graph shows ThT fluorescence intensity at $31 \mathrm{~h} . n=3$ rounds with eight replicates per round. ${ }^{* * * *} p<0.0001$ (Tukey's multiple-comparison test). $\boldsymbol{b}$, Effect of 14-3-3 inhibition on seeding potential of $\alpha$ syn-enriched CM. Left hand graph shows time lapse curves of ThT fluorescence intensity measurements during PMCA assay of recombinant $\alpha$ syn treated with CM from isyn/difopein-eYFP (isyn/dif) and isyn/mutant difopein-eYFP (isyn/yfp) control cells. Right graph shows ThT fluorescence intensity at $42 \mathrm{~h} . n=3$ rounds with eight replicates per round. ${ }^{*} p=0.027,{ }^{* * *} p=0.0003,{ }^{* * * *} p<0.0001$ (Tukey's multiple-comparison test).
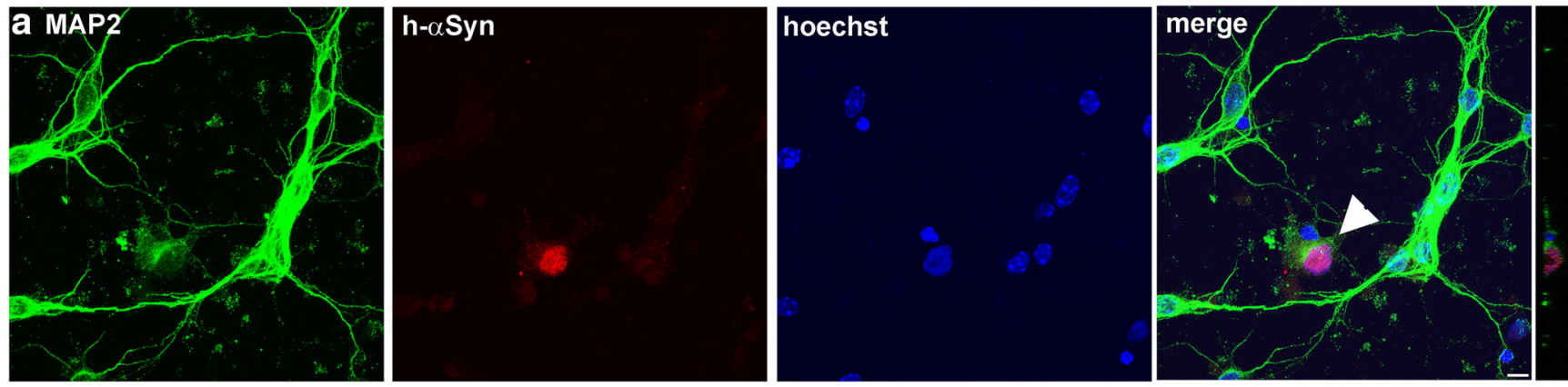

b

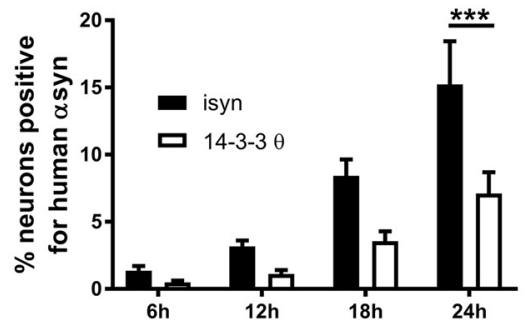

C

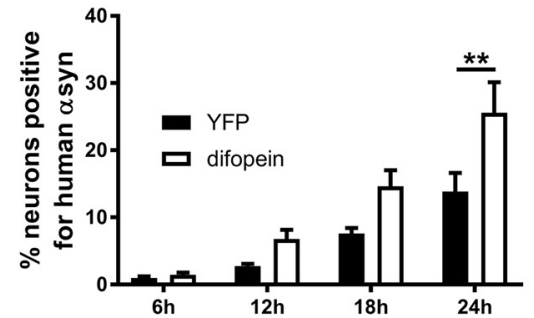

Figure 10. $14-3-3 \theta$ blocks uptake and internalization of released $\alpha$ syn by primary neurons. $\boldsymbol{a}$, Confocal microscopy demonstrating immunocytochemistry for human $\alpha$ syn (red) and MAP2 (green) in primary hippocampal neurons treated with CM from induced isyn/difopein-eYFP cells at $24 \mathrm{~h}$ after treatment. Arrow shows dying neuron that has internalized human $\alpha$ syn. Scale bar, 10 $\mu \mathrm{m} . \boldsymbol{b}$, Quantification of percentage of primary neurons that are positive for human $\alpha$ syn immunoreactivity after treatment with CM from induced isyn or isyn/14-3-3 $\theta$ cells. $n=3$ independent rounds with 2 replicates per round. ${ }^{* *} p=0.0007$ (Tukey's multiple-comparison test). c, Quantification of percentage of primary neurons that are positive for human $\alpha$ syn immunoreactivity after treatment with CM from induced isyn/difopein-eYFP or isyn/mutant difopein-eYFP control cells. $n=3$ independent rounds with two replicates per round. ${ }^{* *} p=0.0016$ (Tukey's multiplecomparison test). Error bars represent SEM. 


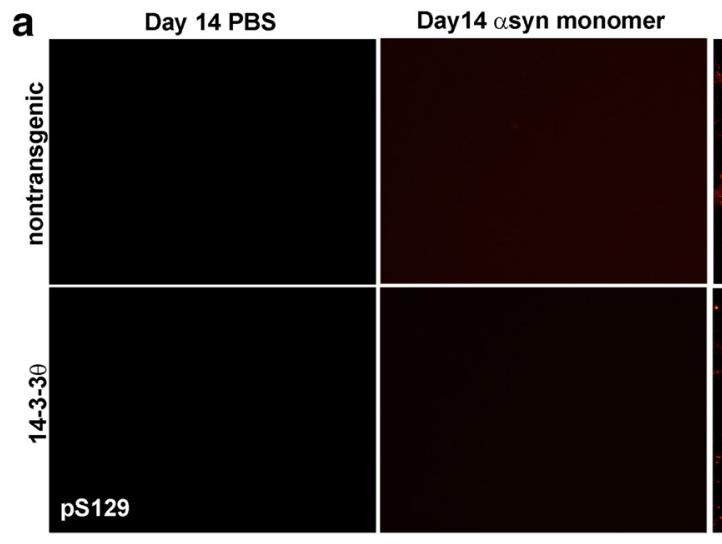

b
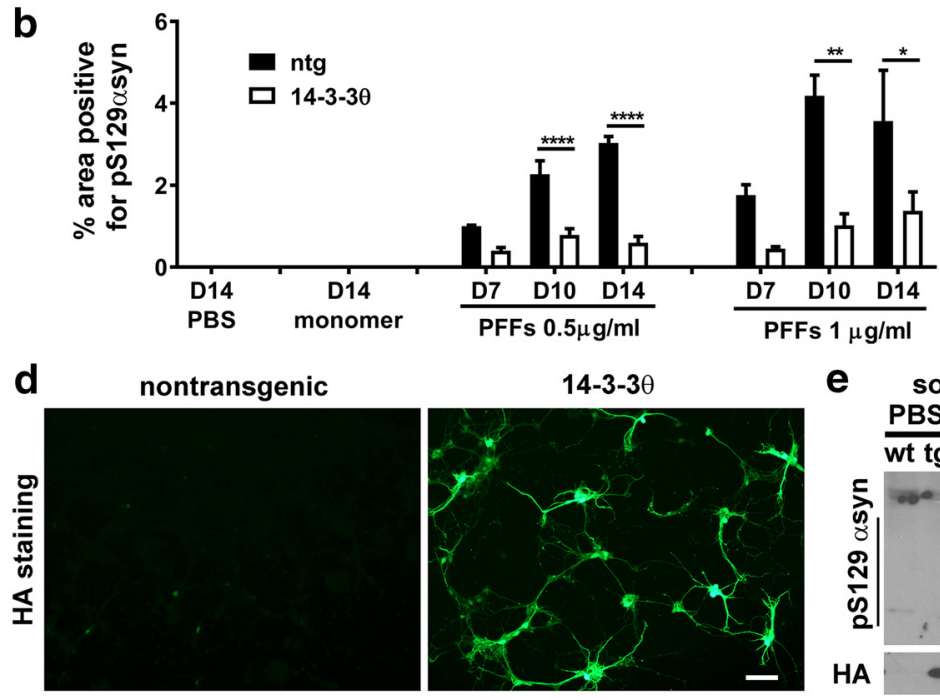
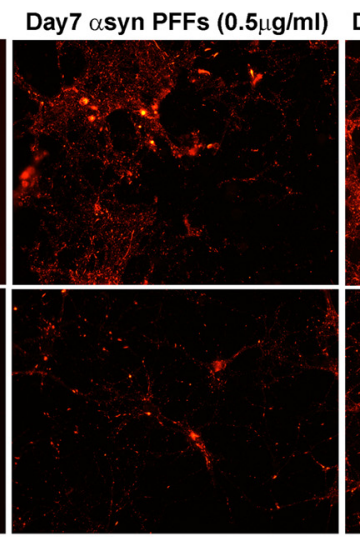

C
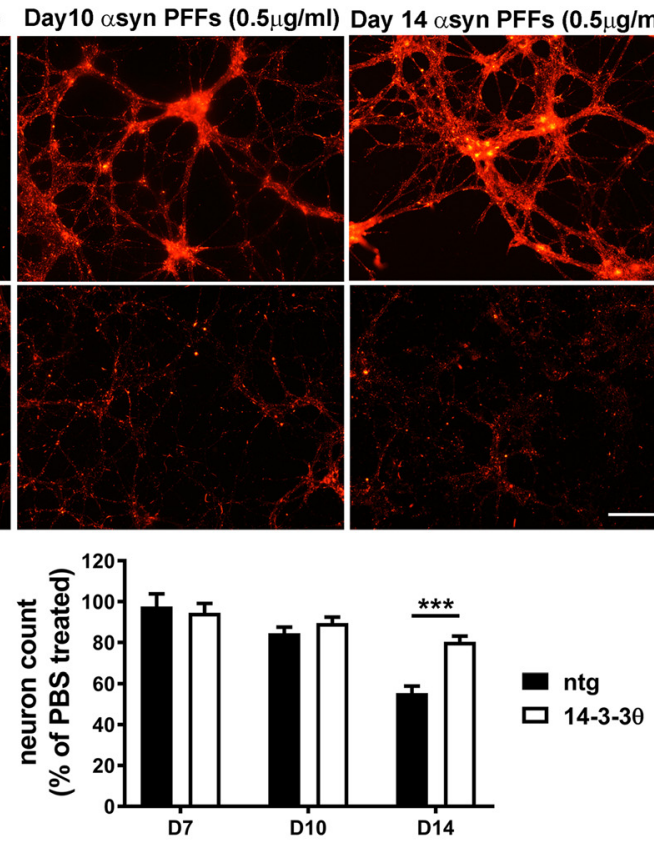
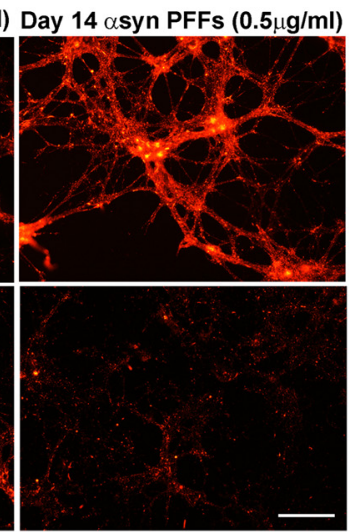

e soluble

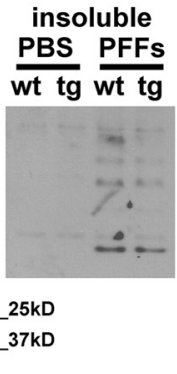

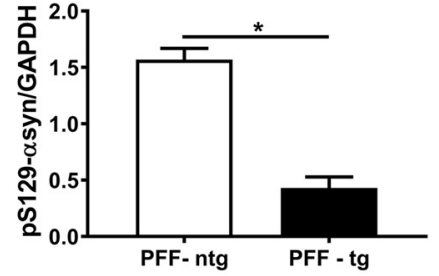

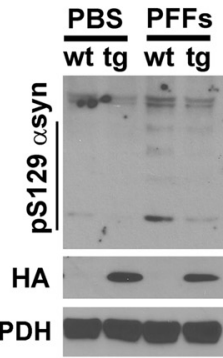

GAPDH

Figure 11. 14-3-3 $\theta$ reduces whereas 14-3-3 inhibition promotes formation of pathologic, insoluble $\alpha$ syn aggregates by PFF treatment. $\boldsymbol{a}$, Immunocytochemistry for pS129- $\alpha$ syn in primary hippocampal cultures from nontransgenic and 14-3-3 $\theta$ transgenic mouse littermates. Neurons were treated with PBS, monomeric $\alpha$ syn, or PFFs at 5 DIV and then fixed with Triton X-100 in the fixative to stain for insoluble, pS129-positive $\alpha$ syn. Scale bar, $100 \mu \mathrm{m}$. $\boldsymbol{b}$, Quantification of area covered by pS129- $\alpha$ syn immunoreactivity in primary cultures from nontransgenic and 14-3-3 $\theta$ transgenic mice treated with PBS, monomeric $\alpha$ syn, or PFFs. $n=3$ independent rounds with two replicates per round. ${ }^{*} p=0.045,{ }^{* *} p=0.0025,{ }^{* * * *} p<0.0001$ (Sidak's multiple-comparison test). $c$, Neuronal counts of primary neurons from nontransgenic and $14-3-3 \theta$ mice treated with $1 \mu \mathrm{g} / \mathrm{ml} \mathrm{PFFs} . n=3$ independent rounds with two replicates per round. ${ }^{* * *} p=0.0004$ (Sidak's multiple-comparison test).d, Immunocytochemistry for the HA epitope in primary hippocampal neurons from nontransgenic and HA-tagged 14-3-3 $\theta$ transgenic mouse pups. Scale bar, $100 \mu \mathrm{m}$. $\boldsymbol{e}$, Western blot for pS129 $\alpha$ syn in Triton X-100 soluble and insoluble cell lysates prepared from primary neurons treated with PBS or PFFs for $14 \mathrm{~d}$. Wt, Wild-type; tg, 14-3-30. Longitudinal bar next to pS129 $\alpha$ syn blot shows soluble pS129 $\alpha$ syn bands quantified. $n=2$ independent rounds. ${ }^{*} p=0.0148$ (Student's $t$ test). Error bars represent SEM.

endogenous $\alpha$ syn that results in Lewy body/Lewy neurite-like pathology in primary neurons (Volpicelli-Daley et al., 2011, 2014). Aggregation of $\alpha$ syn is associated with insolubilization and phosphorylation of endogenous $\alpha$ syn at S129, and fibrils cannot induce these changes in neurons from $\alpha$ syn knock-out mice, pointing to misfolding of endogenous $\alpha$ syn (VolpicelliDaley et al., 2011). We first tested the ability of human $\alpha$ syn PFFs to induce pathologic aggregation in primary hippocampal cultures from nontransgenic and 14-3-3 $\theta$ transgenic mice, which demonstrated HA-tagged 14-3-3 $\theta$ expression in the hippocampus (Fig. 11d; Lavalley et al., 2016). Treatment of nontransgenic cultures with PFFs induced the formation of Triton X-100 insoluble inclusions that were positive for S129-phosphorylated (pS129) $\alpha$ syn, and the amount of pS129- $\alpha$ syn-positive aggregation increased over time, as previously described (Fig. 11a,b). Neither PBS nor monomeric $\alpha$ syn induced any pS129- $\alpha$ syn signal (Fig. 11a,b). The amount of pS129- $\alpha$ syn staining was dramatically reduced in 14-3-3 $\theta$ transgenic neurons treated with 0.5 $\mu \mathrm{g} / \mathrm{ml}$ PFFs at 10 and $14 \mathrm{~d}$ after PFF treatment (Fig. 11a,b; two- way ANOVA, genotype: $F_{(1,29)}=102, p<0.0001$; time: $F_{(2,29)}=$ $19.51, p<0.0001$; interaction: $\left.F_{(2,29)}=12.53, p=0.0001\right)$. Similar results were observed with $1 \mu \mathrm{g} / \mathrm{ml}$ PFF treatment at 10 and $14 \mathrm{~d}$ (Fig. 11b; two-way ANOVA, genotype: $F_{(1,30)}=20.45, p<$ 0.0001; time: $F_{(2,30)}=3.789, p=0.0341$; interaction: $F_{(2,30)}=$ $1.177, p=0.3219)$. Western blot analysis confirmed these findings, with less pS129 $\alpha$ syn in the soluble and insoluble fractions from 14-3-3 $\theta$ neurons compared with nontransgenic neurons treated with PFFs (Fig. 11e; unpaired, two-tailed $t$ test: $t_{(2)}=8.14$, $p=0.0148)$.

PFF treatment induces significant neuronal death at $14 \mathrm{~d}$ after PFF treatment, after the initiation of $\alpha$ syn aggregation (Volpicelli-Daley et al., 2011). We measured neuronal counts in primary neuronal cultures treated with PFFs at $1 \mu \mathrm{g} / \mathrm{ml}$, and observed a $45 \%$ loss in neuronal counts in nontransgenic cultures treated with PFFs compared with those treated with PBS (Fig. 11c). Neuronal loss induced by PFFs was mitigated to $20 \%$ in 14-3-3 $\theta$ neuronal cultures (Fig. 11c; two-way ANOVA, genotype: 
a

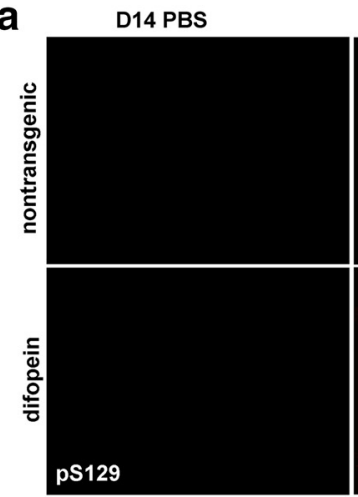

b

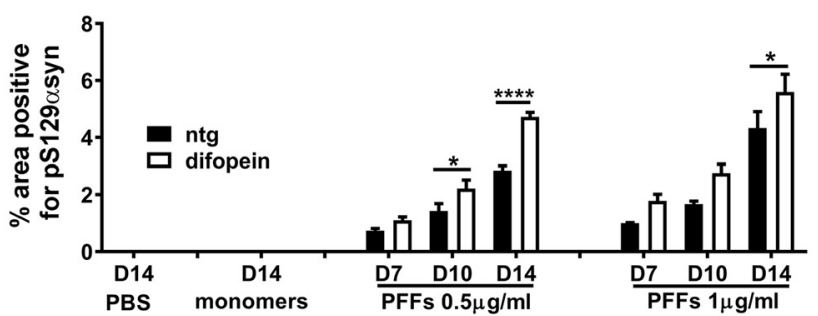

Day 7 PFFs $(0.5 \mu \mathrm{g} / \mathrm{ml})$
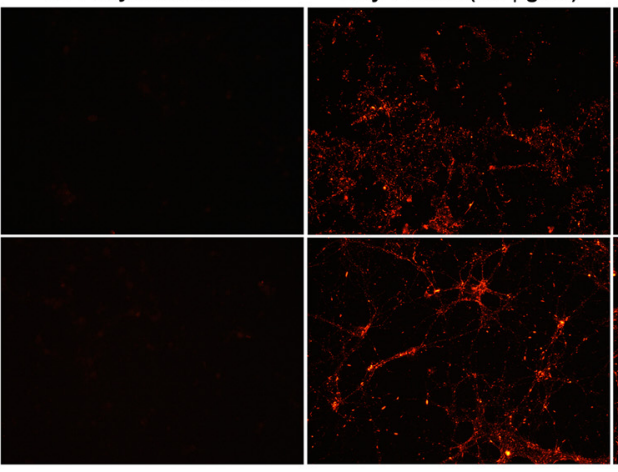

C

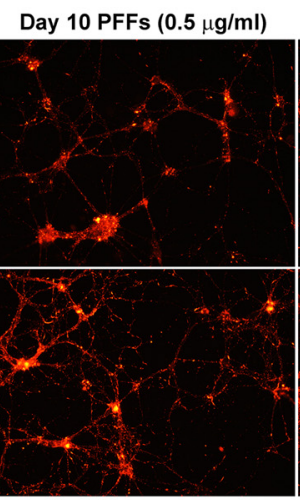

Day 14 PFFs $(0.5 \mu \mathrm{g} / \mathrm{ml})$

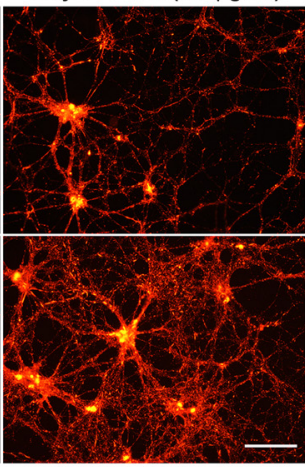

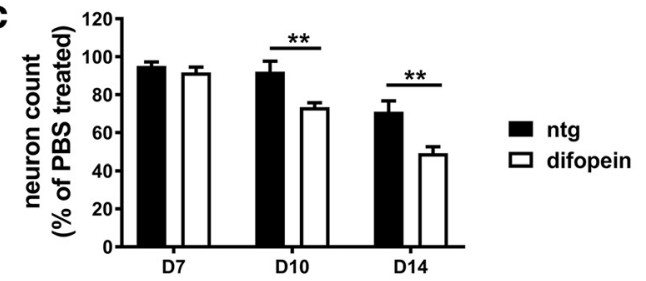

d
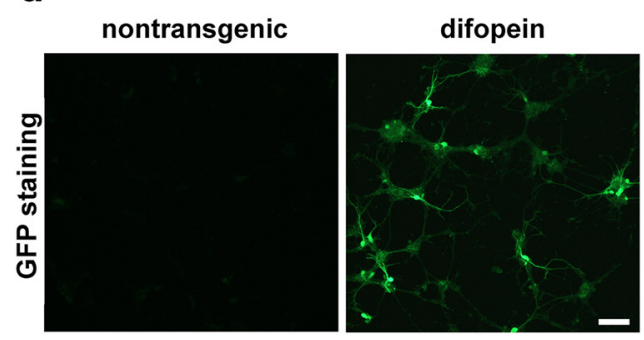

e

soluble

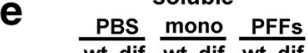

insoluble
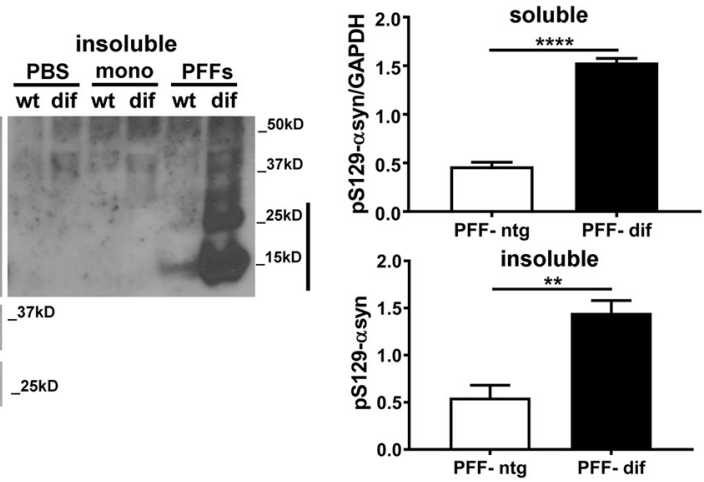

Figure 12. 14-3-3 inhibition promotes formation of pathologic, insoluble $\alpha$ syn aggregates by PFF treatment. $a$, Immunocytochemistry for pS129- $\alpha$ syn in primary hippocampal cultures from nontransgenic and difopein-eYFP transgenic mouse littermates. Neurons were treated with PBS, monomeric $\alpha$ syn, or PFFs at 5 DIV and then fixed with Triton X-100 in the fixative to stain for insoluble, pS129-positive $\alpha$ syn. Scale bar, $100 \mu \mathrm{m}$. $\boldsymbol{b}$, Quantification of area covered by pS129- $\alpha$ syn immunoreactivity in primary cultures from nontransgenic and difopein-eYFP transgenic mice treated with PBS, monomeric $\alpha$ syn, or PFFs. $n=4$ independent rounds with two replicates per round. ${ }^{*} p<0.05,{ }^{* * * *} p<0.0001$ (Sidak's multiple-comparison test). Error bars represent SEM. $c$, Neuronal counts of primary neurons from nontransgenic and difopein-eYFP mice treated with $0.5 \mu \mathrm{g} / \mathrm{ml} \mathrm{PFFs.} n=3$ independent rounds with two replicates per round. ${ }^{* *} p<0.01$ (Sidak's multiple-comparison test). Error bars represent SEM. $\boldsymbol{d}$, Immunocytochemistry for GFP in primary hippocampal neurons from nontransgenic and difopein-eYFP transgenic mouse pups. Scale bar, 100 $\mu \mathrm{m} . \boldsymbol{e}$, Western blot for pS129 and total $\alpha$ syn in Triton X-100 soluble and insoluble cell lysates prepared from primary neurons treated with PBS, $\alpha$ syn monomer, or PFFs for $14 \mathrm{~d}$. Wt, Wild-type; dif, difopein. Longitudinal bar next to pS129 $\alpha$ syn blot shows pS129 $\alpha$ syn bands quantified. Arrows point out pS129 $\alpha$ syn bands. $n=3$ independent rounds. ${ }^{* *} p=0.0085$, ${ }^{* * * *} p<0.0001$ (Student's $t$ test). Error bars represent SEM.

$F_{(1,30)}=7.431, p=0.0106 ;$ time: $F_{(2,30)}=25.86, p<0.0001$; interaction: $\left.F_{(2,30)}=6.456, p=0.0047\right)$.

We next examined the effect of 14-3-3 inhibition on PFFinduced aggregation and neuronal death. Hippocampal cultures from difopein-eYFP transgenic mice, which have difopein-eYFP expression in the hippocampus (Fig. 12d; Lavalley et al., 2016), showed no evidence of pS129- $\alpha$ syn staining in response to PBS or monomeric $\alpha$ syn staining (Fig. 12a,b). pS129- $\alpha$ syn-positive aggregation was increased in difopein neurons treated with 0.5 $\mu \mathrm{g} / \mathrm{ml}$ PFFs compared with nontransgenic neurons (Fig. 12a,b; two-way ANOVA, genotype: $F_{(1,30)}=40.17, p<0.0001$; tim:e $F_{(2,30)}=111.8, p<0.0001$; interaction: $F_{(2,30)}=7.966, p=$ $0.0017)$. pS129- $\alpha$ syn-positive aggregation was also increased in difopein neurons treated with $1 \mu \mathrm{g} / \mathrm{ml}$ PFFs (Fig. $12 b$; two-way ANOVA, genotype: $F_{(1,42)}=10.63, p=0.0022$; time: $F_{(2,42)}=$ 48.28, $p<0.0001$; interaction: $\left.F_{(2,42)}=0.5827, p=0.5628\right)$ but not as dramatically, potentially suggesting a upper limit to the amount of aggregation that can be induced. Western blot analysis showed an increase in pS129- $\alpha$ syn levels in the lysates from difo- pein neurons treated with PFFs compared with nontransgenic neurons (Fig. 12e; soluble fraction: unpaired, two-tailed $t$ test: $t_{(4)}=18.19, p<0.0001$; insoluble fraction: unpaired, two-tailed $t$ test: $\left.t_{(4)}=4.82, p=0.0085\right)$. Neuronal loss induced by PFFs was observed earlier in difopein cultures at $10 \mathrm{~d}$ after PFF treatment at $0.5 \mu \mathrm{g} / \mathrm{ml}$, at a time point when neuronal loss is normally not observed in wild-type cultures (Fig. 12c; two-way ANOVA, genotype: $F_{(1,30)}=21.37, p<0.0001$; time: $F_{(2,30)}=38.37, p<0.0001$; interaction: $\left.F_{(2,30)}=3.256, p=0.0525\right)$. At $14 \mathrm{~d}$ after treatment, difopein cultures showed a $31 \%$ increase in neuronal death compared with nontransgenic cultures (Fig. 12c).

\section{4-3-3 $\theta$ reduces propagation in the preformed fibril model}

To test whether 14-3-3 $\theta$ can block cell-to-cell spread of pathogenic $\alpha$ syn in the PFF model, we used microfluidic culture devices with three separate compartments connected by microgrooves. We plated nontransgenic or 14-3-3 $\theta$ neurons in the first compartment and nontransgenic neurons into the second and third compartments (Fig. 13b). PFFs were added to the first com- 


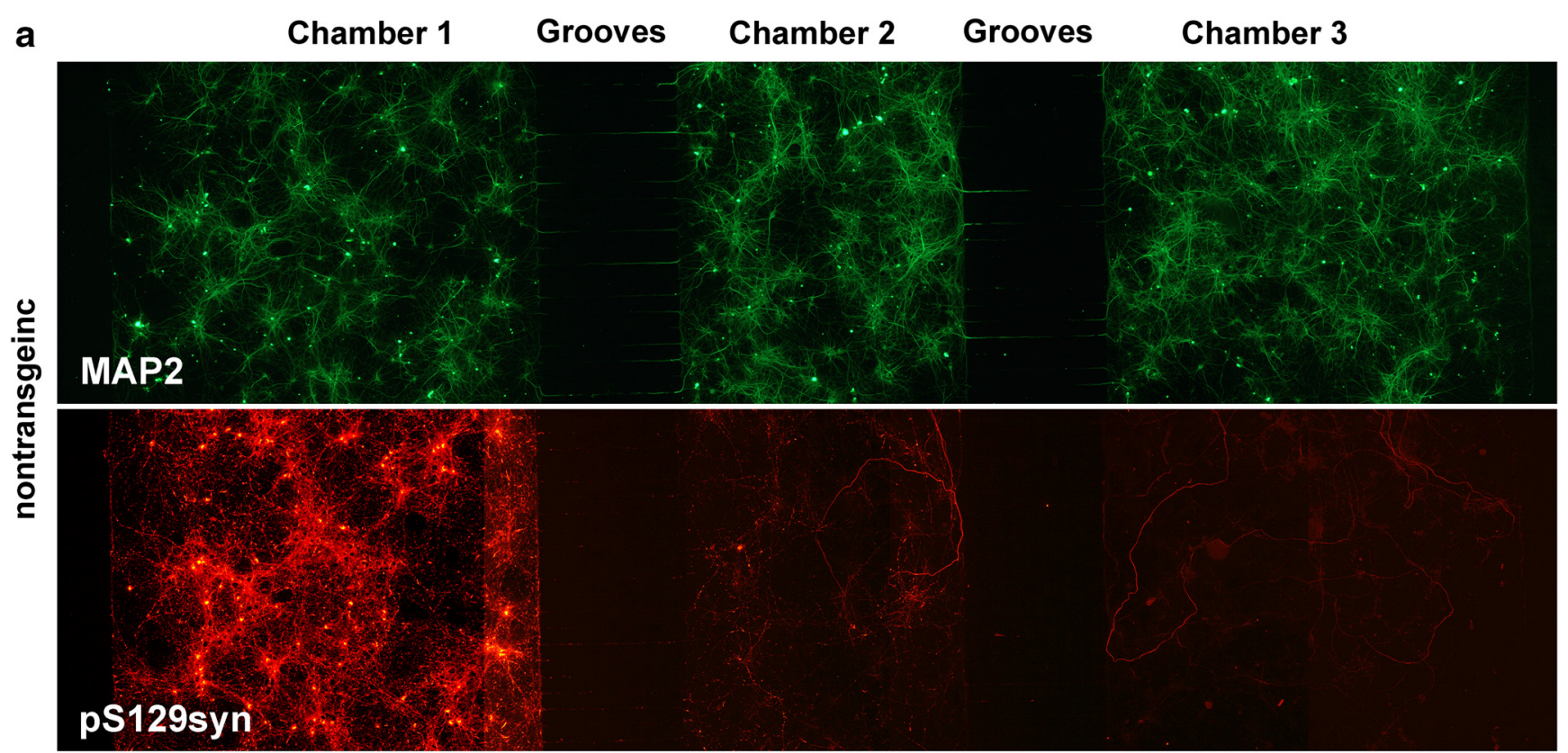

\section{\% MAP2}

I

\section{pS129syn}

b

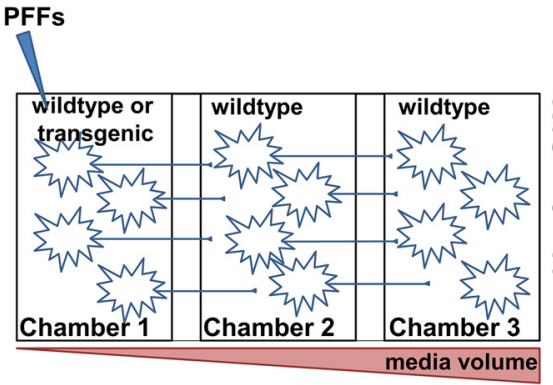

C

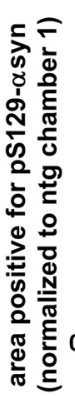

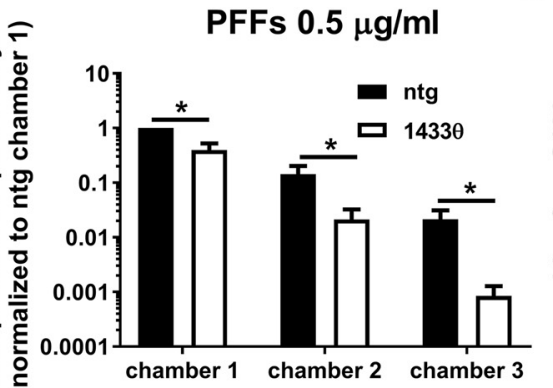

chamber 1 chamber 2 chamber 3 d

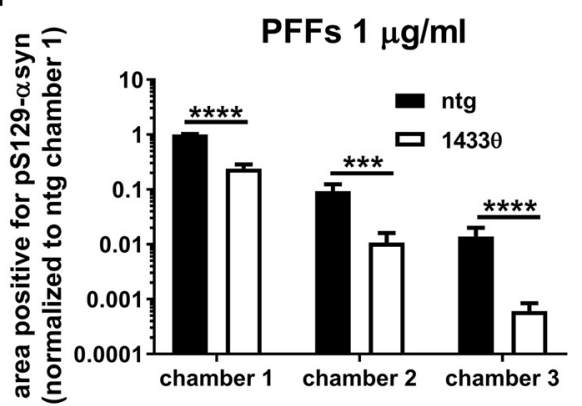

Figure 13. 14-3-3 $\theta$ reduces $\alpha$ syn spread in the PFF model. $\boldsymbol{a}$, Immunocytochemistry for pS129- $\alpha$ syn (red) and MAP2 (green) in primary neurons in multichamber, microfluidic culture devices. Primary neurons from nontransgenic or 14-3-30 mice were plated in chamber 1, and nontransgenic mouse neurons were plated in the other chambers of multichamber, microfluidic devices. Neurons in chamber 1 were treated with $0.5 \mu \mathrm{g} / \mathrm{ml} \mathrm{PFFs}$. $\boldsymbol{b}$, Schematic of experimental design. Neurons from nontransgenic or 14-3-3 $\theta$ mice were plated in chamber 1 , and nontransgenic mouse neurons were plated in chambers 2 and 3. At DIV5, neurons in chamber 1 were treated with PFFs. Spread of PFFs into the other chambers was prevented by hydrostatic pressure differences between chambers. c, Quantification of area covered by pS129- $\alpha$ syn immunoreactivity in each chamber of primary cultures from nontransgenic and 14-3-3 $\theta$ transgenic mice treated with $0.5 \mu \mathrm{g} / \mathrm{ml} \mathrm{PFFs.}$ $n=4$. $\boldsymbol{d}$, Quantification of area covered by pS129- $\alpha$ syn immunoreactivity in each chamber of primary cultures from nontransgenic and 14-3-3 $\theta$ transgenic mice treated with $1 \mu \mathrm{g} / \mathrm{ml}$ PFFs. $n=$ $8 .{ }^{*} p<0.05,{ }^{* * *} p<0.001,{ }^{* * *} p<0.0001$ (Student's $t$-test, with correction for multiple comparisons using Holm-Sidak method; adjusted $p$ values shown). Error bars represent SEM. 

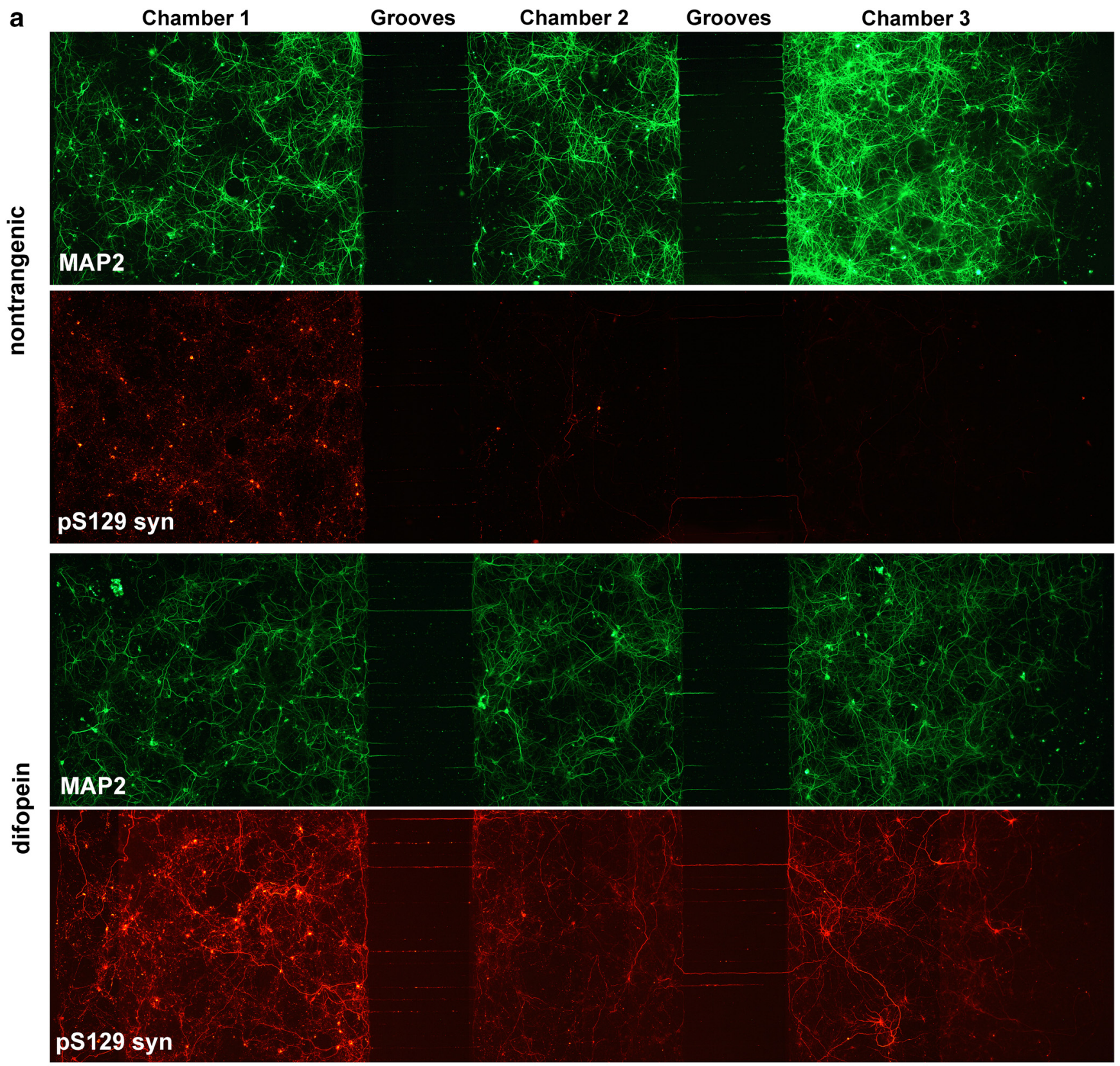

b

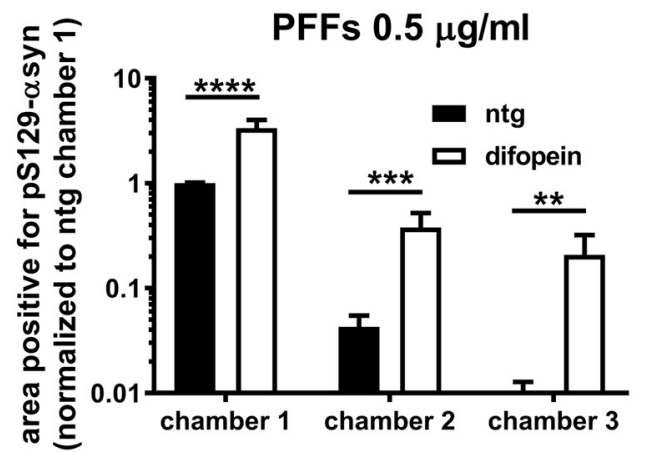

\section{c}

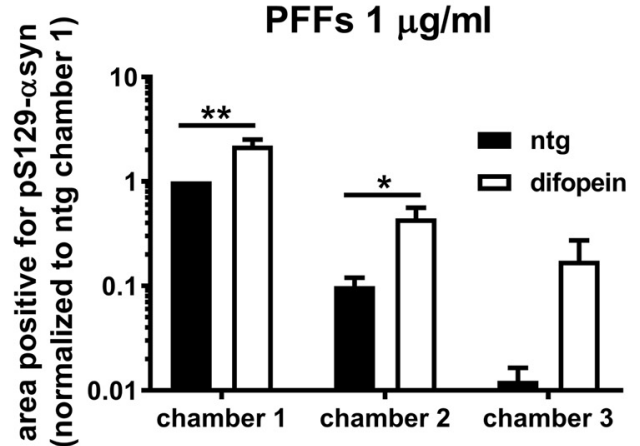

Figure 14. 14-3-3 inhibition potentiates $\alpha$ syn spread in the PFF model. $\boldsymbol{a}$, Immunocytochemistry for pS129- $\alpha$ syn (red) and MAP2 (green) in primary neurons in multichamber, microfluidic culture devices. Primary neurons from nontransgenic or difopein mice were plated in Chamber 1, and nontransgenic mouse neurons were plated in Chambers 2 and 3 . At 5 DIV, neurons in Chamber 1 were treated with $1 \mu \mathrm{g} / \mathrm{ml} \mathrm{PFFs.} \mathrm{Staining} \mathrm{in} \mathrm{chamber} \mathrm{plated} \mathrm{with} \mathrm{wild-type} \mathrm{neurons} \mathrm{appears} \mathrm{less} \mathrm{intense} \mathrm{than} \mathrm{in} \mathrm{Figure} 13$ because the images here were captured at a lower exposure to prevent saturation of the pS129- $\alpha$ syn signal in the difopein chamber. $\boldsymbol{b}$, Quantification of area covered by pS129- $\alpha$ syn immunoreactivity in each chamber of primary cultures from nontransgenic and difopein transgenic mice treated with $0.5 \mu \mathrm{g} / \mathrm{ml} \mathrm{PFFs.} n=7$. c, Quantification of area covered by pS129- $\alpha$ syn immunoreactivity in each chamber of primary cultures from nontransgenic and difopein transgenic mice treated with $1 \mu \mathrm{g} / \mathrm{ml}$ PFFs. $n=4 .{ }^{*} p<0.05,{ }^{* *} p<0.01,{ }^{* *} p<0.001,{ }^{* * * *} p<0.0001$ (Student's $t$ test with correction for multiple comparisons using Holm-Sidak method; adjusted $p$ values shown). Error bars represent SEM. 


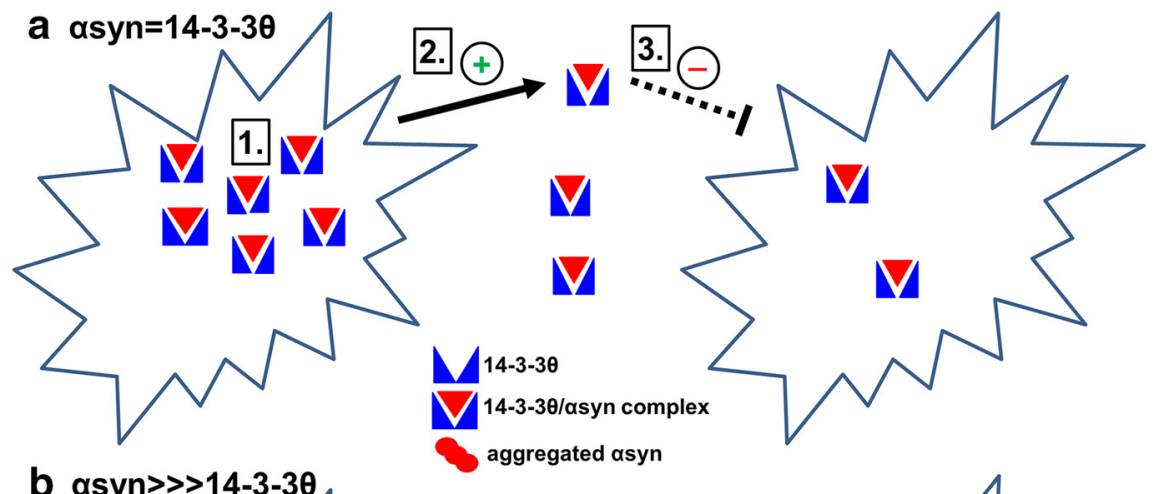

b asyn $\gg>14-3-3 \theta$

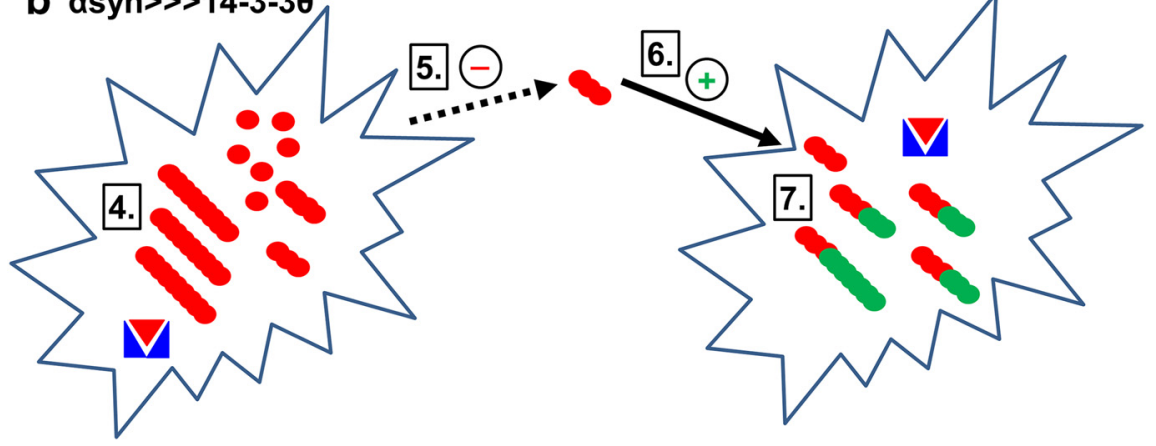

Figure 15. Model for 14-3-3 $\theta^{\prime}$ s effects on $\alpha$ syn propagation. $\boldsymbol{a}$, Under normal circumstances, $14-3-3 \theta$ prevents intracellular $\alpha$ syn aggregation by acting as a chaperone to prevent misfolding of intracellular $\alpha$ syn (1) and by promoting the release of $\alpha$ syn (2). Extracellularly, $\alpha$ syn is complexed with $14-3-3 \theta$ which prevents its uptake and seeding in surrounding neurons (3). $\boldsymbol{b}$, In the disease state, there is a deficiency of 14-3-3 $\theta$ compared with $\alpha$ syn. 14-3-3 $\theta$ no longer adequately acts as a chaperone to prevent $\alpha$ syn misfolding (4). In addition, with reduced levels of 14-3-3 $\theta$, less $\alpha$ syn is released such that more misfolding $\alpha$ syn substrate remains intracellularly to initiate more misfolding (5). Any $\alpha$ syn that is released is not adequately complexed with $14-3-3 \theta$ and is available for uptake by surrounding neurons (6). $\alpha$ Syn that is taken up by surrounding neurons has seeding capabilities and induces the misfolding of $\alpha$ syn (green) in these neurons (7).

partment at DIV5 (Fig. 13b). PFF spread into the other compartments is prevented by hydrostatic pressure differences between compartments (Park et al., 2006). At $14 \mathrm{~d}$ after PFF treatments, pS129- $\alpha$ syn was detectable in all three chambers when nontransgenic neurons were plated in all three compartments, with a gradient of highest pS129- $\alpha$ syn in Chamber 1 to lowest pS129- $\alpha$ syn in the most distal chamber (Fig. 13a,c,d). When 14-3-3 $\theta$ neurons were plated in the first compartment and treated with $0.5 \mu \mathrm{g} / \mathrm{ml}$ PFFs, pS129- $\alpha$ syn staining was dramatically reduced in all three compartments, with almost no detectable pS129- $\alpha$ syn in Chambers 2 and 3 (Fig. 13c; unpaired, two-tailed $t$ test corrected for multiple comparisons by Holm-Sidak method; Chamber 1: $t_{(6)}=3.547$, adjusted $p=0.0359$; Chamber 2: $t_{(6)}=2.679$, adjusted $p=0.0366$; Chamber $3: t_{(5)}=3.769, p=0.0359$ ). Similar results were observed when neurons were treated with $1 \mu \mathrm{g} / \mathrm{ml}$ PFFs (Fig. 13a,d; unpaired, two-tailed $t$ test corrected for multiple comparisons by Holm-Sidak method; Chamber 1: $t_{(14)}=8.001$, adjusted $p<0.0001$; Chamber 2: $t_{(14)}=5.033$, adjusted $p=$ 0.00018; Chamber 3: $\left.t_{(14)}=7.126, p<0.0001\right)$. Conversely, when difopein neurons were plated in the first compartment, we saw a significant increase in pS129- $\alpha$ syn-positive aggregates in Chambers 2 and 3 compared with microfluidic devices plated with only nontransgenic neurons in all chambers at $14 \mathrm{~d}$ after $0.5 \mu \mathrm{g} / \mathrm{ml}$ PFF treatment (Fig. 14b; unpaired, two-tailed $t$ test corrected for multiple comparisons by Holm-Sidak method; Chamber 1: $t_{(12)}=6.879$, adjusted $p<0.0001$; Chamber 2: $t_{(12)}=4.797$, adjusted $p=0.00087$; Chamber 3: $\left.t_{(12)}=4.209, p=0.00121\right)$ or $1 \mu \mathrm{g} / \mathrm{ml}$ PFF treatment (Fig. 14a,c; unpaired, two-tailed $t$ test corrected for multiple comparisons by Holm-Sidak method;
Chamber 1: $t_{(6)}=5.369$, adjusted $p=$ 0.00513; Chamber 2: $t_{(6)}=3.879$, adjusted $p=0.0163$; Chamber $3: t_{(6)}=$ $1.935, p=0.101)$.

\section{Discussion}

Our data demonstrates that 14-3-30 regulates the pathologic transmission and toxicity of $\alpha$ syn in two different $\alpha$ syn models. Using a paracrine model, we observed that $14-3-3 \theta$ overexpression in isyn cells blocked $\alpha$ syn oligomerization, seeding, and toxicity, whereas 14-3-3 inhibition in isyn cells promoted $\alpha$ syn oligomerization, seeding, and toxicity. In the fibril model, $\alpha$ syn fibrils induced less $\alpha$ syn aggregation and neuron loss in 14-3-3 $\theta$ cultures, whereas 14-3-3 inhibition accelerated $\alpha$ syn aggregation and neuron death. The ability of $14-3-3 \theta$ to reduce $\alpha$ syn spread from neuron to neuron was highlighted by our studies in multichamber devices. 14-3-3 inhibition promoted spread of $\alpha$ syn pathology to distal chamber neurons not exposed directly to $\alpha$ syn fibrils, whereas 14-3-3 $\theta$ overexpression blocked the spread to distal chamber neurons.

The advantage of the paracrine model is that it allows us to tease apart the different cellular processes required for spread, including release, seeding, and uptake. Our studies in the paracrine model illustrate the mechanisms by which 14-3-30 regulates pathogenic $\alpha$ syn spread. Our findings point to $14-3-3 \theta$ as a chaperone to regulate $\alpha$ syn propagation: despite promoting $\alpha$ syn release, 14-3-3 $\theta$ was complexed with released $\alpha$ syn and the released $\alpha$ syn was less likely to oligomerize or promote $\alpha$ syn seeding. This conformational change in $\alpha$ syn by the presence of 14-3-3 $\theta$ also prevented $\alpha$ syn internalization and/or promoted $\alpha$ syn degradation by surrounding neurons.

These findings point to the following model of $14-3-3 \theta$ as an endogenous regulator of pathogenic $\alpha$ syn transmission (Fig. 15). Under normal conditions, we propose 14-3-3 $\theta$ levels are sufficient to promote normal $\alpha$ syn folding and prevent its ability to take on conformations that promote seeding. Misfolded $\alpha$ syn molecule is secreted by 14-3-30-dependent mechanisms to prevent its interaction with normally folded intracellular $\alpha$ syn molecules and thus reduce the likelihood of intracellular propagation. Any released $\alpha$ syn is complexed with $14-3-3 \theta$ which can help to refold $\alpha$ syn into a less seed-competent state. As a result, 14-3-3 $\theta$ may reduce the uptake of released $\alpha$ syn by other neurons and/or indirectly promotes its degradation if internalized. 143-3 $\theta$ could potentially interfere with $\alpha$ syn uptake through cell surface receptors, such as LAG3 (Mao et al., 2016).

Under conditions in which $\alpha$ syn levels are increased, the amount of $14-3-3 \theta$ is not sufficient to appropriately regulate $\alpha$ syn folding. Indeed the stoichiometric ratio of $\alpha$ syn to $14-3-3 \mathrm{~s}$ is critical in 14-3-3s' ability to regulate $\alpha$ syn in vitro (Plotegher et al., 2014). With a reduction in 14-3-3 $\theta$, less $\alpha$ syn is released extracellularly, thus potentially allowing for more intracellular misfolded $\alpha$ syn substrate molecules to potentiate intracellular misfolding. Although $\alpha$ syn release may be reduced under low 
14-3-3 $\theta$ conditions, any $\alpha$ syn that is released is not appropriately complexed with 14-3-3 $\theta$ and takes on a pathologic conformation that promotes its oligomerization, seeding, and uptake as supported our data. Overexpression of 14-3-3 $\theta$ is able to reestablish this homeostatic process: when we overexpress $14-3-3 \theta$ in the presence of excess $\alpha$ syn, 14-3-3 $\theta$ resets the cellular balance by refolding intracellular $\alpha$ syn directly through chaperone function and potentially indirectly by kicking out aggregation-prone $\alpha$ syn out of the cell. Any released $\alpha$ syn is complexed with $14-3-3 \theta$ to reduce its seeding potential and uptake.

Whether low 14-3-3 levels are a prerequisite to initiate $\alpha$ syn transmission or if they perpetuate $\alpha$ syn propagation after the process has first started is unknown. An age-related reduction in soluble 14-3-3 levels has been observed in Caenorhabditis elegans and rodent aging models (David et al., 2010; VanGuilder et al., 2011). Low 14-3-3s during aging could set the stage for $\alpha$ syn misfolding, which could be accelerated by other genetic and environmental factors. Another possibility is that other processes, such as age-related dysfunction of protein degradation (Tonoki et al., 2009; Yamaguchi and Otsu, 2012; Tan et al., 2014), lead to elevated $\alpha$ syn levels which then causes the reduction in 14-3-3 levels; leading to a vicious cycle to further potentiate $\alpha$ syn pathology. We previously showed that elevated $\alpha$ syn reduces $14-3-3$ expression in cellular and mouse $\alpha$ syn models (Yacoubian et al., 2010; Ding et al., 2013). We also observed reduced soluble 14-3-3 levels in human DLB (McFerrin et al., 2017), yet whether this occurs early or late in the disease process is unknown. Whether misfolded $\alpha$ syn or low 14-3-3 levels initiate the process, it is clear that the balance of 14-3-3 $\theta$ levels to $\alpha$ syn levels is critical to slowing or accelerating $\alpha$ syn propagation.

A surprising finding is that an increase in the total amount of $\alpha$ syn released into the CM did not translate to increased toxicity as one may predict. Our studies reveal that $\alpha$ syn release is required for non-cell autonomous $\alpha$ syn toxicity but is not sufficient. The form of $\alpha$ syn released is critical; based on our data, release of oligomeric and seed-competent $\alpha$ syn is implicated in toxicity. Buffering of released $\alpha$ syn with chaperones such as 143 -3s may allow for the release of misfolded $\alpha$ syn from cells in which it is produced without causing inadvertent "friendly fire" toxicity to normal neighboring neurons. In the disease state, levels of 14-3-3s are relatively reduced compared with excess $\alpha$ syn and thus could fail to buffer misfolded $\alpha$ syn. 14-3-3 $\theta$ overexpression reduces oligomerization and seeding capability of released $\alpha$ syn in our studies.

Our findings suggesting that 14-3-3 $\theta$ reduces $\alpha$ syn internalization also point to the likelihood that uptake of $\alpha$ syn is also important to its toxicity. We hypothesize that uptake of released $\alpha$ syn in the paracrine model causes seeding of endogenous $\alpha$ syn into aggregates and ultimately toxicity, similar to that observed in the fibril model. However, we cannot rule out the possibility that released $\alpha$ syn could cause direct neuronal death that is not dependent on uptake into the cytoplasm. Additionally, our data showing a reduction in staining for human $\alpha$ syn in neurons exposed to CM from 14-3-30-overexpressing isyn cells (Fig. 10) may instead reflect alterations in protein degradation instead of differences in uptake. Human $\alpha$ syn in the CM from isyn cells overexpressing 14-3-3 $\theta$ may be more readily degraded in exposed neurons, possibly due to its conformation state.

$\alpha$ Syn associated with exosomes was not toxic in our paracrine model, in contrast to other studies suggesting that $\alpha$ syn release through exosomes is responsible for $\alpha$ syn toxicity (Emmanouilidou et al., 2010; Danzer et al., 2012; Stuendl et al., 2016; Ngolab et al., 2017). Only $\sim 0.6 \%$ of total $\alpha$ syn was found in the exosomes when released from isyn cells. It is unclear whether $\alpha$ syn released by the non-exosomal fraction has properties that make it more toxic, or whether it is the relative quantity of pathogenic $\alpha$ syn released that is responsible for the difference noted in the toxicities of these fractions. Multiple release mechanisms, including possibly exosomal release, are likely responsible for $\alpha$ syn release and could vary between different neuronal populations and at different stages of disease.

In conclusion, $14-3-3 \theta$ regulates $\alpha$ syn transmission in two separate $\alpha$ syn models. Given evidence that $14-3-3$ s are reduced in $\alpha$ syn models and disease, methods to restore 14-3-3 function could serve as a means to reduce $\alpha$ syn propagation in synucleinopathies.

\section{References}

Abdelmotilib H, Maltbie T, Delic V, Liu Z, Hu X, Fraser KB, Moehle MS, Stoyka L, Anabtawi N, Krendelchtchikova V, Volpicelli-Daley LA, West A (2017) $\alpha$-Synuclein fibril-induced inclusion spread in rats and mice correlates with dopaminergic neurodegeneration. Neurobiol Dis 105:84-98. CrossRef Medline

Abounit S, Bousset L, Loria F, Zhu S, de Chaumont F, Pieri L, Olivo-Marin JC, Melki R, Zurzolo C (2016) Tunneling nanotubes spread fibrillar alphasynuclein by intercellular trafficking of lysosomes. EMBO J 35:2120 2138. CrossRef Medline

Alvarez-Erviti L, Seow Y, Schapira AH, Gardiner C, Sargent IL, Wood MJ, Cooper JM (2011) Lysosomal dysfunction increases exosome-mediated alpha-synuclein release and transmission. Neurobiol Dis 42:360-367. CrossRef Medline

Becker K, Wang X, Vander Stel K, Chu Y, Kordower J, Ma J (2018) Detecting Alpha Synuclein Seeding Activity in Formaldehyde-Fixed MSA Patient Tissue by PMCA. Mol Neurobiol. Advance online publication. Retrieved Mar 12, 2018. doi: 10.1007/s12035-018-1007-y.

Berg D, Riess O, Bornemann A (2003) Specification of 14-3-3 proteins in Lewy bodies. Ann Neurol 54:135. CrossRef Medline

Chutna O, Goncalves S, Villar-Piqué A, Guerreiro P, Marijanovic Z, Mendes T, Ramalho J, Emmanouilidou E, Ventura S, Klucken J, Barral DC, Giorgini F, Vekrellis K, Outeiro TF (2014) The small GTPase Rab11 co-localizes with alpha-synuclein in intracellular inclusions and modulates its aggregation, secretion and toxicity. Hum Mol Genet 23:67326745. CrossRef Medline

Danzer KM, Ruf WP, Putcha P, Joyner D, Hashimoto T, Glabe C, Hyman BT, McLean PJ (2011) Heat-shock protein 70 modulates toxic extracellular alpha-synuclein oligomers and rescues trans-synaptic toxicity. FASEB J 25:326-336. CrossRef Medline

Danzer KM, Kranich LR, Ruf WP, Cagsal-Getkin O, Winslow AR, Zhu L, Vanderburg CR, McLean PJ (2012) Exosomal cell-to-cell transmission of alpha synuclein oligomers. Mol Neurodegener 7:42. CrossRef Medline

David DC, Ollikainen N, Trinidad JC, Cary MP, Burlingame AL, Kenyon C (2010) Widespread protein aggregation as an inherent part of aging in $C$. elegans. PLoS Biol 8: e1000450. CrossRef Medline

Dearborn AD, Wall EA, Kizziah JL, Klenow L, Parker LK, Manning KA, Spilman MS, Spear JM, Christie GE, Dokland T (2017) Competing scaffolding proteins determine capsid size during mobilization of staphylococcus aureus pathogenicity islands. eLife 6:e30822. CrossRef Medline

Desplats P, Lee HJ, Bae EJ, Patrick C, Rockenstein E, Crews L, Spencer B, Masliah E, Lee SJ (2009) Inclusion formation and neuronal cell death through neuron-to-neuron transmission of alpha-synuclein. Proc Natl Acad Sci U S A 106:13010-13015. CrossRef Medline

Ding H, Fineberg NS, Gray M, Yacoubian TA (2013) $\alpha$-Synuclein overexpression represses 14-3-3 $\theta$ transcription. J Mol Neurosci 51:1000-1009. CrossRef Medline

Ding H, Underwood R, Lavalley N, Yacoubian TA (2015) 14-3-3 inhibition promotes dopaminergic neuron loss and 14-3-3 $\theta$ overexpression promotes recovery in the MPTP mouse model of Parkinson's disease. Neuroscience 307:73-82. CrossRef Medline

Dzamko N, Deak M, Hentati F, Reith AD, Prescott AR, Alessi DR, Nichols RJ (2010) Inhibition of LRRK2 kinase activity leads to dephosphorylation of $\operatorname{Ser}(910) / \operatorname{Ser}(935)$, disruption of 14-3-3 binding and altered cytoplasmic localization. Biochem J 430:405-413. CrossRef Medline

Emmanouilidou E, Melachroinou K, Roumeliotis T, Garbis SD, Ntzouni M, 
Margaritis LH, Stefanis L, Vekrellis K (2010) Cell-produced alphasynuclein is secreted in a calcium-dependent manner by exosomes and impacts neuronal survival. J Neurosci 30:6838-6851. CrossRef Medline

Fauvet B, Mbefo MK, Fares MB, Desobry C, Michael S, Ardah MT, Tsika E, Coune P, Prudent M, Lion N, Eliezer D, Moore DJ, Schneider B, Aebischer P, El-Agnaf OM, Masliah E, Lashuel H (2012) $\alpha$-Synuclein in central nervous system and from erythrocytes, mammalian cells, and Escherichia coli exists predominantly as disordered monomer. J Biol Chem 287:15345-15364. CrossRef Medline

Foote M, Qiao H, Graham K, Wu Y, Zhou Y (2015) Inhibition of 14-3-3 proteins leads to schizophrenia-related behavioral phenotypes and synaptic defects in mice. Biological psychiatry 78:386-395. CrossRef Medline

Fraser KB, Moehle MS, Daher JP, Webber PJ, Williams JY, Stewart CA, Yacoubian TA, Cowell RM, Dokland T, Ye T, Chen D, Siegal GP, Galemmo RA, Tsika E, Moore DJ, Standaert DG, Kojima K, Mobley JA, West AB (2013) LRRK2 secretion in exosomes is regulated by 14-3-3. Hum Mol Genet 22:4988-5000. CrossRef Medline

Gonçalves SA, Macedo D, Raquel H, Simões PD, Giorgini F, Ramalho JS, Barral DC, Ferreira Moita L, Outeiro TF (2016) shRNA-based screen identifies endocytic recycling pathway components that act as genetic modifiers of $\alpha$-synuclein aggregation, secretion and toxicity. PLoS genetics 12, e1005995. CrossRef Medline

Hansen C, Angot E, Bergström AL, Steiner JA, Pieri L, Paul G, Outeiro TF, Melki R, Kallunki P, Fog K, Li JY, Brundin P (2011) alpha-synuclein propagates from mouse brain to grafted dopaminergic neurons and seeds aggregation in cultured human cells. J Clin Invest 121:715-725. CrossRef Medline

Hasegawa T, Konno M, Baba T, Sugeno N, Kikuchi A, Kobayashi M, Miura E, Tanaka N, Tamai K, Furukawa K, Arai H, Mori F, Wakabayashi K, Aoki M, Itoyama Y, Takeda A (2011) The AAA-ATPase VPS4 regulates extracellular secretion and lysosomal targeting of alpha-synuclein. PLoS One 6:e29460. CrossRef Medline

Herva ME, Zibaee S, Fraser G, Barker RA, Goedert M, Spillantini MG (2014) Anti-amyloid compounds inhibit alpha-synuclein aggregation induced by protein misfolding cyclic amplification (PMCA). J Biol Chem 289: 11897-11905. CrossRef Medline

Jang A, Lee HJ, Suk JE, Jung JW, Kim KP, Lee SJ (2010) Non-classical exocytosis of alpha-synuclein is sensitive to folding states and promoted under stress conditions. J Neurochem 113:1263-1274. CrossRef Medline

Kajiwara Y, Buxbaum JD, Grice DE (2009) SLITRK1 binds 14-3-3 and regulates neurite outgrowth in a phosphorylation-dependent manner. Biol Psychiatry 66:918-925. CrossRef Medline

Kaplan A, Morquette B, Kroner A, Leong S, Madwar C, Sanz R, Banerjee SL, Antel J, Bisson N, David S, Fournier AE (2017) Small-molecule stabilization of 14-3-3 protein-protein interactions stimulates axon regeneration. Neuron 93:1082-1093.e5. CrossRef Medline

Kawamoto Y, Akiguchi I, Nakamura S, Honjyo Y, Shibasaki H, Budka H (2002) 14-3-3 proteins in Lewy bodies in Parkinson disease and diffuse Lewy body disease brains. J Neuropathol Exp Neurol 61:245-253. CrossRef Medline

Kordower JH, Chu Y, Hauser RA, Freeman TB, Olanow CW (2008) Lewy body-like pathology in long-term embryonic nigral transplants in Parkinson's disease. Nat Med 14:504-506. CrossRef Medline

Lashuel HA, Overk CR, Oueslati A, Masliah E (2013) The many faces of alpha-synuclein: from structure and toxicity to therapeutic target. Nat Rev Neurosci 14:38-48. CrossRef Medline

Lavalley NJ, Slone SR, Ding H, West AB, Yacoubian TA (2016) 14-3-3 proteins regulate mutant LRRK2 kinase activity and neurite shortening. Hum Mol Genet 25:109-122. CrossRef Medline

Lee HJ, Patel S, Lee SJ (2005) Intravesicular localization and exocytosis of $\alpha$-synuclein and its aggregates. J Neurosci 25:6016-6024. CrossRef Medline

Lee HJ, Cho ED, Lee KW, Kim JH, Cho SG, Lee SJ (2013) Autophagic failure promotes the exocytosis and intercellular transfer of alpha-synuclein. Exp Mol Med 45:e22. CrossRef Medline

Li X, Wang QJ, Pan N, Lee S, Zhao Y, Chait BT, Yue Z (2011) Phosphorylation-dependent 14-3-3 binding to LRRK2 is impaired by common mutations of familial Parkinson's disease. PLoS One 6:e17153. CrossRef Medline

Liu J, Zhang JP, Shi M, Quinn T, Bradner J, Beyer R, Chen S, Zhang J (2009) Rab1la and HSP90 regulate recycling of extracellular alpha-synuclein. J Neurosci 29:1480-1485. CrossRef Medline
Luk KC, Kehm V, Carroll J, Zhang B, O’Brien P, Trojanowski JQ, Lee VM (2012) Pathological $\alpha$-synuclein transmission initiates Parkinson-like neurodegeneration in nontransgenic mice. Science 338:949-953. CrossRef Medline

Mao X, Ou MT, Karuppagounder SS, Kam TI, Yin X, Xiong Y, Ge P, Umanah GE, Brahmachari S, Shin JH, Kang HC, Zhang J, Xu J, Chen R, Park H, Andrabi SA, Kang SU, Gonçalves RA, Liang Y, Zhang S, et al. (2016) Pathological $\alpha$-synuclein transmission initiated by binding lymphocyteactivation gene 3. Science 353:aah3374. CrossRef Medline

Marzinke MA, Mavencamp T, Duratinsky J, Clagett-Dame M (2013) 14-33epsilon and NAV2 interact to regulate neurite outgrowth and axon elongation. Arch Biochem Biophys 540:94-100. CrossRef Medline

Masters SC, Fu H (2001) 14-3-3 proteins mediate an essential antiapoptotic signal. J Biol Chem 276:45193-45200. CrossRef Medline

Masuda-Suzukake M, Nonaka T, Hosokawa M, Kubo M, Shimozawa A, Akiyama H, Hasegawa M (2014) Pathological $\alpha$-synuclein propagates through neural networks. Acta Neuropathol Commun 2:88. CrossRef Medline

McFerrin MB, Chi X, Cutter G, Yacoubian TA (2017) Dysregulation of 143-3 proteins in neurodegenerative diseases with Lewy body or Alzheimer pathology. Ann Clin Transl Neurol 4:466-477. CrossRef Medline

Mrowiec T, Schwappach B (2006) 14-3-3 proteins in membrane protein transport. Biol Chem 387:1227-1236. CrossRef Medline

Ngolab J, Trinh I, Rockenstein E, Mante M, Florio J, Trejo M, Masliah D, Adame A, Masliah E, Rissman RA (2017) Brain-derived exosomes from dementia with Lewy bodies propagate alpha-synuclein pathology. Acta Neuropathol Commun 5:46. CrossRef Medline

Nichols RJ, Dzamko N, Morrice NA, Campbell DG, Deak M, Ordureau A, Macartney T, Tong Y, Shen J, Prescott AR, Alessi DR (2010) 14-3-3 binding to LRRK2 is disrupted by multiple Parkinson's disease-associated mutations and regulates cytoplasmic localization. Biochem J 430:393404. CrossRef Medline

Ostrerova N, Petrucelli L, Farrer M, Mehta N, Choi P, Hardy J, Wolozin B (1999) $\alpha$-Synuclein shares physical and functional homology with 143-3 proteins. J Neurosci 19:5782-5791. CrossRef Medline

Park JW, Vahidi B, Taylor AM, Rhee SW, Jeon NL (2006) Microfluidic culture platform for neuroscience research. Nat Protoc 1:2128-2136. CrossRef Medline

Paumier KL, Luk KC, Manfredsson FP, Kanaan NM, Lipton JW, Collier TJ, Steece-Collier K, Kemp CJ, Celano S, Schulz E, Sandoval IM, Fleming S, Dirr E, Polinski NK, Trojanowski JQ, Lee VM, Sortwell CE (2015) Intrastriatal injection of pre-formed mouse alpha-synuclein fibrils into rats triggers alpha-synuclein pathology and bilateral nigrostriatal degeneration. Neurobiol Dis 82:185-199. CrossRef Medline

Plotegher N, Kumar D, Tessari I, Brucale M, Munari F, Tosatto L, Belluzzi E, Greggio E, Bisaglia M, Capaldi S, Aioanei D, Mammi S, Monaco HL, Samo B, Bubacco L (2014) The chaperone-like protein 14-3-3 $\eta$ interacts with human alpha-synuclein aggregation intermediates rerouting the amyloidogenic pathway and reducing alpha-synuclein cellular toxicity. Hum Mol Genet 23:5615-5629. CrossRef Medline

Porter GW, Khuri FR, Fu H (2006) Dynamic 14-3-3/client protein interactions integrate survival and apoptotic pathways. Semin Cancer Biol 16: 193-202. CrossRef Medline

Qiao H, Foote M, Graham K, Wu Y, Zhou Y (2014) 14-3-3 proteins are required for hippocampal long-term potentiation and associative learning and memory. J Neurosci 34:4801-4808. CrossRef Medline

Ramser EM, Buck F, Schachner M, Tilling T (2010) Binding of alphaII spectrin to $14-3-3 \beta$ is involved in NCAM-dependent neurite outgrowth. Mol Cell Neurosci 45:66-74. CrossRef Medline

Sato S, Chiba T, Sakata E, Kato K, Mizuno Y, Hattori N, Tanaka K (2006) $14-3-3 \eta$ is a novel regulator of parkin ubiquitin ligase. EMBO J 25:211221. CrossRef Medline

Schneider CA, Rasband WS, Eliceiri KW (2012) NIH image to ImageJ: 25 years of image analysis. Nat Methods 9:671-675. CrossRef Medline

Shahnawaz M, Tokuda T, Waragai M, Mendez N, Ishii R, Trenkwalder C, Mollenhauer B, Soto C (2017) Development of a biochemical diagnosis of parkinson disease by detection of $\alpha$-synuclein misfolded aggregates in cerebrospinal fluid. JAMA Neurol 74:163-172. CrossRef Medline

Shandala T, Woodcock JM, Ng Y, Biggs L, Skoulakis EM, Brooks DA, Lopez AF (2011) Drosophila $14-3-3 \epsilon$ has a crucial role in anti-microbial peptide secretion and innate immunity. J Cell Sci 124:2165-2174. CrossRef Medline 
Shin KJ, Wall EA, Zavzavadjian JR, Santat LA, Liu J, Hwang JI, Rebres R, Roach T, Seaman W, Simon MI, Fraser ID (2006) A single lentiviral vector platform for microRNA-based conditional RNA interference and coordinated transgene expression. Proc Natl Acad Sci U S A 103:1375913764. CrossRef Medline

Slone SR, Lesort M, Yacoubian TA (2011) 14-3-30 protects against neurotoxicity in a cellular Parkinson's disease model through inhibition of the apoptotic factor bax. PLoS One 6:e21720. CrossRef Medline

Slone SR, Lavalley N, McFerrin M, Wang B, Yacoubian TA (2015) Increased 14-3-3 phosphorylation observed in Parkinson's disease reduces neuroprotective potential of 14-3-3 proteins. Neurobiol Dis 79:1-13. CrossRef Medline

Sluchanko NN, Gusev NB (2017) Moonlighting chaperone-like activity of the universal regulatory 14-3-3 proteins. FEBS J 284:1279-1295. CrossRef Medline

Stuendl A, Kunadt M, Kruse N, Bartels C, Moebius W, Danzer KM, Mollenhauer B, Schneider A (2016) Induction of $\alpha$-synuclein aggregate formation by CSF exosomes from patients with Parkinson's disease and dementia with Lewy bodies. Brain 139:481-494. CrossRef Medline

Tan CC, Yu JT, Tan MS, Jiang T, Zhu XC, Tan L (2014) Autophagy in aging and neurodegenerative diseases: implications for pathogenesis and therapy. Neurobiology of aging 35:941-957. CrossRef Medline

Théry C, Amigorena S, Raposo G, Clayton A (2006) Isolation and characterization of exosomes from cell culture supernatants and biological fluids. Curr Protoc Cell Biol Chapter 3: Unit 3 22. CrossRef Medline

Tonoki A, Kuranaga E, Tomioka T, Hamazaki J, Murata S, Tanaka K, Miura M (2009) Genetic evidence linking age-dependent attenuation of the $26 \mathrm{~S}$ proteasome with the aging process. Mol Cell Biol 29:1095-1106. CrossRef Medline

Ulitsky I, Krishnamurthy A, Karp RM, Shamir R (2010) DEGAS: de novo discovery of dysregulated pathways in human diseases. PLoS One 5:e13367. CrossRef Medline

VanGuilder HD, Farley JA, Yan H, Van Kirk CA, Mitschelen M, Sonntag WE, Freeman WM (2011) Hippocampal dysregulation of synaptic plasticityassociated proteins with age-related cognitive decline. Neurobiol Dis 43: 201-212. CrossRef Medline
Vincenz C, Dixit VM (1996) 14-3-3 proteins associate with A20 in an isoform-specific manner and function both as chaperone and adapter molecules. J Biol Chem 271:20029-20034. CrossRef Medline

Volpicelli-Daley LA, Luk KC, Patel TP, Tanik SA, Riddle DM, Stieber A Meaney DF, Trojanowski JQ, Lee VM (2011) Exogenous alphasynuclein fibrils induce Lewy body pathology leading to synaptic dysfunction and neuron death. Neuron 72:57-71. CrossRef Medline

Volpicelli-Daley LA, Luk KC, Lee VM (2014) Addition of exogenous $\alpha$-synuclein preformed fibrils to primary neuronal cultures to seed recruitment of endogenous $\alpha$-synuclein to Lewy body and Lewy neuritelike aggregates. Nat Protoc 9:2135-2146. CrossRef Medline

Winter JF, Höpfner S, Korn K, Farnung BO, Bradshaw CR, Marsico G, Volkmer M, Habermann B, Zerial M (2012) Caenorhabditis elegans screen reveals role of PAR-5 in RAB-11-recycling endosome positioning and apicobasal cell polarity. Nat Cell Biol 14:666-676. CrossRef Medline

Xu J, Kao SY, Lee FJ, Song W, Jin LW, Yankner BA (2002) Dopaminedependent neurotoxicity of $\alpha$-synuclein: a mechanism for selective neurodegeneration in Parkinson disease. Nat Med 8:600-606. CrossRef Medline

Yacoubian TA, Cantuti-Castelvetri I, Bouzou B, Asteris G, McLean PJ, Hyman BT, Standaert DG (2008) Transcriptional dysregulation in a transgenic model of parkinson disease. Neurobiol Dis 29:515-528. CrossRef Medline

Yacoubian TA, Slone SR, Harrington AJ, Hamamichi S, Schieltz JM, Caldwell KA, Caldwell GA, Standaert DG (2010) Differential neuroprotective effects of 14-3-3 proteins in models of Parkinson's disease. Cell Death Dis 1:e2. CrossRef Medline

Yamaguchi O, Otsu K (2012) Role of autophagy in aging. J Cardiovasc Pharmacol 60:242-247. CrossRef Medline

Yano M, Nakamuta S, Wu X, Okumura Y, Kido H (2006) A novel function of 14-3-3 protein: $14-3-3 \zeta$ is a heat-shock-related molecular chaperone that dissolves thermal-aggregated proteins. Mol Biol Cell 17:4769-4779. CrossRef Medline

Yoon BC, Zivraj KH, Strochlic L, Holt CE (2012) 14-3-3 proteins regulate retinal axon growth by modulating ADF/cofilin activity. Dev Neurobiol 72:600-614. CrossRef Medline 